\title{
Methyl Chloride Via Oxyhydrochlorination of Methane
}

\author{
Quarterly Technical Progress Report No.7 \\ For the period April-June 1993
}

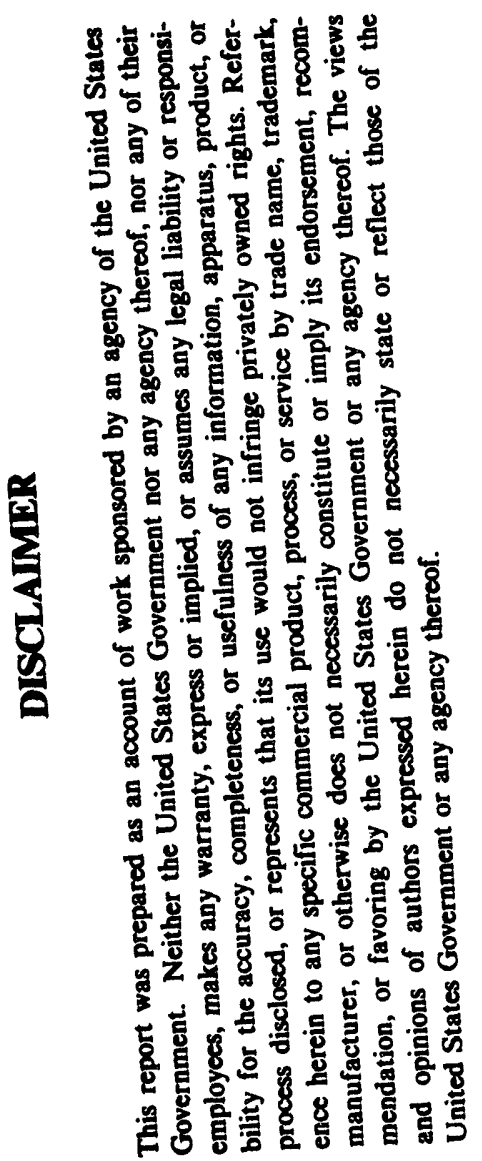

Gas Research Institute

Contract No. 5091-222-2300 


\section{Table of Contents}

Notices ...................... 3

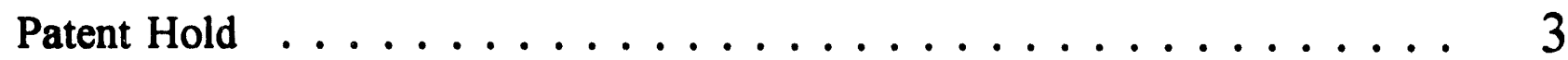

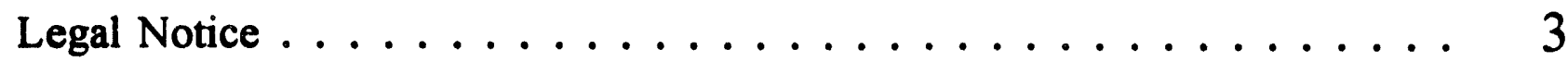

Disclaimer .................... 3

Contract Objective $\ldots \ldots \ldots \ldots \ldots \ldots \ldots \ldots \ldots$

Summary of Technical Progress $\ldots \ldots \ldots \ldots \ldots$

Technical Results ................... 5

Task 1. Catalyst Definition and Separation Unit Operation Development. . . 5

Task 2.0 Miniplant Design Engineering . . . . . . . . . . . . . 19

Data Appendices (following Figures) 
Notices
This repport fontains information which is potentially patentable. U.S. patent applications covering these concepts will be filed with the U.S. Patent Office shortly. As per instruction from the Office of Patent Counsel, U. S. Department of Energy, Argonne, Illinois, the following notides are in effect:

This document copy since it is transmitted in advance of patent clearance, is made available in confidence solely for use in perfokmance of work under contracts with the U.S. Department of Energy This document is not to be published nor its contents otherwise disseminated or used for purposes other than specified above before patent approval for such release or use has been secured, upon request, from the Chief Office of Patent Counsel, U.S. Department of Energy 9800 South Cass Avanue, Argange, Illipois 60439.

\section{Legal Notice}

This report was prepared by Dow Corning Corporation as an account of work co-sponsored by Dow Corning Corporation, Texas Gas Transmission Company ('Texas Gas'), Gas Research Institute ('GRI'), and by the United States Department of Energy ('DOE'). Neither GRI, members of GRI, DOE, Texas Gas, Dow Corning Corporation, nor any person acting on behalf of any of them:

a. Makes any warranty or representation, express or implied with respect to the accuracy, completeness, or usefulness of the information contained in this report, or that the use of any information, apparatus, method, or process disclosed in the report may not infringe privately-owned rights, or

b. Assumes any liability with respect to the use of, or for damages resulting from the use of, any information, apparatus, method, or process disclosed in this report.

\section{Disclaimer}

This work was prepared as an account of work co-sponsored by the United States Government. Neither the United States nor the United States Department of Energy, nor any of their employees, makes any warranty, express or implied, or assumes any legal liability for the accuracy, completeness, or usefulness of any information, apparatus, product, or process disclosed, or represents that its use would not infringe privately owned rights. Reference herein to any specific commercial product, process, or service by trade name, mark, manufacturer, or otherwise, does not necessarily constitute or imply its endorsement, recommendation, or favoring by the United States Government or any agency thereof. The views and opinions of authors expressed herein do not necessarily state or reflect those of the United States Government or any agency thereof. 


\section{Contract Objective}

The purpose of this contract is to develop a process for converting light alkane gases to methyl chloride via oxyhydrochlorination using highly selective, stable catalysts in fixed-bed reactors designed to remove the large amount of heat generated, so as to control the reaction temperature. Further, the objective is to obtain the engineering data base necessary for developing a commercially feasible process and to evaluate the economics of the process.

Task 1.0 Catalyst Definition and Separation Unit Operation Development

Task 2.0 Process Development Unit (PDU) Design Engineering

Task 3.0 PDU Construction and Procurement

Task 4.0 PDU Start-Up

Task 5.0 Evaluation of Packed Bed Technology

Task 6.0 Separation Optimization

Task 7.0 Process Optimization

Task 8.0 Economic Evaluation

Task 9.0 Preliminary Engineering Design Phase II

Task 10.0 Scale-Up Decision and Business Plan to Phase II 


\section{Summary of Technical Progress}

Several key technology areas were evaluated this quarter.

The catalyst definition effort focused on the determination of the role of the $\mathrm{Li}$ and La promoters that have been found to be useful in enhancing $\mathrm{Cu}$ based oxyhydrochlorination of methane catalysts. Initial experiments show that the $\mathrm{La}$ acts to provide a much more active catalyst than the $\mathrm{Cu}$ only case. The role of the $\mathrm{Li}$ is ambiguous at this point. The $\mathrm{Li}$ enhances the stability of the $\mathrm{La}$ promoted catalyst, but gives only marginal improvement by itself. This work will be continued, with additional emphasis on the analysis of the catalysts to determine the structural role that the promoters may play.

The separation unit operation definition made significant progress by demonstrating in a laboratory system that a process solvent may be used to remove the product $\mathrm{CH}_{3} \mathrm{Cl}$ from the reactor effluent stream. To date the data has been qualitative, but clear. Work will continue to gather the information possible in the laboratory to help with PDU design.

An extensive amount of testing was performed on the chosen process solvent, Multitherm. A comprehensive review of all the thermal testing and associated FTIR, UV/VIS, and physical property testing is included in this report. This work shows that Multitherm should give the desired stability and solubility that are necessary to make the separation unit operation successful.

\section{Technical Results}

\section{Task 1. Catalyst Definition and Separation Unit Operation Development.}

\section{Catalyst Definition-}

Table 1 gives an overview of the catalyst screening reactions that occurred during this time period. All reactions were performed at ambient pressure, with the $\% \mathrm{Cu}$ on the catalyst, Temperature, Space Velocity, measured $\mathrm{CH}_{4}$ conversion, calculated $\mathrm{HCl}$ and $\mathrm{O}_{2}$ conversion, and product selectivities listed by catalyst number. Comprehensive data with associated graphs of the $\mathrm{CH}_{4}$ conversion and $\mathrm{CH}_{3} \mathrm{Cl}$ selectivity vs. time are given in Data Appendix A. Reactor temperature profile data is given when available. Additional catalyst synthesis information for the catalysts cited in this report is given in Appendix B.

Experimental Data Set 1 in Appendix A shows a data set obtained from a $\mathrm{Cu}-\mathrm{Li}$ based catalyst labelled catalyst \#513. Page 1 of this actual laboratory data set shows experimental identifiers as well as selectivity and conversion data. In the data section columns Al6CO, Al6CO2, Al6COX, Al6M1, Al6M2, Al6M3, and Al6M4 refer to the carbon mole based selectivities to $\mathrm{CO}, \mathrm{CO}_{2}, \mathrm{CO}+\mathrm{CO}_{2}, \mathrm{CH}_{3} \mathrm{Cl}, \mathrm{CH}_{2} \mathrm{Cl}_{2}, \mathrm{CHCl}_{3}$, and $\mathrm{CCl}_{4}$. Columns $\mathrm{Q}_{6} \mathrm{CH}_{4} \mathrm{C}$ and $\mathrm{Q} 6 \mathrm{HClC}$ refer to the measured $\mathrm{CH}_{4}$ conversion and the resultant calculated $\mathrm{HCl}$ conversion. This will be the general format in which all raw laboratory data will be presented. Pages 2 and 3 of this data set show the conversion and selectivity vs time in graphical form. Note that this catalyst was relatively stable for the duration of this 140 hour experiment. The decrease in activity over this time was about $25 \%$. The selectivity data has a significant variability due to some gas chromatography problems that occurred during the experiment. The temperature profile on page 4 shows that there was no significant exotherm that occurred during this reaction as measured by the difference between the thermocouple placed inside the reactor and that place on the outside wall of the reactor. Indeed the temperature profile for the entire experiment was very flat. 
Data Set 2 shows the results of the first in a series of experiments designed to evaluate the impact of the $\mathrm{Li}$ and $\mathrm{La}$ promoters that are used in some oxychlorination catalysts. Catalyst \#538 A is simply the $\mathrm{Cu}$ complex used as a $\mathrm{Cu}$ donor which is supported on silica. As summarized in Table 1, other catalysts which are labelled \#538B, \#538C, and \#538D were synthesized utilizing sequential impregnation. \#538B has $\mathrm{La}$ only as a added promoter, \#538C has $\mathrm{Li}$ only, and \#538D has both $\mathrm{Li}$ and $\mathrm{La}$ added. As will be discussed, these promoters have both stability and activity impacts. The summary shown on page 2 of Data Set 2 gives the conversion of catalyst \#538A as an average of $4 \%$ for $340 \mathrm{C}$ and $5 \%$ for a $350 \mathrm{C}$ reactor furnace set point. Note that the temperature was changed at about 100 hours into the run as seen on page $\mathrm{S}$ in the temperature profile. This data clearly indicates that the system containing only $\mathrm{Cu}$ does not give the desired catalyst activity. In addition, the deactivation over this 280 hour experiment is significant, as shown on pages 3 and 4 of Data Set 2.

Table 1 Copper Based Catalysts for the Oxyhydrochlorination of Methane

\begin{tabular}{|l|l|l|l|l|l|l|l|l||}
\hline & & & & & & & & \\
\hline$\% \mathrm{Cu}$ on Catalyst & 2.3 & 2.5 & 2.5 & 1.8 & 1.8 & 25 & 2.5 & 2.5 \\
\hline Temperature (C) & 340 & 340 & 350 & 340 & 340 & 340 & 340 & 340 \\
\hline Space Velocity (cm/s) & 9.0 & 9.0 & 9.0 & 9.0 & 9.0 & 9.0 & 9.0 & 9.0 \\
\hline $\mathrm{CH}_{4}$ Conversion & 16 & 4 & 5 & 16 & 8 & 3 & 6 & 16 \\
\hline $\mathrm{HCl}$ Conversion & 57 & 14 & 18 & 62 & 30 & 10 & 22 & 65 \\
\hline $\mathrm{O}_{2}$ Conversion & 41 & 10 & 13 & 46 & 21 & 7 & 15 & 46 \\
\hline$\% \mathrm{CH}_{3} \mathrm{Cl}$ & 81 & 85 & 77 & 68 & 81 & 85 & 85 & 72 \\
\hline$\% \mathrm{CH}_{2} \mathrm{Cl}_{2}$ & 12 & 8 & 14 & 19 & 13 & 7 & 11 & 20 \\
\hline$\% \mathrm{CHCl}_{3}$ & 0 & 0 & 0 & 3 & 1 & 0 & 0 & 3 \\
\hline$\% \mathrm{CCl}_{4}$ & 0 & 0 & 0 & 0 & 0 & 0 & 0 & 0 \\
\hline$\% \mathrm{CO}^{\% \mathrm{CO}_{2}}$ & 4 & 6 & 6 & 3 & 3 & 5 & 1 & 2 \\
\hline
\end{tabular}

Data Set 3 shows the impact of adding La as a promoter to this catalyst. The La was added by sequential impregnation of the same base catalyst, \#538A, to form catalyst \#538B. In this case, the experiment had to be aborted at about 40 hours due to plugging of the reactor system, and therefore, stability information was not obtained. However, the activity impact is quite clear. The conversion for the La promoted catalyst is four times that of the non-promoted catalyst. As shown on page 3 of the data set the selectivity was significantly lower at $16 \%$ conversion than was seen in Data Set 1 at the same conversion for the $\mathrm{Cu}-\mathrm{Li}$ catalyst. Based on this limited observation it appears that the La serves to enhance the activity of the catalyst, but a selectivity penalty may be also seen. However, the selectivity penalty is not certain because the selectivity differences are of the same order as the detection ability. Another interesting fact, shown on page 4 of Data Set 3, is that a small but measurable increase in the reaction exotherm was seen during this experiment. 
Data Set 4 shows another experiment with catalyst \#538B. In this case, the reaction was carried out for 265 hours. This data clearly shows that the La promoter alone does not give the desired catalyst stability. The conversion of the catalyst dropped from $15 \%$ to about $7 \%$ over the course of the experiment. As seen on page 5 of Data Set 4, another temperature effect was seen in this experiment. In this case, a significant exotherm was noted in the first 20 hours of the experiment. This may have caused the observed activity loss due to catalyst deactivation at higher temperatures.

Data Set 5 is included for the sake of cumpleteness. This is a rerun of catalyst \#538A for 290 hours. Note that the conversion stayed relatively steady, but was quite low at an average of $3 \%$. Significant portions of the data are missing due to problems in the Camile control system during this experiment. This again illustrates the lack of activity of the base $\mathrm{Cu}$ catalyst used in this study.

Data Set 6 gives the results for the Li promoted version of catalyst \#538A, catalyst \#538C. Again, the data is spotty due to instrumental problems. However, it is quite clear that this catalyst again possesses much lower activity than the La promoted version. The average conversion was $6 \%$. As shown on the page 3 graph, the initial conversion was about $10 \%$, and it declined steadily. In this system, there was essentially no temperature differential noted between the two monitoring thermocouples as shown on page 5 .

Data Set 7 shows the initial results from catalyst \#538D. This catalyst has both $\mathrm{Li}$ and $\mathrm{La}$ as promoters. The experiment lasted 210 hours and was ended due to a plug in the system. Temperature data was inadvertently monitored for another 60 hours. The page 5 thermocouple data clearly shows the "heat of reaction" by showing an approximate $7 \mathrm{C}$ temperature drop when the reactant feed was stopped. This catalyst gave very good results. As shown on page 3 of the data set, the initial conversion was about $19 \%$, dropping to about $15 \%$ after 210 hours. Although this is still not great, this level of deactivation is consistent with the best catalysts we have evaluated thus far. The selectivity averaged $72 \%$ for the experiment. This data indicates that both the $\mathrm{Li}$ and the $\mathrm{La}$ promoters are necessary in this system for optimization of the catalyst performance. Work in the next reporting period will focus on further evaluations of these catalysts. Testing to evaluate the physical changes in the catalyst structure associated with the addition of these promoters is planned.

\section{Separation Process Definition-}

There were two significant efforts this quarter in the definition of the separation process to be used in the PDU. The first was the demonstration in the laboratory that the product, $\mathrm{CH}_{3} \mathrm{Cl}$, could be removed via absorption into the desired process solvent in a laboratory column.

Data Set 8 shows the results of the first successful demonstration of the laboratory separation system. This 1 page data set shows the experimental conditions and results for an oxyhydrochlorination reaction at a pressure of 30 psig followed by removal of the product chlorocarbons in an absorber column. The $\mathrm{CH}_{4}$ conversion and product selectivities are shown, as well as the $\% \mathrm{Ml}$ removed from the reactor effluent. This was monitored via on-line gas chromatography by the use of a switching valve that sampled the stream before and after the absorber column. This first shakedown experiment simply shows that $60+\%$ of the $\mathrm{CH}_{3} \mathrm{Cl}$ was removed. 
Data Set 9 shows the next shakedown run for this system. In this case data was collected at a system pressure of both 30 and 40 psig. It appeared that the removal efficiency was higher, as expected, at the higher system pressure. With both Data Sets 8 and 9, it is important not to over interpret these very interesting results. These were not viewed as steady state experiments, and this work will be continued next quarter to obtain more quantitative information. It is, however, exciting to note that the increase in system pressure appears to help rather that hurt the process selectivity to $\mathrm{CH}_{3} \mathrm{Cl}$. This could prove to be a major advantage in the development of this technology.

The second effort this quarter in the definition of the separation process involved the evaluation of the chosen process solvent. The oxyhydrochlorination of methane process requires the use of a solvent that will prove stable through temperature and pressure changes over an extended time period. Due to the nature in which this solvent is used, it is necessary that the chosen solvent be resistant to degradation that may be caused from thermal aging, pressure fluctuations, or acid attack. The following section will describe the processes used to determine the reliability of one solvent, Multitherm 503, under these varying circumstances.

PROPERTIES OF MULTITHERM 503

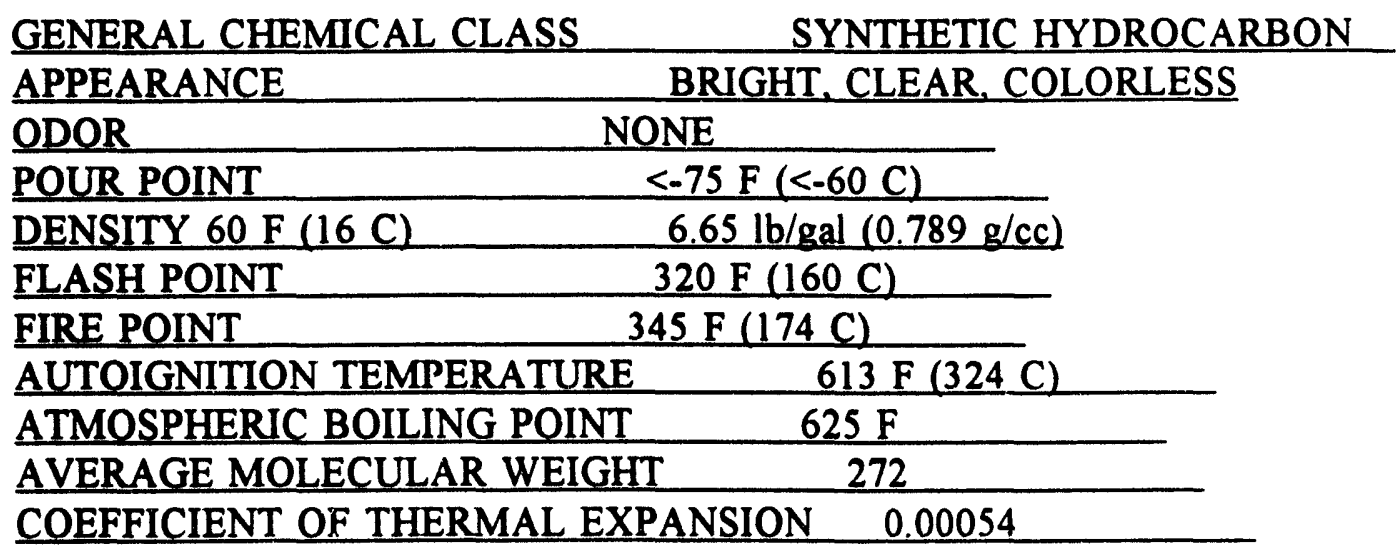

\section{EXPERIMENTAL OVERVIEW}

Several tests were conducted in an effort to better determine the reliability of Multitherm 503 while varying both time and temperature. These tests include: the Bomem Michelson series FTIR (Fourier Transform Infrared Spectroscopy) which utilizes Galactic, Inc. Lab Calc software, the Perkin Elmer Lambda 3B UV/VIS (Ultraviolet/Visible Spectrophotometer), the automatic Houllian Viscometer which utilizes ATPEM Visco-Houllian software, and an experimental design that will allow for the absorption of gases into a liquid.

The FTIR, with resolution set at $2 \mathrm{~cm}-1$ and scan number set at 50, measures peaks in the infrared region of the color spectrum. The limits placed on an FTIR spectrum range from 400-4000 wavenumbers.

The UV/VIS measures peaks in the near ultraviolet/visible region of the color spectrum. The limits placed on a UV/VIS trace range from 190-900 nanometers. 
The Houllian Viscometer measures, in centistokes, the kinetic viscosity of a sample as it passes through a capillary tube. The absorption test, for our purposes, measures the amount of methyl chloride absorbed into a solvent.

\section{DISCUSSION AND RESULTS}

\section{A. MULTITHERM 503 - THERMALLY AGED}

\section{RUN TIME AND TEMPERATURE}

Thermal stability testing provides a way to observe the effects of thermal aging on samples of Multitherm 503. However, this testing alone only allows for a visual observation of the sample. The sample, nevertheless, can provide valuable information when exposed to other tests (i.e. FTIR, UV/VIS, viscosity, and absorption tests).

Table 2 lists the time and temperature at which each sample was thermally aged. Samples 1-8 were thermally aged at $175 \mathrm{C}$. Of these eight samples, samples $1-6$ underwent a color change during the thermal aging process. As the thermal aging time for each sample increased, the yellowing of the sample intensified. However, samples 7-10 remained clear and colorless.

Samples 1-6 were run in metal containers while samples 7-10 were run in glass vials. Therefore, the discoloration of the first six samples could be due to the presence of metals during the thermal aging process.

Table 2 - Thermally Aged Multitherm Samples

\begin{tabular}{||l|l|l|}
\hline Sample & Hours Thermally Aged & Temperature (C) \\
\hline 1 & 4 & 175 \\
\hline 2 & 8 & 175 \\
\hline 3 & 11 & 175 \\
\hline 4 & 30 & 175 \\
\hline 5 & 106 & 175 \\
\hline 6 & 202 & 175 \\
\hline 7 & 200 & 175 \\
\hline 8 & 400 & 175 \\
\hline 9 & 200 & 200 \\
\hline 10 & 4 & 275 \\
\hline
\end{tabular}




\section{FTIR}

Figures 1-7 (located in the appendix) are spectra of virgin Multitherm 503. Figure 1 shows the broad spectrum ranging from $400-4000$ wavenumbers. Figures 2-7 are smaller regions of the spectrum which are enlarged for better viewing of peak formation. These figures may be used as a reference for the thermally aged spectra.

When slight changes were seen in two separate runs of clean Multitherm, a question arose as to the reproducibility of each spectra. Therefore, a baseline study was conducted in which three separate FTIR runs were performed on virgin Multitherm 503. A grassy region was seen in the spectrum ranging from 1550-2400 wavenumbers. After a comparison of this spectrum was made with the two other runs, it was decided that the scatter was probably a result of equipment noise. Nevertheless, all of the spectra peaks were located at the same wavenumber. No new peaks were seen for any of the spectra.

FTIR tests were run for samples 1-10. No significant peak changes could be found.

Figures 8 and 9 serve to illustrate this point. These are the broad spectra for samples 2 and 6 . They are very similar. The peaks for both samples are located at the same wavenumbers, and no new peaks were observed.

It is necessary to divide the initial large spectrum into several smaller, "blown-up" spectra in order to better view peak activity. All sample spectra were enlarged with no new peaks being seen. For example, see Figures 10-15. These are spectra of samples 7 and 8. The runs have been overlayed to provide an easier way to detect peak fluctuation. Each region of the spectrum is very similar with no new pronounced peak formations. No new peaks were detected for the other thermally aged samples either.

\section{VISCOSITY}

Before viscosity measurements of the thermally aged samples began, eight different runs were made using clean Multitherm 503 with no thermal aging. This created a baseline with which the thermally aged samples could be compared.

The following results were obtained:

\begin{tabular}{lll} 
SAMPLE & VISCOSITY (centistokes) \\
\cline { 1 - 2 } 1 & 7.7 \\
2 & 7.4 \\
3 & 7.7 \\
4 & 7.4 \\
5 & 7.8 \\
6 & 7.8 \\
7 & 7.8 \\
8 & 7.8 \\
9 & 7.7 \\
10 & 7.7
\end{tabular}

Most of the viscosity results fell within the statistical process control limits calculated from the eight runs with clean Multitherm 503. However, samples 2 and 4 fell curiously below the calculated limits. As of 
yet, the reason for this drop in viscosity is unknown. See Figure 16 for a representative graph.

\section{UV/VIS}

The ultraviolet-visibility test measures the intensity of transmitted light at wavelengths between $190-900$ nanometers. This provides data in the near ultraviolet region $(<400 \mathrm{~nm})$, visible region $(400-800 \mathrm{~nm})$, and the near infrared region $(>800 \mathrm{~nm})$. UV/VIS testing was conducted on the 10 thermally aged samples. No peaks were seen in the near IR or visible regions for these samples. However, for samples 1-6, the area under each curve in the near ultraviolet region gradually increased. The absorption of violet light caused these samples to appear yellow. Samples 7-10 were clear and colorless. Their UV/VIS trace varied only slightly from the trace producc $\rfloor$ from a run with clean Multitherm.

See Figure 17, virgin Multitherm 503, as a reference UV/VIS trace. Figures 18-20 display the UV regions of samples 3, 4, and 6. Note the progressive broadening of the curve. Figures 21 and 22 display the UV regions for samples 9 and 10 . Note the resemblance that these traces have to the trace of virgin Multitherm. After thermal aging, these samples remained clear and colorless.

\section{ABSORPTION}

An absorption test was conducted on Multitherm samples 1-6, 11, and two clean Multitherm samples. Sample eleven, to be discussed shortly, involves aging Multitherm with $\mathrm{HCl}$ at elevated temperatures. The following results were obtained:

Table 3 - Temperature, Pressure, and Saturation Data for Methyl Chloride in Multitherm

\begin{tabular}{||l||l|l|l||}
\hline Sample & Temperature (C) & Pressure ( psig) & \% Saturation \\
\hline 1 & -3 & 11 & 15.4 \\
\hline 2 & -2 & 11 & 16.4 \\
\hline 3 & -3 & 10 & 16.0 \\
\hline 4 & 3 & 11 & 16.2 \\
\hline 5 & -5 & 7 & 11.7 \\
\hline 6 & -5 & 10 & 10.9 \\
\hline 11 & 0 & 12 & 19.5 \\
\hline clean & -3 & 8 & 12.4 \\
\hline clean & 1 & 19 & 22.2 \\
\hline
\end{tabular}

According to the data collected, an increase in pressure correlates with an increase in saturation point. Figure 23 illustrates this hypothesis. Sample six, the only point not to fit the proposed pressure vs. saturation point correlation, is attributed to a variance in sample testing methods. 


\section{B. MULTITHERM 503 - THERMALLY AGED WITH HCI}

\section{RUN TIME AND TEMPERATURE}

Since $\mathrm{HCl}$ is present in the oxyhydrochlorination process, it is important that its effects on Multitherm are observed. Samples 11-14 serve to fulfill this purpose. The amount of $\mathrm{HCl}$ to be added was determined by calculating approximately 25 weight \% of the amount of Multitherm added. These samples also yellowed during the thermal aging process. It is believed that the presence of $\mathrm{HCl}$ causes this color change.

TABLE 4 - Thermally Aged Multitherm and HCl Samples

\begin{tabular}{||l|l|l||}
\hline Sample & Hours Thermally Aged & Temperature (C) \\
\hline 11 & 100 & 175 \\
\hline 12 & 200 & 175 \\
\hline 13 & 400 & 175 \\
\hline 14 & 28 & 200 \\
\hline
\end{tabular}

\section{FTIR}

FTIR tests were run on samples 11-14. No significant peak changes were found. See Figures 24-29. These spectra are an overlay of samples 12 and 13. When compared to each other, no peak changes are seen. Even more importantly, when compared to a run with clean Multitherm (Figures 2-7), no new peak formations are noted. The other Multitherm and $\mathrm{HCl}$ samples display the same behavior.

\section{VISCOSITY}

Viscosity testing was conducted on samples 12-14. The following results were obtained:

\section{SAMPLE VISCOSITY (cSt)}

$\begin{array}{ll}12 & 7.8 \\ 13 & 7.8 \\ 14 & 7.8\end{array}$

These viscosity results fall within the statistical process control limits previously calculated from the eight runs with clean Multitherm. As of yet, no significant change in viscosity has been noted. See Figure 16 for a representative graph.

\section{UV/VIS}

UV/VIS testing was conducted on samples 12-14. The run limits were placed at 190 (near UV region) and 900 (near IR region). No new peaks were seen in the IR or visible regions for samples 12-14. However, when compared to the clean Multitherm trace, the area under the curve in the UV region gradually increased. Again, it should be noted that these samples underwent a color change during the aging process. It is believed that the presence of $\mathrm{HCl}$ causes this color change. 
See Figure 17, virgin Multitherm 503, as a reference UV/VIS trace. Figures 30 and 31 display the UV regions of runs 12 and 14 . Using the virgin Multitherm trace as a reference, note the broadening of the curve.

\section{ABSORPTION}

One absorption test was conducted on a Multitherm and $\mathrm{HCl}$ sample aged 100 hours at $175 \mathrm{C}$. The following results were obtained:

\section{TEMP. (Deg C) PRESSURE (psig) \% SATURATION}

0

11.5

19.48

\section{MULTITHERM 503 - THERMALLY AGED WITH METALS}

\section{RUN TIME AND TEMPERATURE}

Samples 15-18, discussed further in TABLE 5, are samples thermally aged with Multitherm and a metal. The metals include: Hastelloy "C", Monel, Stainless Steel, and Inconel. A piece of metal tubing was placed in a vial with Multitherm and thermally aged at $175 \mathrm{C}$. After the thermal aging process was completed, the Multitherm sample was collected for further testing.

TABLE 5 - Thermally Aged Multitherm and Metal Samples

\begin{tabular}{||l|l|l|l|}
\hline Sample & Metal & Hours Thermally Aged & Temperature (C) \\
\hline 15 & Hastelloy C & 100 & 175 \\
\hline 16 & Monel & 100 & 175 \\
\hline 17 & Stainless Steel & 100 & 175 \\
\hline 18 & Inconel & 100 & 175 \\
\hline
\end{tabular}

COMMENTS : Samples 16-18 turned bright yellow after thermal aging. Sample 15 remained clear and colorless.

\section{FTIR}

FTIR spectra were run for samples 15-18. In analyzing the data obtained, a comparison was made with an FTIR spectrum of clean Multitherm with no thermal aging. Because Multitherm aged with $\mathrm{HCl}$ causes no changes in the FTIR, Figures 32 and 33 compare samples aged with metal to samples aged with $\mathrm{HCl}$. Changes could be seen in all of the FTIR spectra for samples 15-18.

Multitherm and Hastelloy " $\mathrm{C}$ " - new peak forming around 1740 wavenumbers in the $\mathrm{C}=0$ region (see Figure 32).

Multitherm and Monel - new peak forming around 1740 wavenumbers in the $\mathrm{C}=0$ region (see Figure 33). 
Multitherm and Stainless Steel - new peaks forming in the $\mathrm{OH}$ deformation and $\mathrm{C}-\mathrm{O}, \mathrm{C}=\mathrm{O}$ regions. A new peak forming around 1740 wavenumbers in the $C=0$ region (see Figures 34-39).

Multitherm and Inconel - new peaks forming in the $\mathrm{OH}$ deformation and $\mathrm{C}-\mathrm{O}, \mathrm{C}=\mathrm{O}$ regions. $\mathrm{A}$ new peak forming around 1740 wavenumbers in the $C=0$ region (see Figures 40 and 41 ).

\section{VISCOSITY}

No viscosity testing was conducted on samples 15-18. This test does not allow for sample recovery after testing is completed. Therefore, due to small amounts of sample, a decision was made to hold off on this test.

\section{UVIVIS}

The traces for samples 15-18, when compared to a trace of clean Multitherm, prove to have a significant increase in the area under the curve in the UV region. Although samples 16-18 were yellow, a characteristic that seems to correlate with the fact that the peaks in the UV region are of greater intensity than those samples visibly unaffected by thermal aging, sample 15 was clear and colorless. Yet, sample 15 displayed the same behavior as samples 16-18. This seems to indicate that the presence of metals during the thermal aging process intensifies the frequency in the UV region of the spectrum.

See Figure 17, virgin Multitherm, as a reference UV/VIS trace. Figures 42-44 represent samples 15, 17, and 18. Note the broad curve in the UV regions. This is in direct contrast to the narrower curve produced from a run with clean Multitherm.

A UV/VIS test could not be conducted on sample 16, Multitherm and Monel, due to an insufficient amount of sample.

\section{ABSORPTION}

Absorption tests could not be run on the thermally aged Multitherm and metal samples due to the small amount of sample collected.

\section{MULTITHERM 503 - THERMALLY AGED WITH METALS AND HCI}

\section{RUN TIME AND TEMPERATURE}

Samples 19-22, discussed further in TABLE 6, are samples of Multitherm, metal, and concentrated $\mathrm{HCl}$. The metals used include: Hastelloy "C", Monel, Stainless Steel, and Inconel. A piece of metal tubing was placed in a vial with Multitherm and concentrated $\mathrm{HCl}$. The amount of $\mathrm{HCl}$ added to each vial was determined by calculating 25 weight \% of the Multitherm added. The samples were aged for 100 hours at a temperature of $175 \mathrm{C}$. 
TABLE 6 - Thermally Aged Multitherm, Metal, and HCl Samples

\begin{tabular}{||l|l|l|l||}
\hline Sample & Metal & Hours Thermally Aged & Temperature (C) \\
\hline 19 & Hastelloy C & 100 & 175 \\
\hline 20 & Monel & 100 & 175 \\
\hline 21 & Stainless Steel & 100 & 175 \\
\hline 22 & Inconel & 100 & 175 \\
\hline
\end{tabular}

COMMENTS: Samples 19-22 formed some type of residue. However, the color of the Multitherm remained clear and colorless. No yellowing occurred.

Hastelloy "C" - greenish-black residue

Monel - brownish-green residue

Stainless Steel - green residue

Inconel - green residue

A clear gas, probably hydrogen, was produced during the thermal aging of these samples. A loud pop occurred when the sample vials were opened. Some solvent sprayed out of the vials and was lost upon opening.

\section{FTIR}

An FTIR spectrum could only be run for samples 19 and 20. Due to pressure formed within the vial during the thermal aging process, the samples containing Stainless Steel and Inconel sprayed out of the vial upon opening. Thus, no sample was collected. When both of the sample runs were compared with a spectrum of clean Multitherm, the most significant changes were seen in the $\mathrm{C}=\mathrm{O}, \mathrm{C}-\mathrm{O}$ stretch region. See Figures 45 and 46.

\section{VISCOSITY}

No viscosity testing was conducted on samples 19-22. This test does not allow for sample recovery after testing is completed. Therefore, due to small amounts of sample, a decision was made to hold off on this test.

\section{UV/VIS}

A UV/VIS run was not conducted on samples 19-22 due to the small amount of sample collected.

\section{ABSORPTION}

Absorption tests could not be run on samples 19-22 due to the small amount of sample collected. 


\section{RUN TIME AND TEMPERATURE}

Samples 23-27 are vacuum sealed samples of de-gassed Multitherm and a metal. All samples were aged 400 hours at $175 \mathrm{C}$. Before sample preparation, the Multitherm to be used was de-gassed using a bubbler and nitrogen flow. Nitrogen was allowed to bubble through the Multitherm for two hours. A syringe was then inserted through a septum on the side of the bubbler and Multitherm was withdrawn and inserted in a vial. After each vial was filled, the mouth was covered with a wax wrap. A vacuum pump was used to evacuate the head space in each vial. The vials were then sealed under a vacuum and placed in the sand bath.

TABLE 7 - Thermally Aged De-gassed Vacuum Sealed Multitherm and Metal Samples

\begin{tabular}{||l|l|l|l||}
\hline Sample & Metal & Hours Thermally Aged & Temperature (C) \\
\hline 23 & None & 400 & 175 \\
\hline 24 & Hastelloy C & 400 & 175 \\
\hline 25 & Monel & 400 & 175 \\
\hline 26 & Tantalum & 400 & 175 \\
\hline 27 & Zirconium & 400 & 175 \\
\hline
\end{tabular}

COMMENTS: All samples were clear and colorless

\section{FTIR}

FTIR tests were run for samples 23-27. No new peak formations were seen in any region of the spectra. The plot for each region of the spectra seemed to trace the spectrum for thermally aged, de-gassed Multitherm. Figures 47 and 48 display an overlay of two regions in each sample spectra. The spectra are unlabeled due to their obvious similarity.

\section{VISCOSITY}

Viscosity testing was not conducted on samples 23-27 due an insufficient amount of sample.

\section{UV/VIS}

UV/VIS testing was conducted on samples 23-27. Unlike previous samples that showed a broad curve in the ultraviolet region, these samples showed a very narrow curve that closely resembled the curve produced by a run with both clean Multitherm and thermally aged, de-gassed Multitherm.

Figure 49 is a trace of thermally aged de-gassed Multitherm. This trace can be used as a reference for the samples mentioned. Figures 50 and 51 are traces of samples 24 and 25 . Note the narrow curve resembling the curves produced by both clean Multitherm and de-gassed thermally aged Multitherm. 


\section{ABSORPTION}

Absorption testing was not conducted on samples 23-27 due to an insufficient amount of sample.

F. DE-GASSED MULTITHERM 503 - THERMALLY AGED WITH METALS AND HCl; VACUUM SEALED

\section{RUN TIME AND TEMPERATURE}

Samples 28-31 are vacuum sealed samples containing de-gassed Multitherm, a metal, and concentrated $\mathrm{HCl}$. The same method of sample preparation used for the de-gassed samples void of $\mathrm{HCl}$ was used for the samples exposed to $\mathrm{HCl}$.

TABLE 8 - Thermally Aged De-gassed Vacuum Sealed Multitherm ,Metal, and HCl Samples

\begin{tabular}{||l|l|l|l|}
\hline Sample & Metal & Hours Thermally Aged & Temperature (C) \\
\hline 28 & None & 400 & 175 \\
\hline 29 & Hastelloy C & 400 & 175 \\
\hline 30 & Tantalum & 400 & 175 \\
\hline 31 & Zirconium & 400 & 175 \\
\hline
\end{tabular}

\section{FTIR}

FTIR tests were run for samples 28-31. No new peak formations were seen in any region of the spectra. Figures 52 and 53 are an overlay of two regions for samples 28-31. Note the similarity of the spectra.

\section{VISCOSITY}

Viscosity testing was not conducted due to an insufficient amount of sample.

\section{UV/VIS}

UV/VIS testing was not conducted due to an insufficient amount of sample.

\section{ABSORPTION}

Absorption testing was not conducted due to an insufficient amount of sample. 


\section{SUMMARY AND CONCLUSIONS}

An attempt has been made to determine the reliability of one solvent, Multitherm 503, through such systematic changes as temperature and pressure variation and exposure to concentrated acid. The following is a summary of the test results performed on Multitherm :

FTIR : No significant changes seen in the peaks formed for thermally aged samples with and without concentrated $\mathrm{HCl}$. No significant changes seen in the peaks formed for vacuum sealed samples using degassed Multitherm with/without $\mathrm{HCl}$. The only clear changes could be noted in samples of Multitherm thermally aged with a metal without first degassing the solvent.

VISCOSITY : No significant changes in viscosity for thermally aged samples with and without $\mathrm{HCl}$.

UV/VIS : Heating Multitherm with $\mathrm{HCl}$ and/or metals causes a yellowing of the solvent. This yellowing was found to be preventable by degassing the solvent by bubbling nitrogen through it. It is therefore concluded that water or oxygen in the air react with Multitherm in the presence of $\mathrm{HCl}$ or metal to cause the yellowing.

ABSORPTION : Absorption testing was somewhat limited. However, in the samples tested with/without $\mathrm{HCl}$, there were no significant changes in the absorption of $\mathrm{MeCl}$.

The conclusion of this work is that there is no worrisome evidence of any sort that Multitherm will degrade during the conditions expected in the oxyhydrochlorination PDU. Any significant changes in the battery of evaluations done were found under extreme conditions that would not be found in the absorber or stripper columns of the PDU. 


\section{Task 2.0 Miniplant Design Engineering}

\section{Process Description and Definition}

The major effort this quarter in the PDU Design Engineering effort was the completion of the process design package and the selection of the group that will do detail design and construction. After careful evaluation of both internal and external groups, it was decided to move forward with the project internally. The engineering support for the project will be given by the DCC small capital project group. This work is well underway.

The cost for the PDU in now much more completely defined than was possible at the earlier estimation points. At this initiation of this contract the cost was estimated to be in the $\$ 1.0$ to $\$ 1.4 \mathrm{MM}$ range. The addition of the reactor effluent separation system added significant cost and complexity to the project. The total capital cost is now estimated at $\$ 2.3$ to $\$ 2.5 \mathrm{MM}$. Next quarter will see the start of detail engineering for this project. The estimated PDU start-up date is July 1994. 


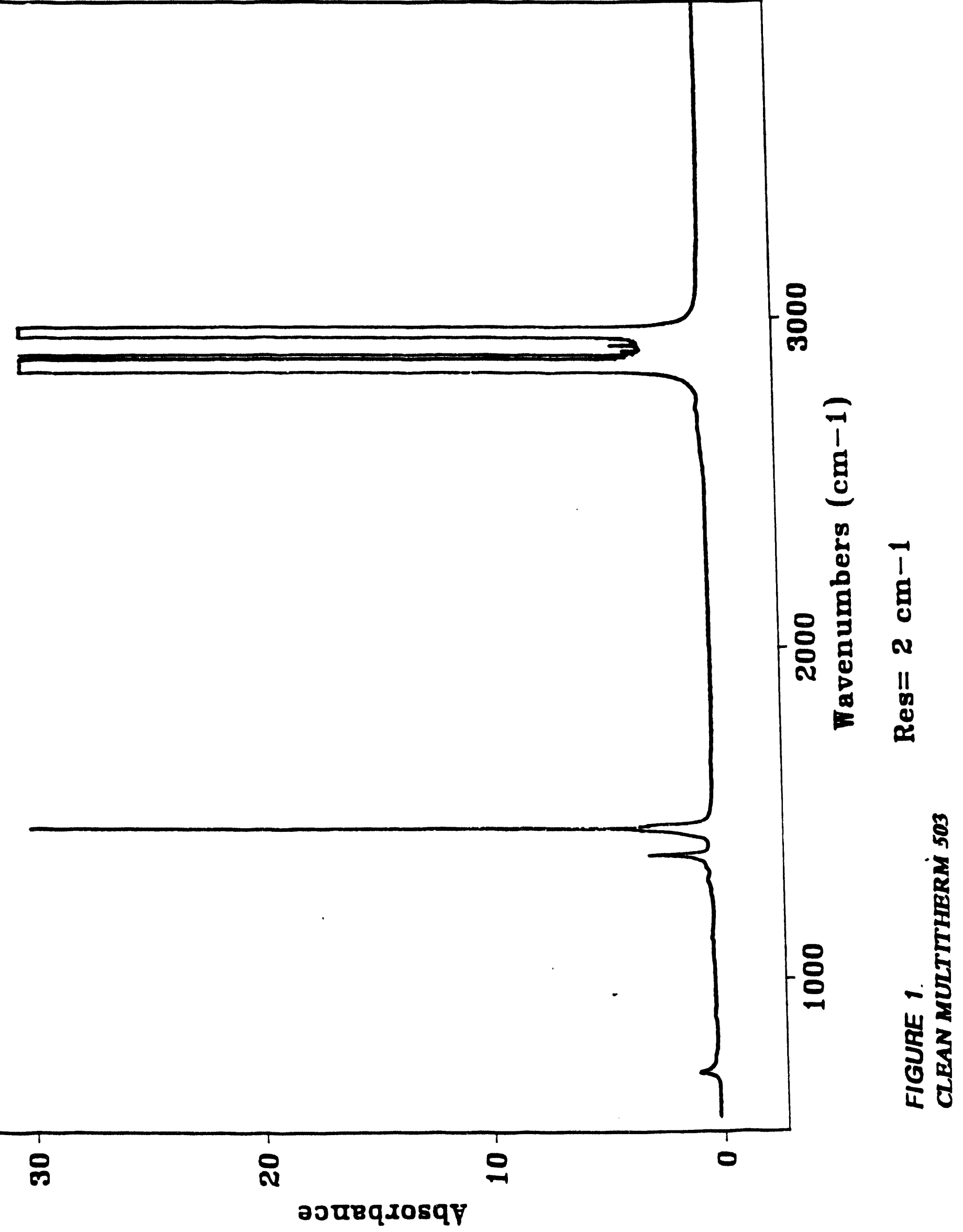




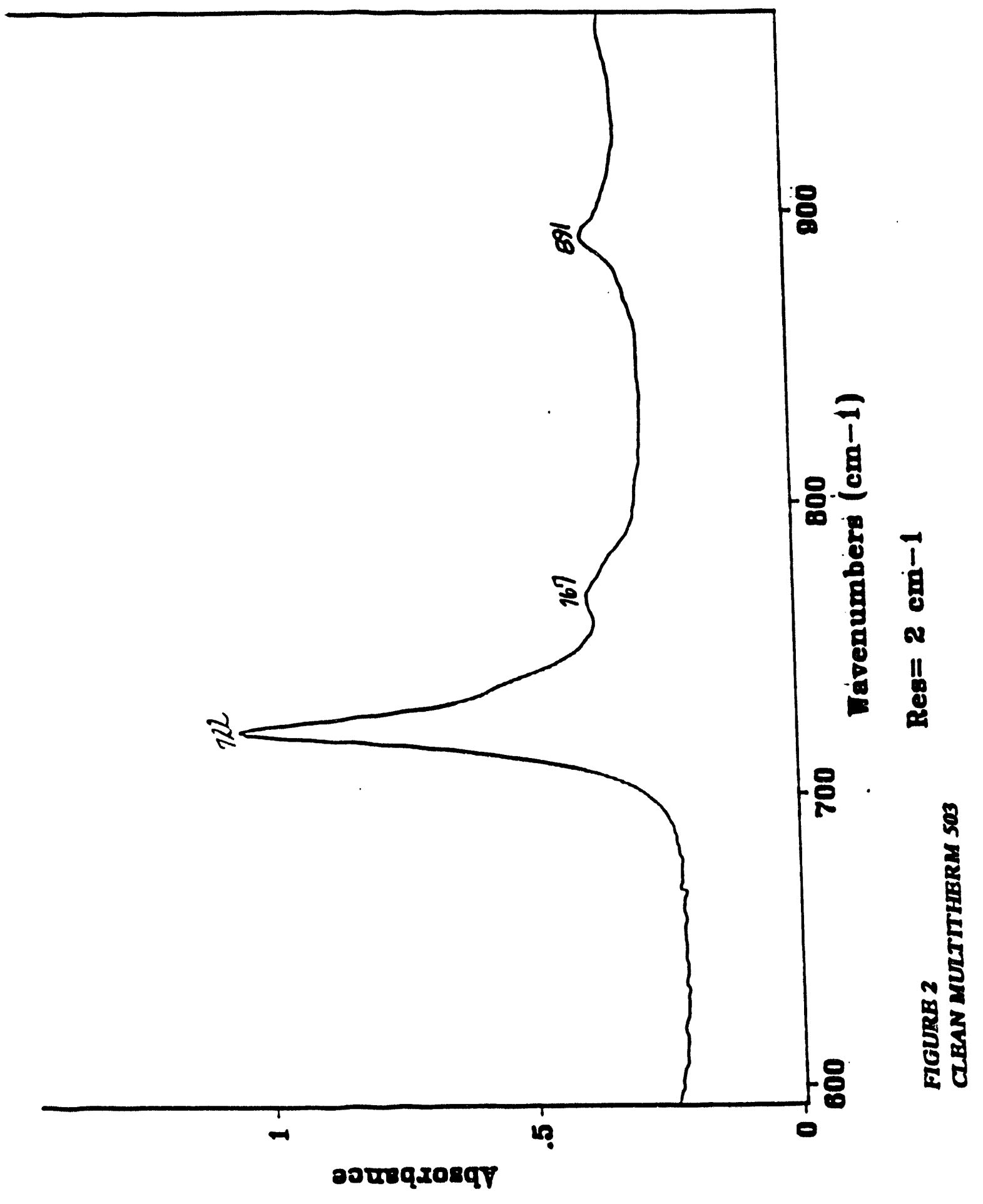




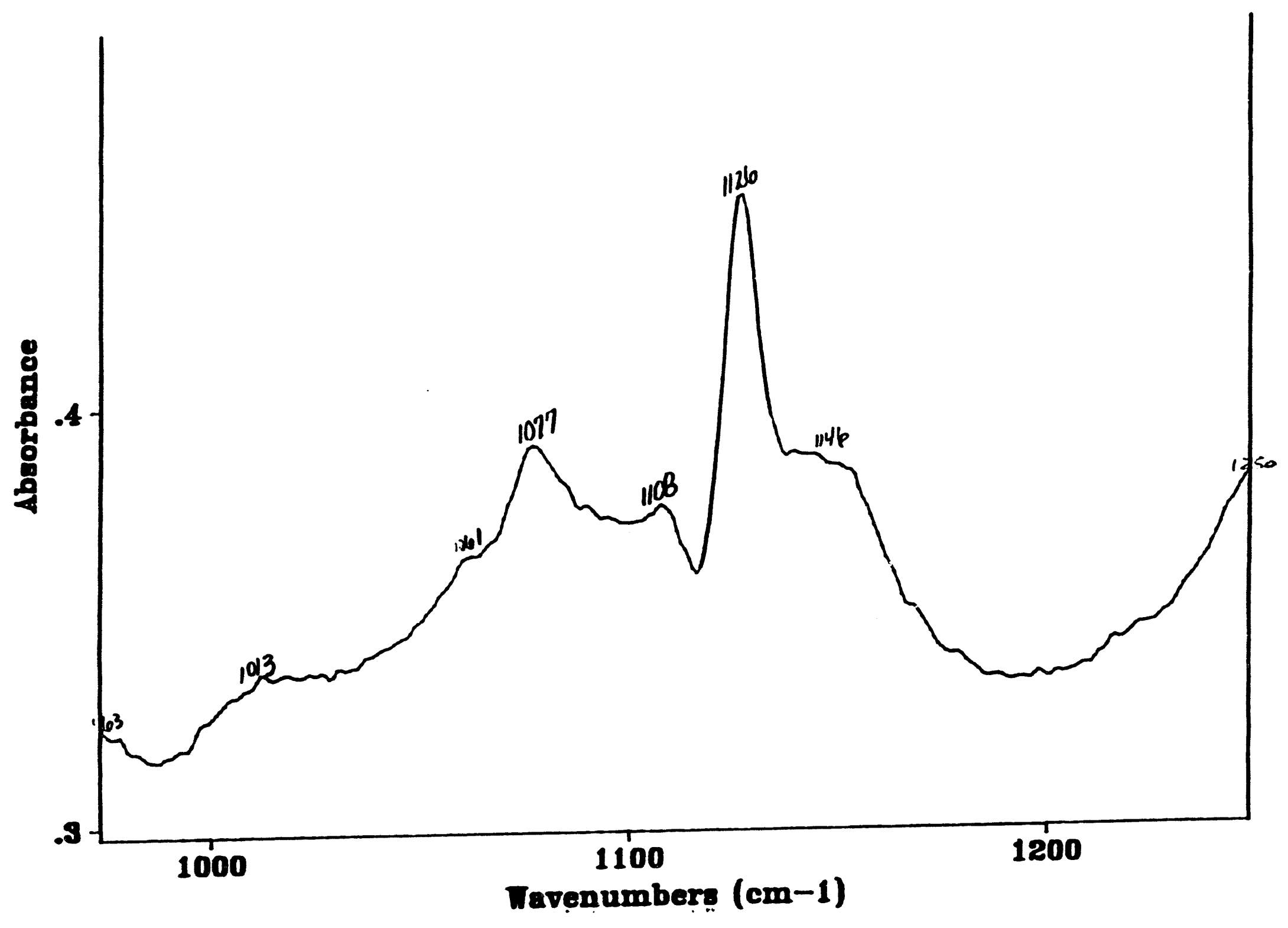

FIGURB 3

Res $=2 \mathrm{~cm}-1$

CLBAN MULTTTHERM 503 


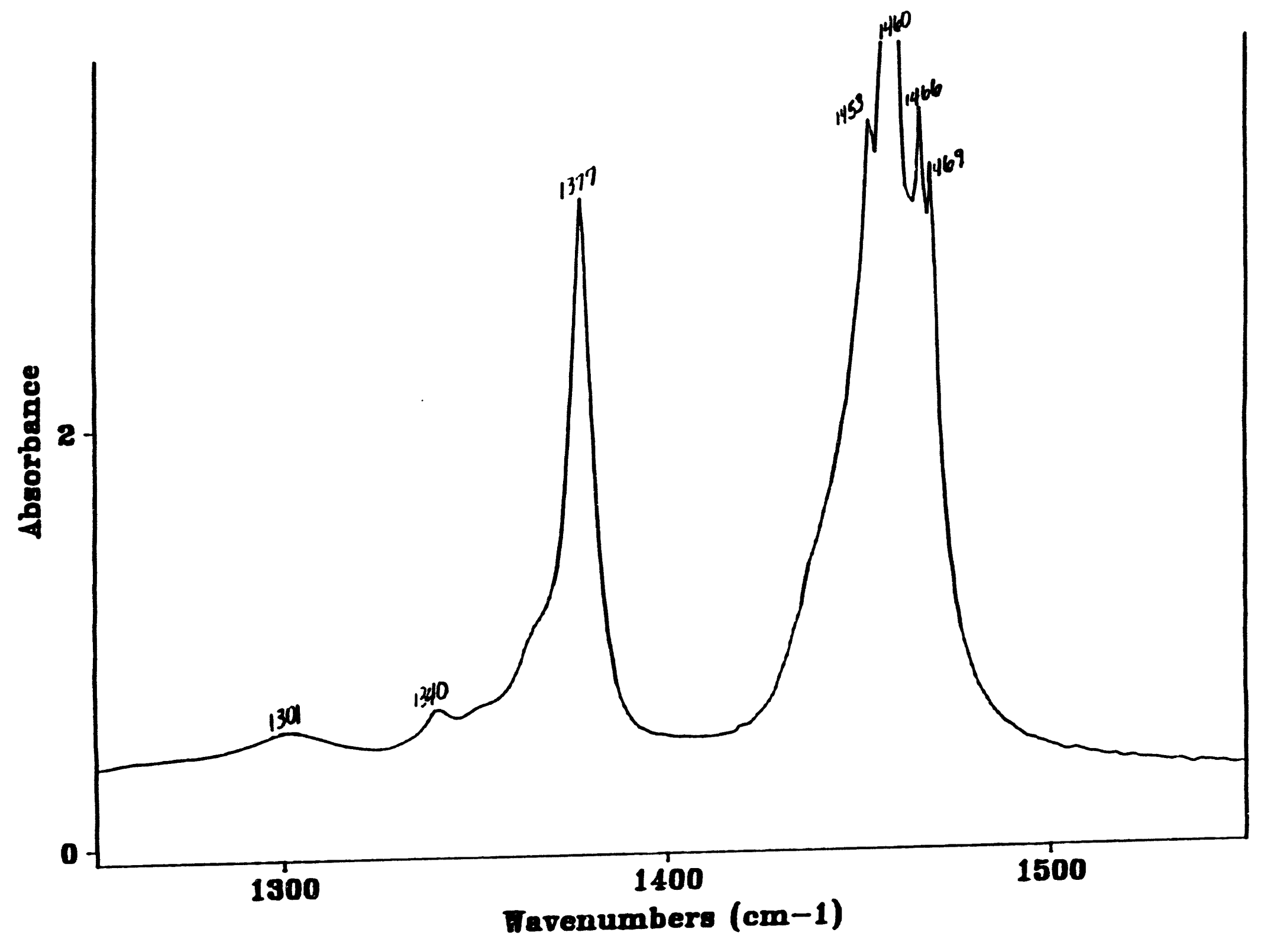

FGURB 4

CLEAN MULTITHERM 503

Res= $2 \mathrm{~cm}-1$ 


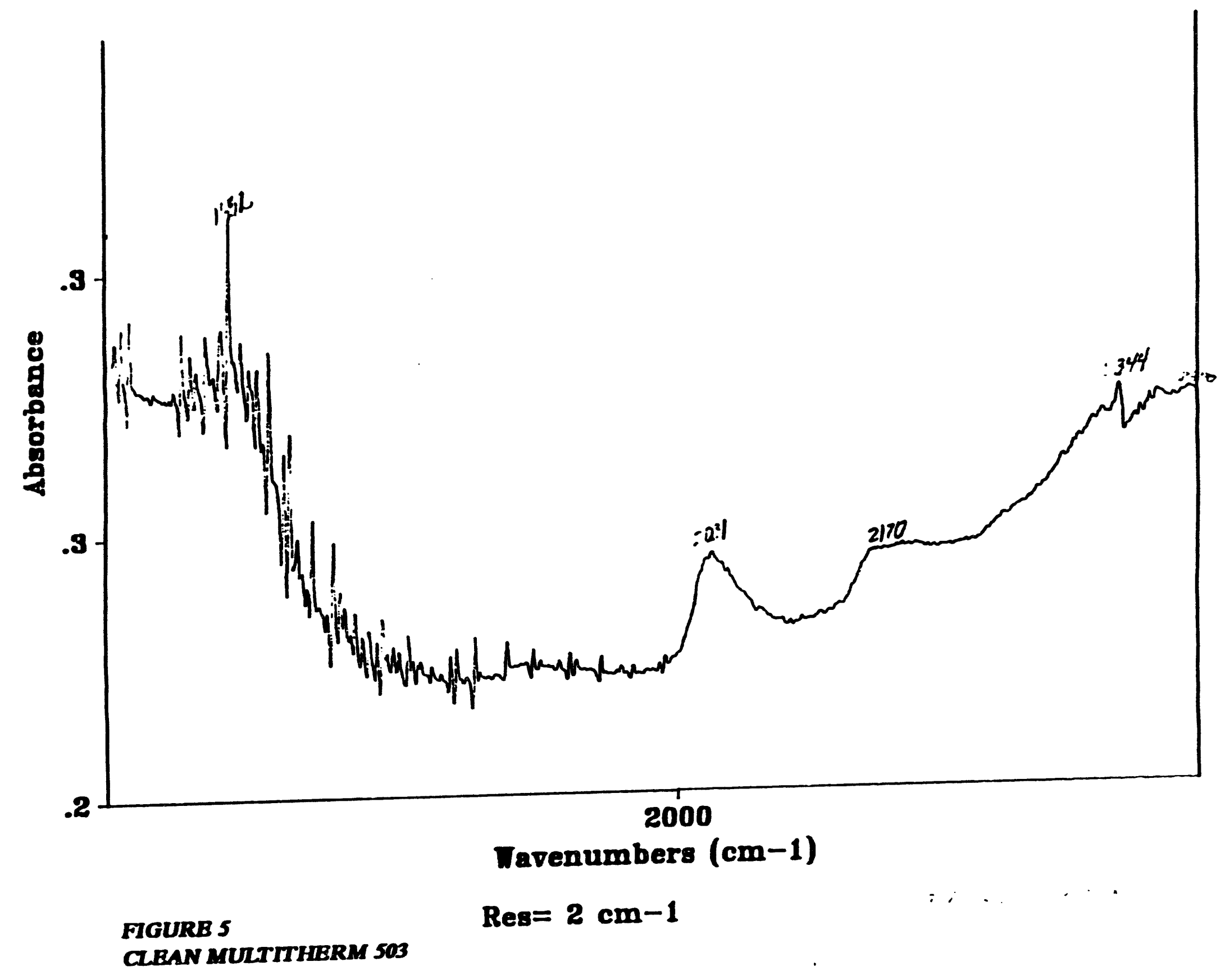




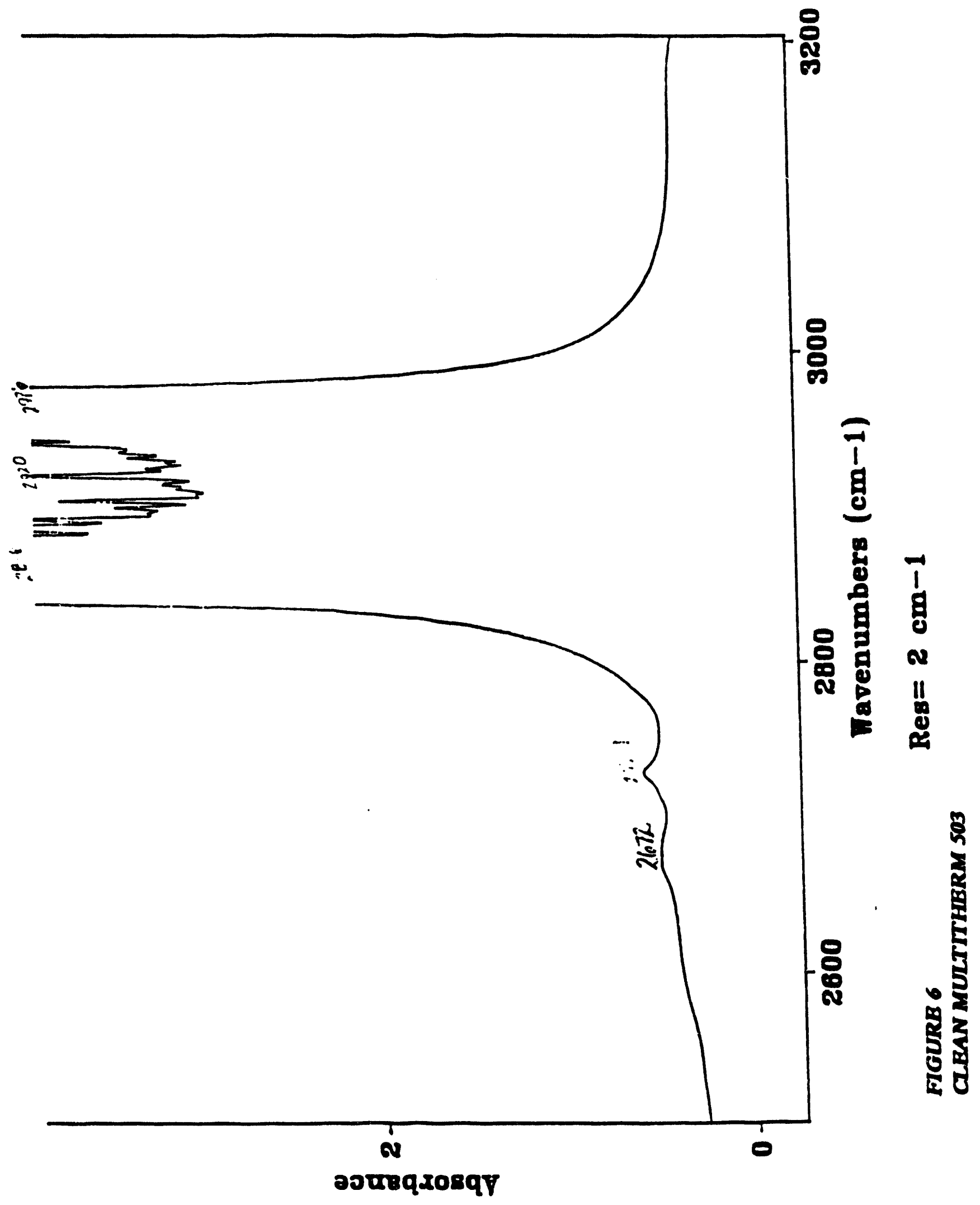




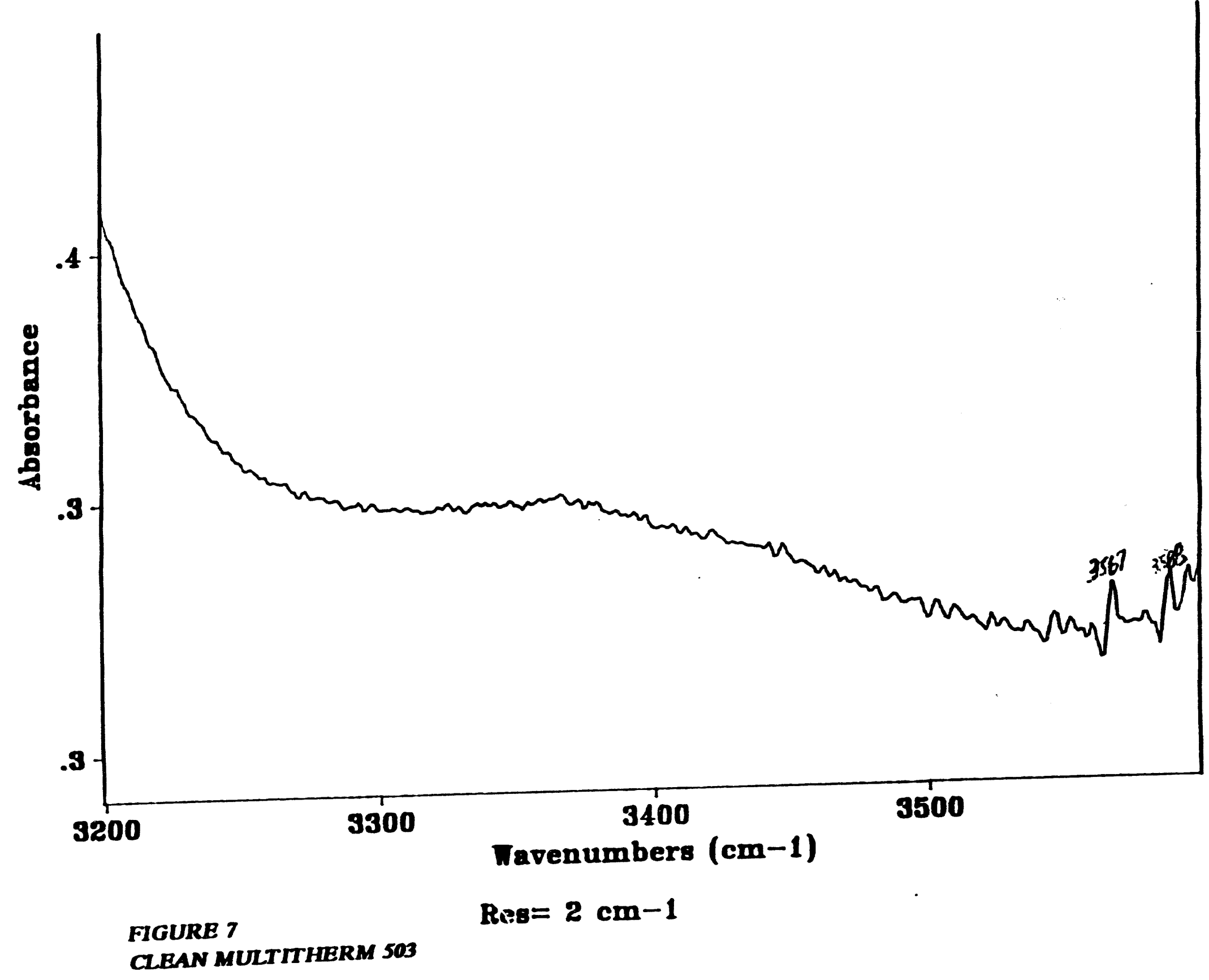




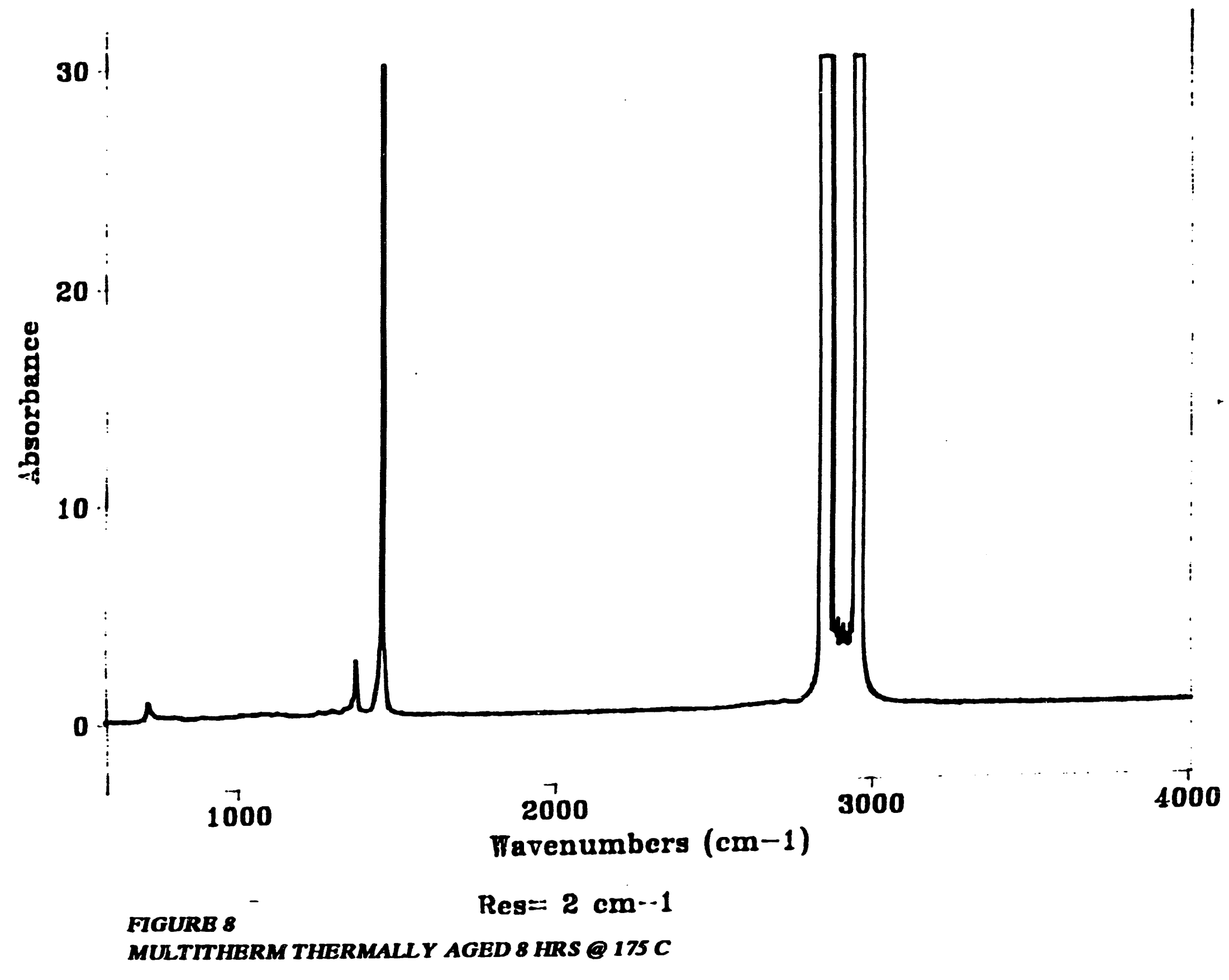




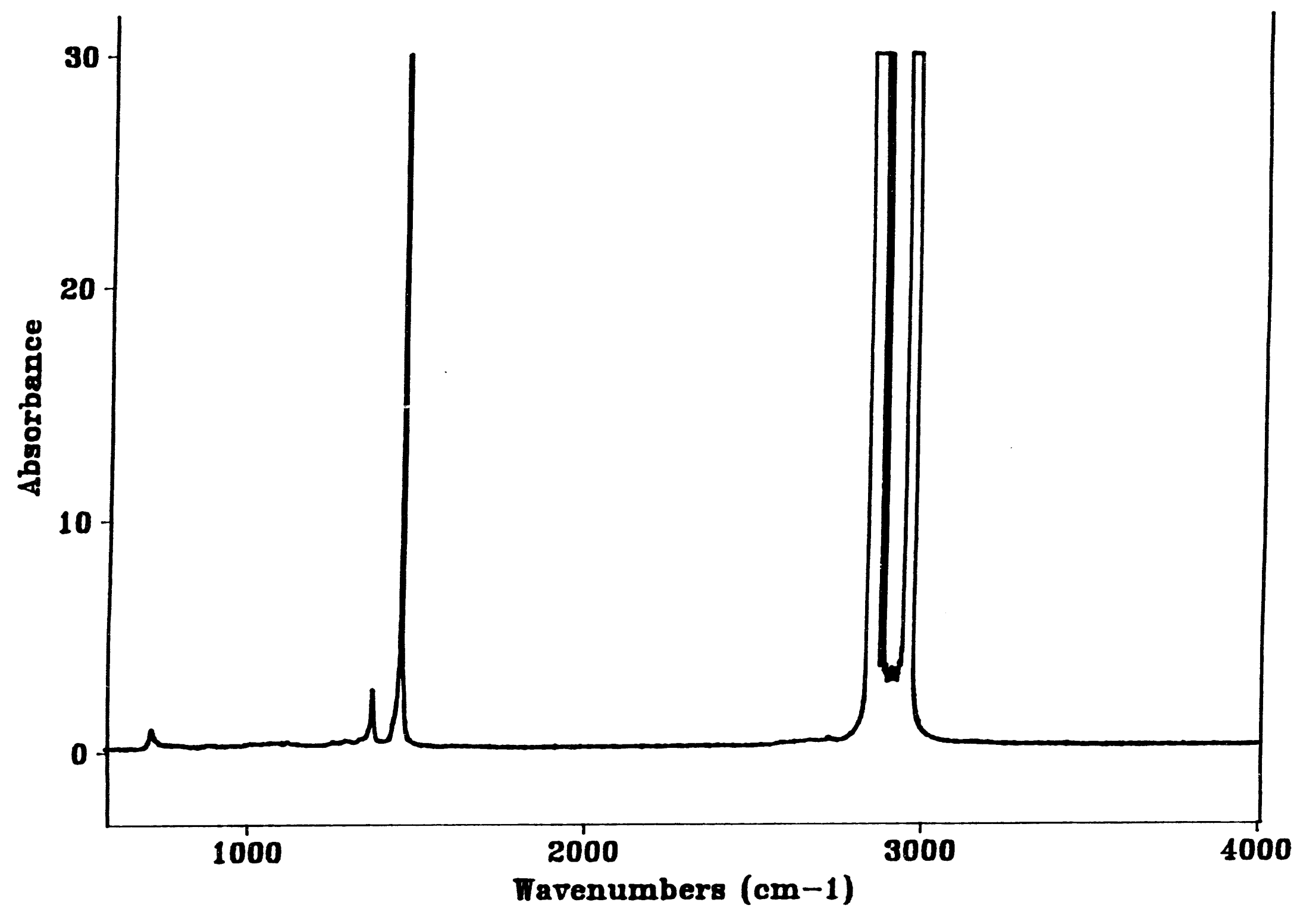

FGURE 9

Res $=2 \mathrm{~cm}-1$

MULTITHERM THERMALY AGED 202 HRS @ 175 C ! 


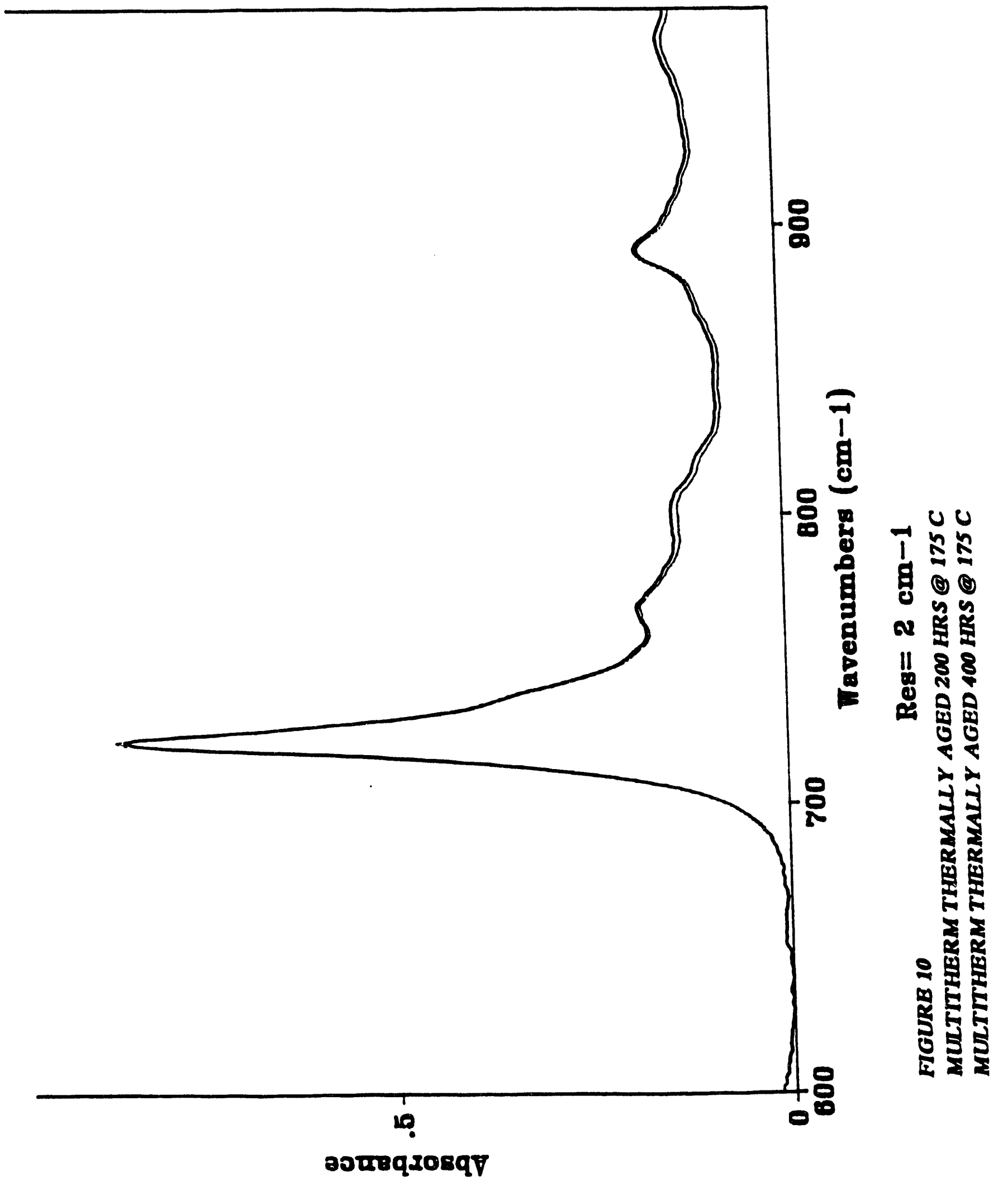




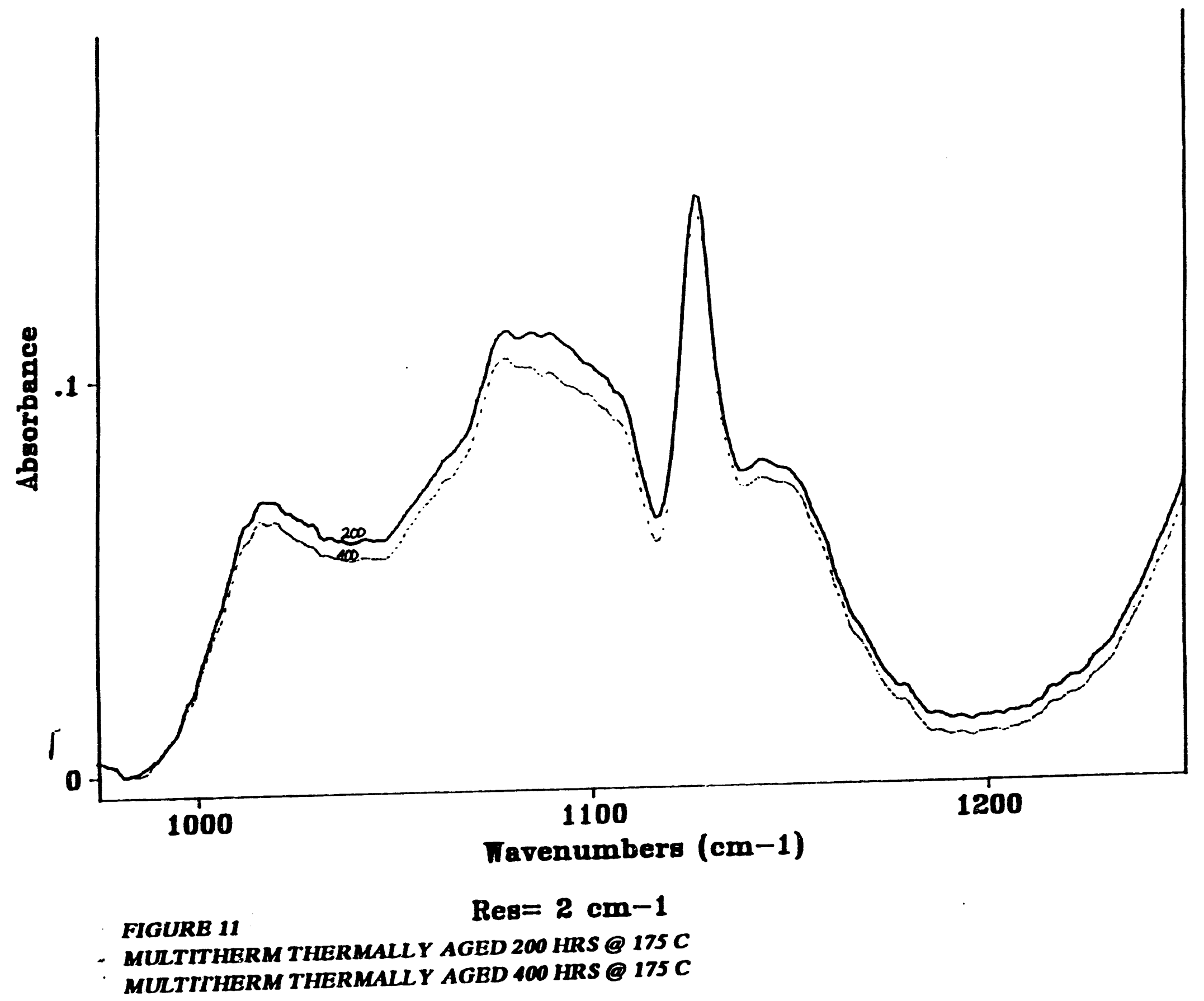




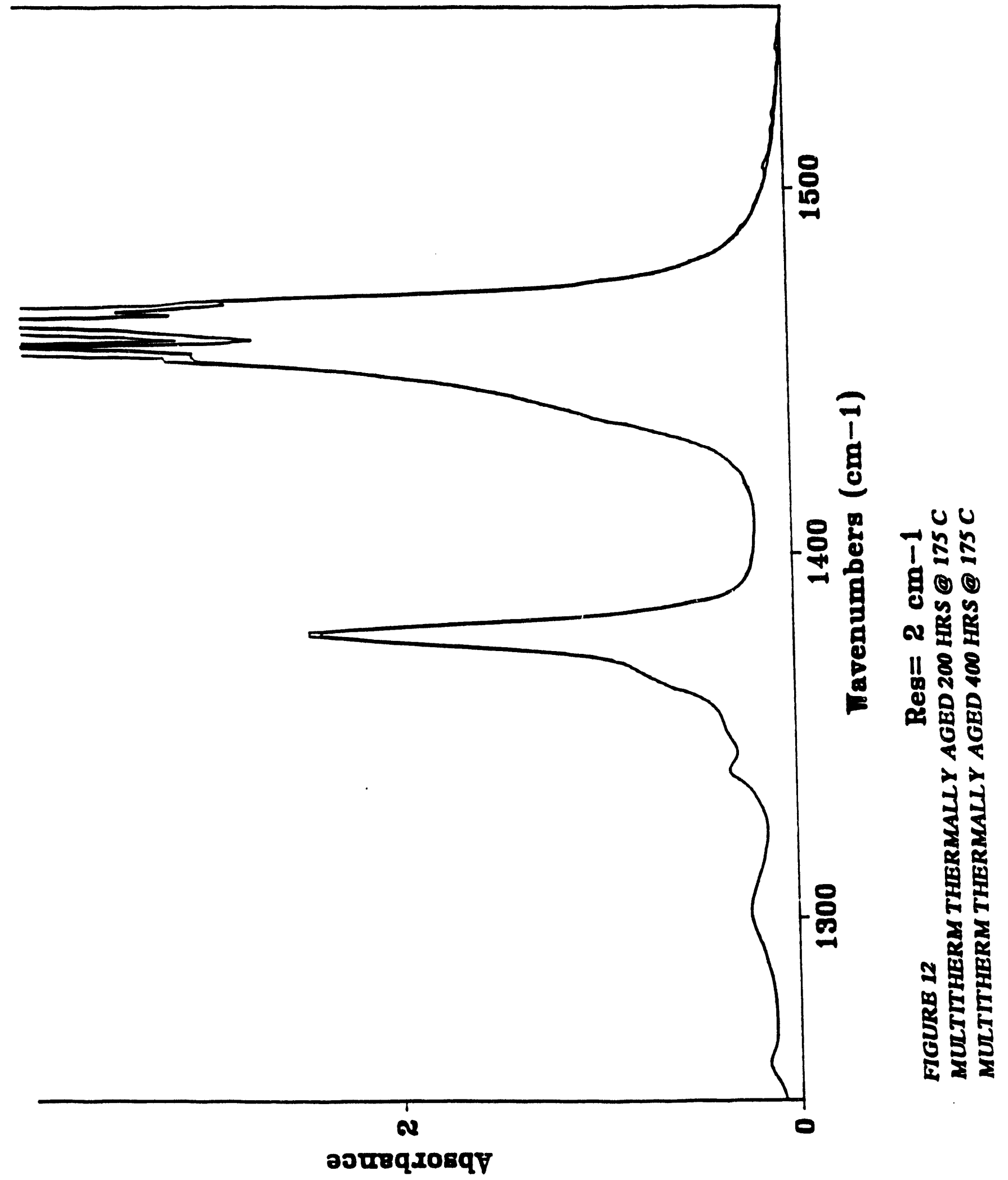




$$
\text { Mw }
$$




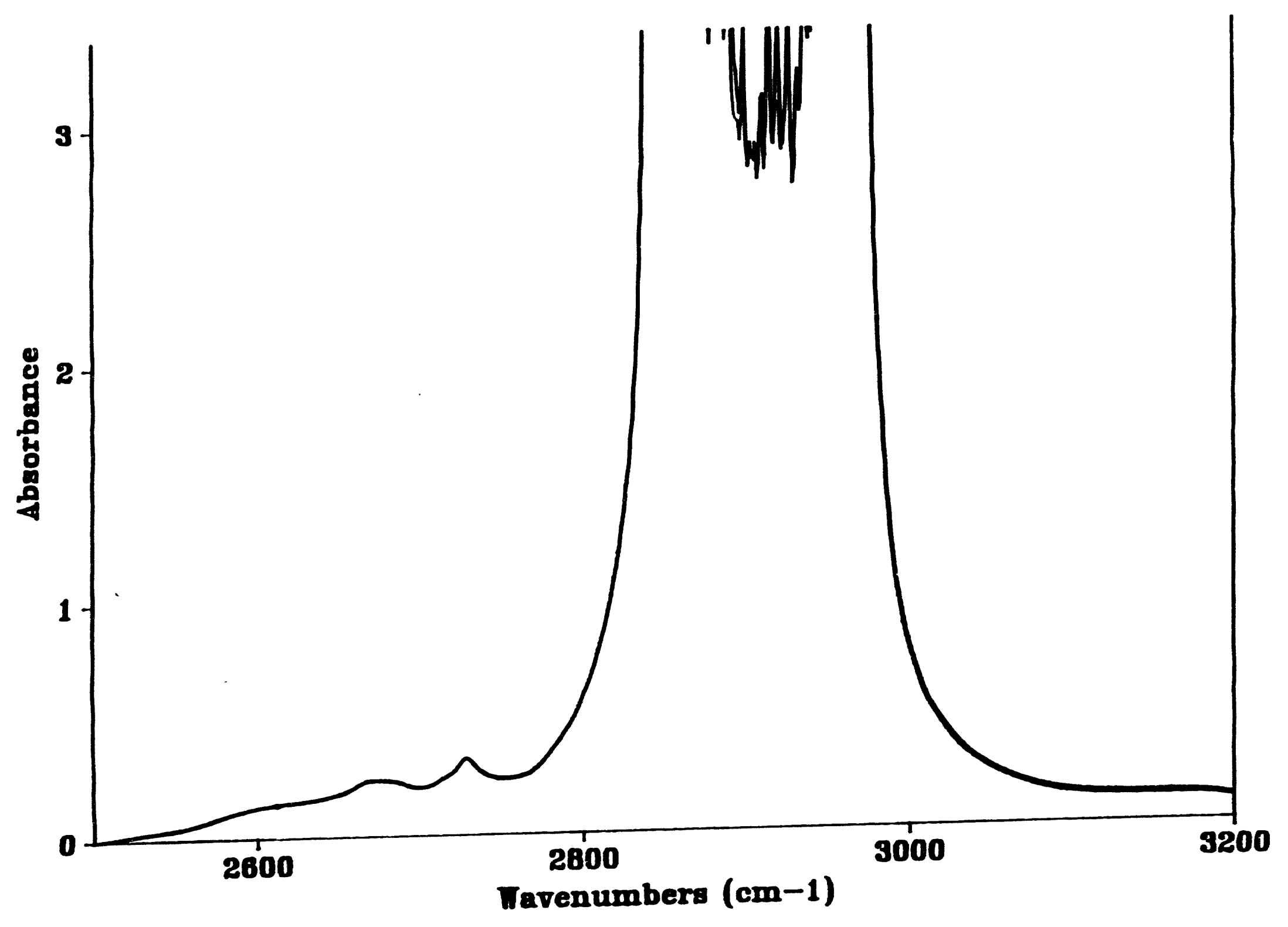

FIGURE 14

Res= $2 \mathrm{~cm}-1$

MULTITHERM THERMALLY AGED 200 HRS @ $175 \mathrm{C}$

MULTITHERM THERMALLY AGED 400 HRS@ 175 C 


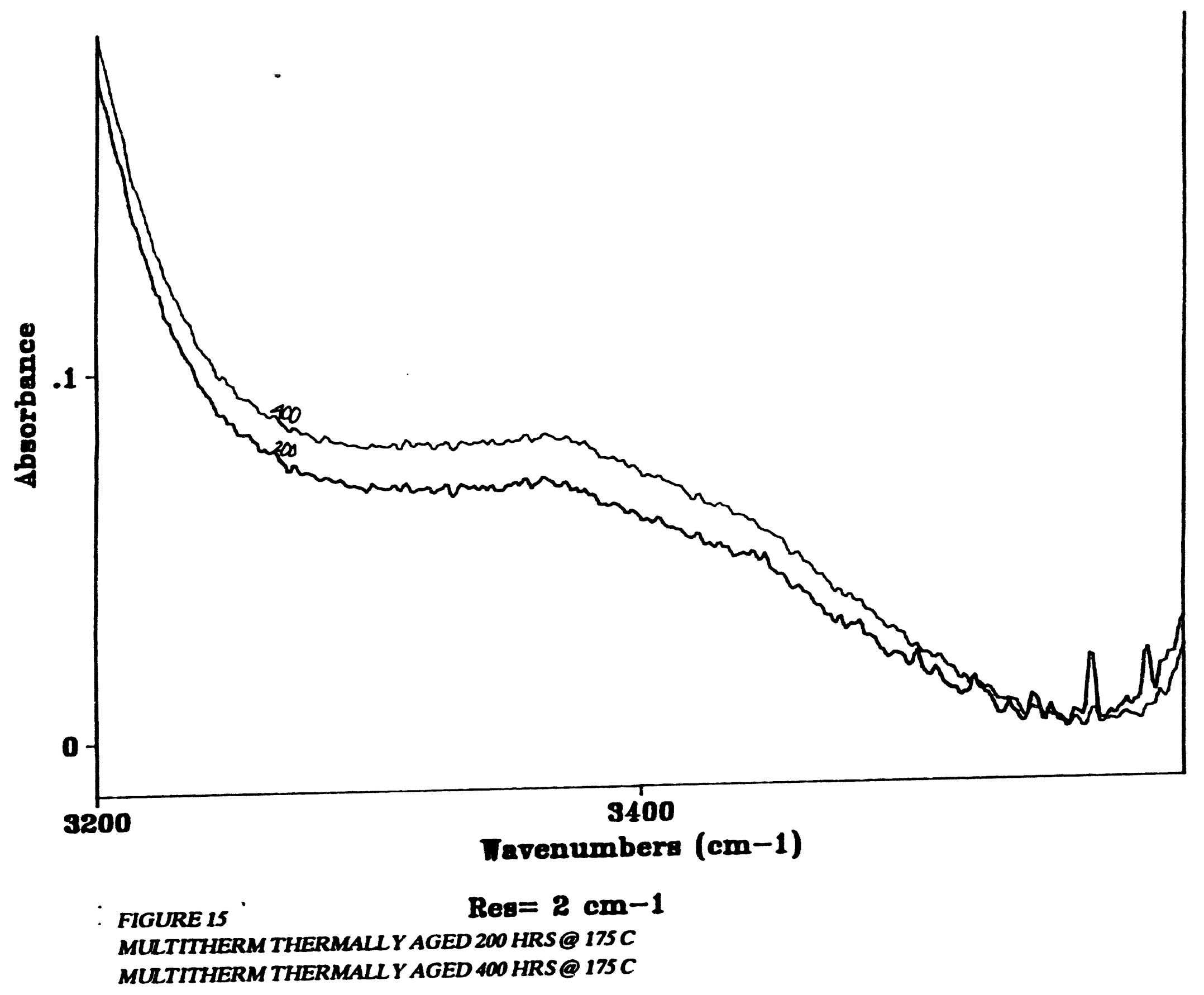




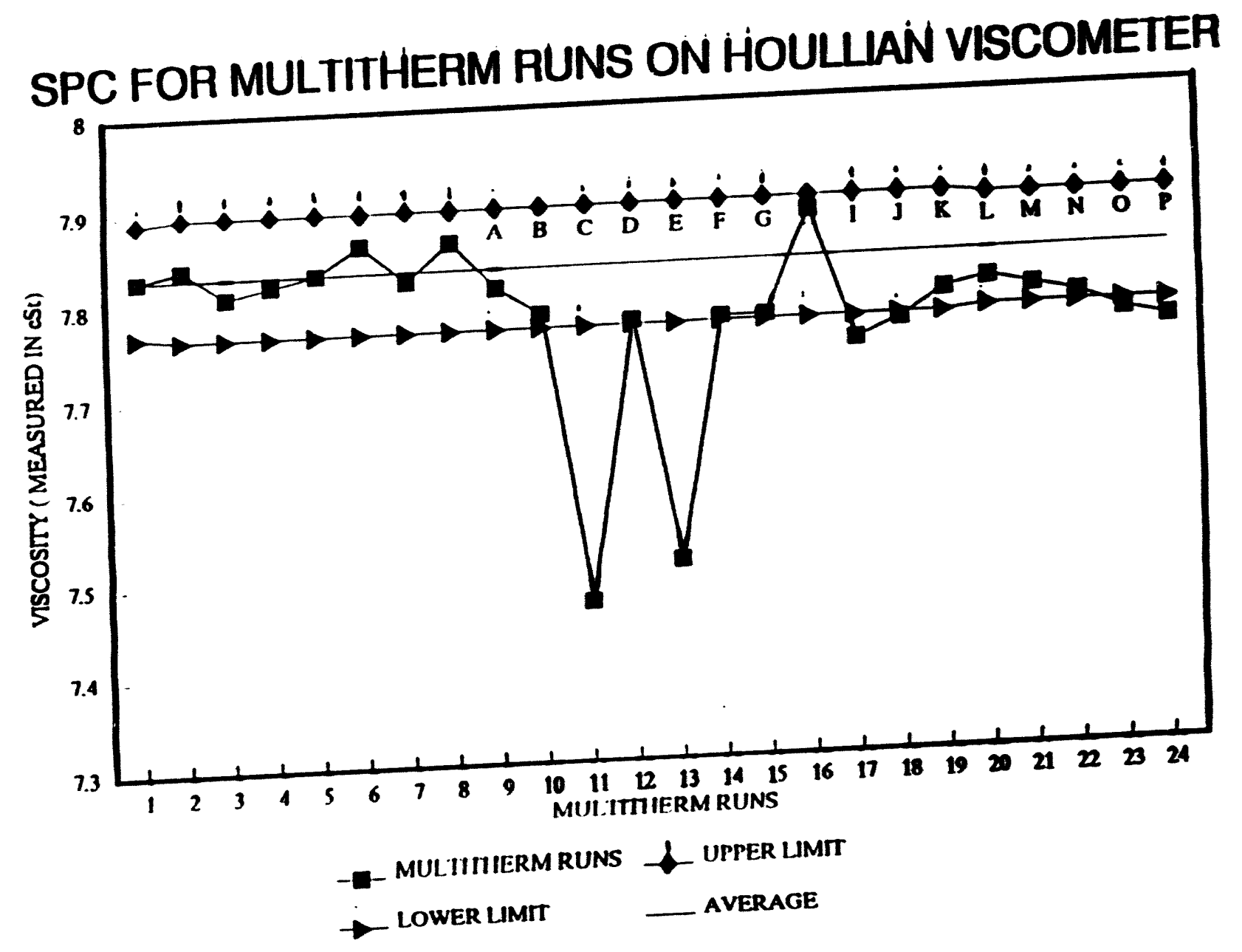

= chen moLriruen:

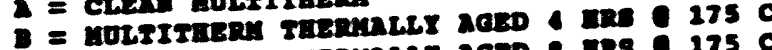

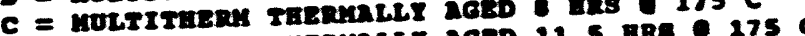

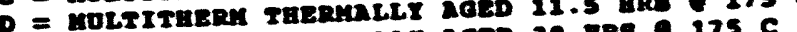

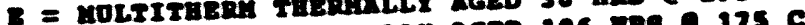

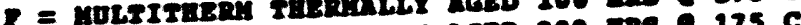

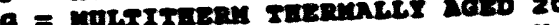

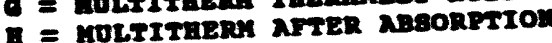

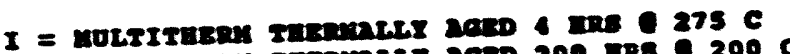

(200 C 200

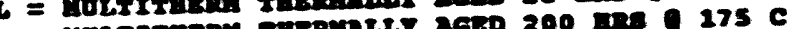

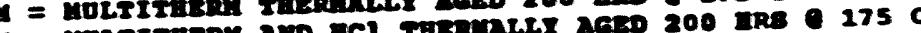

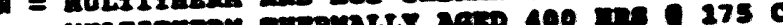

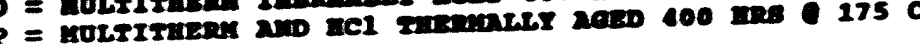




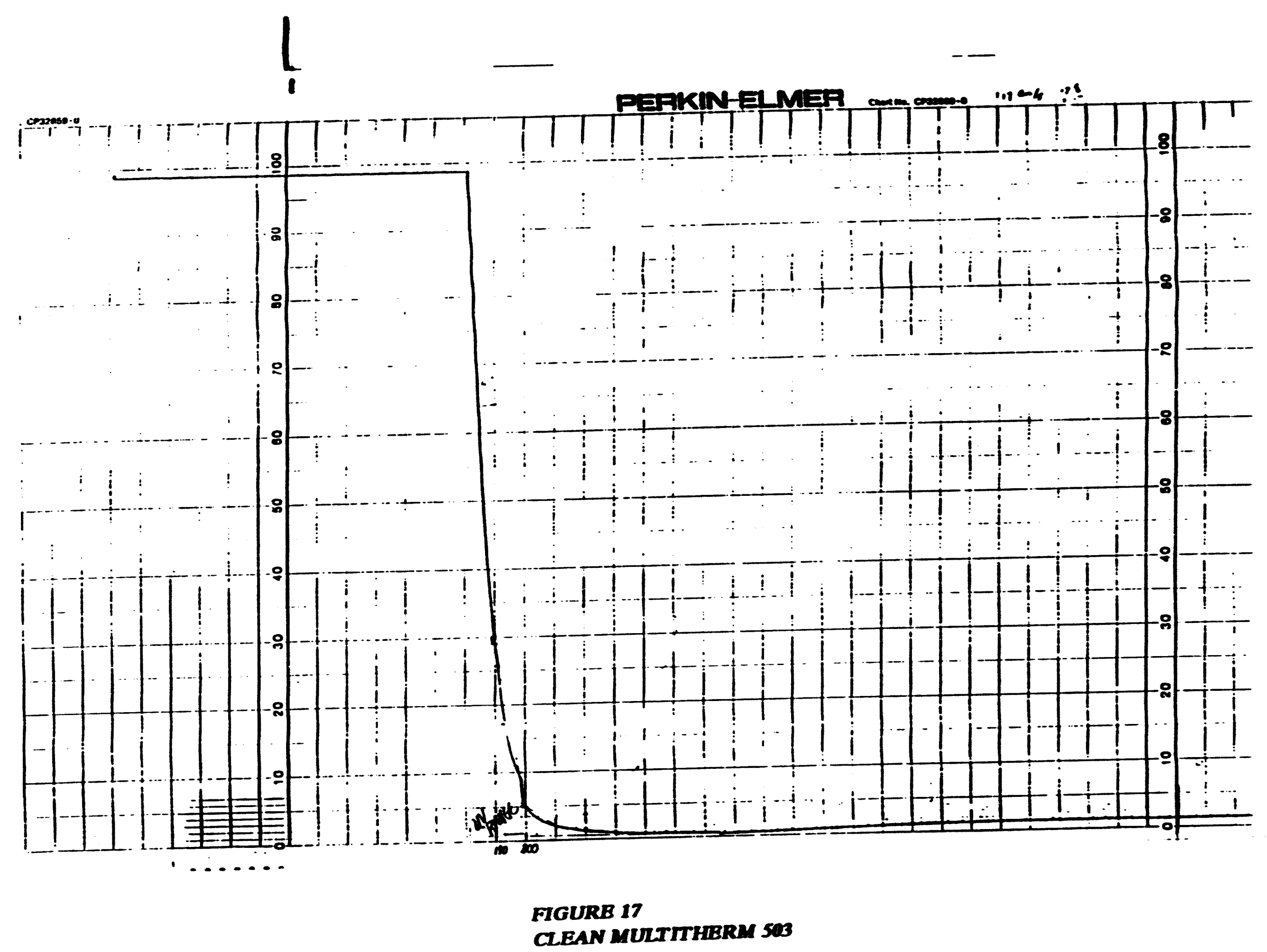




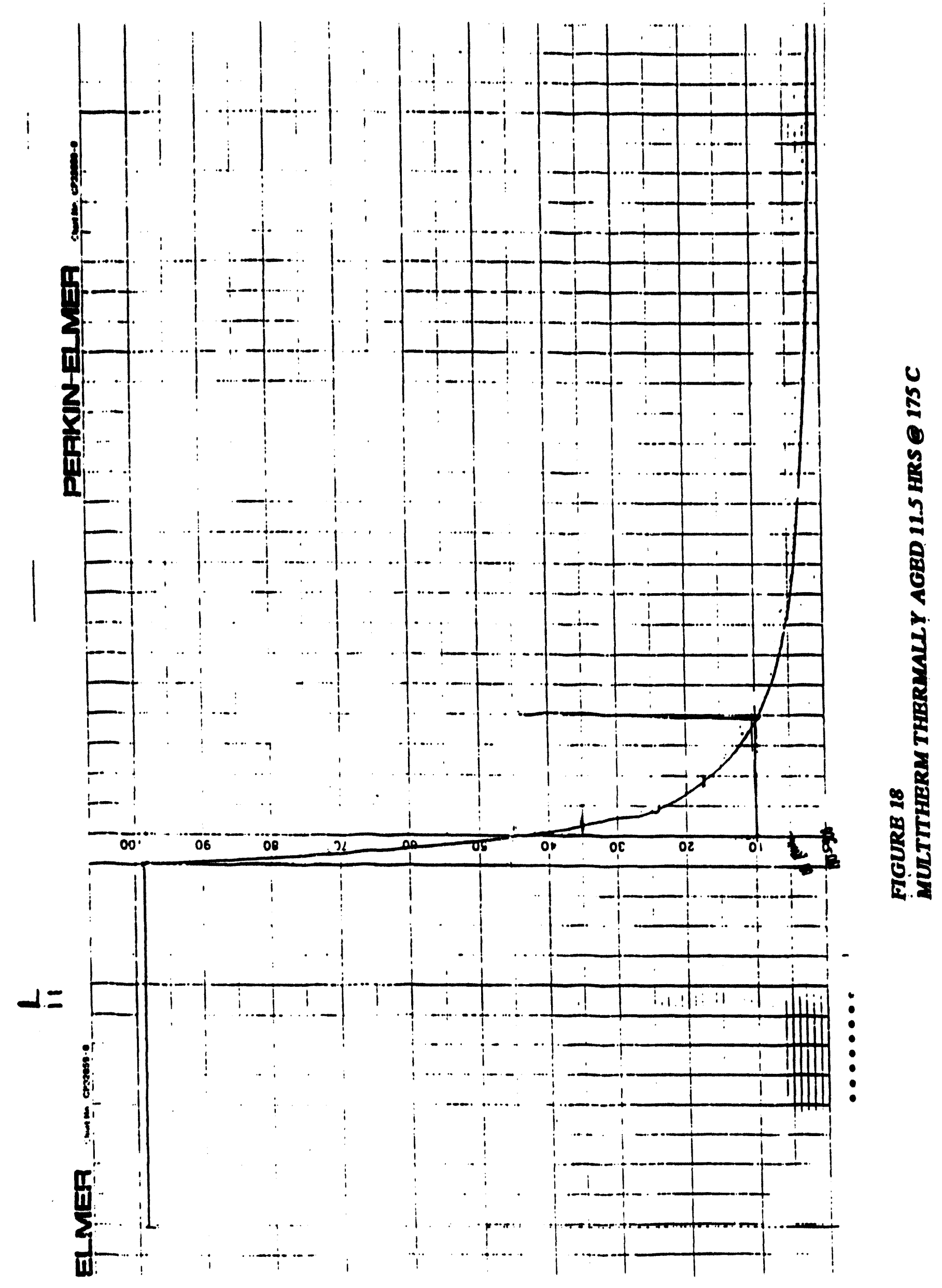




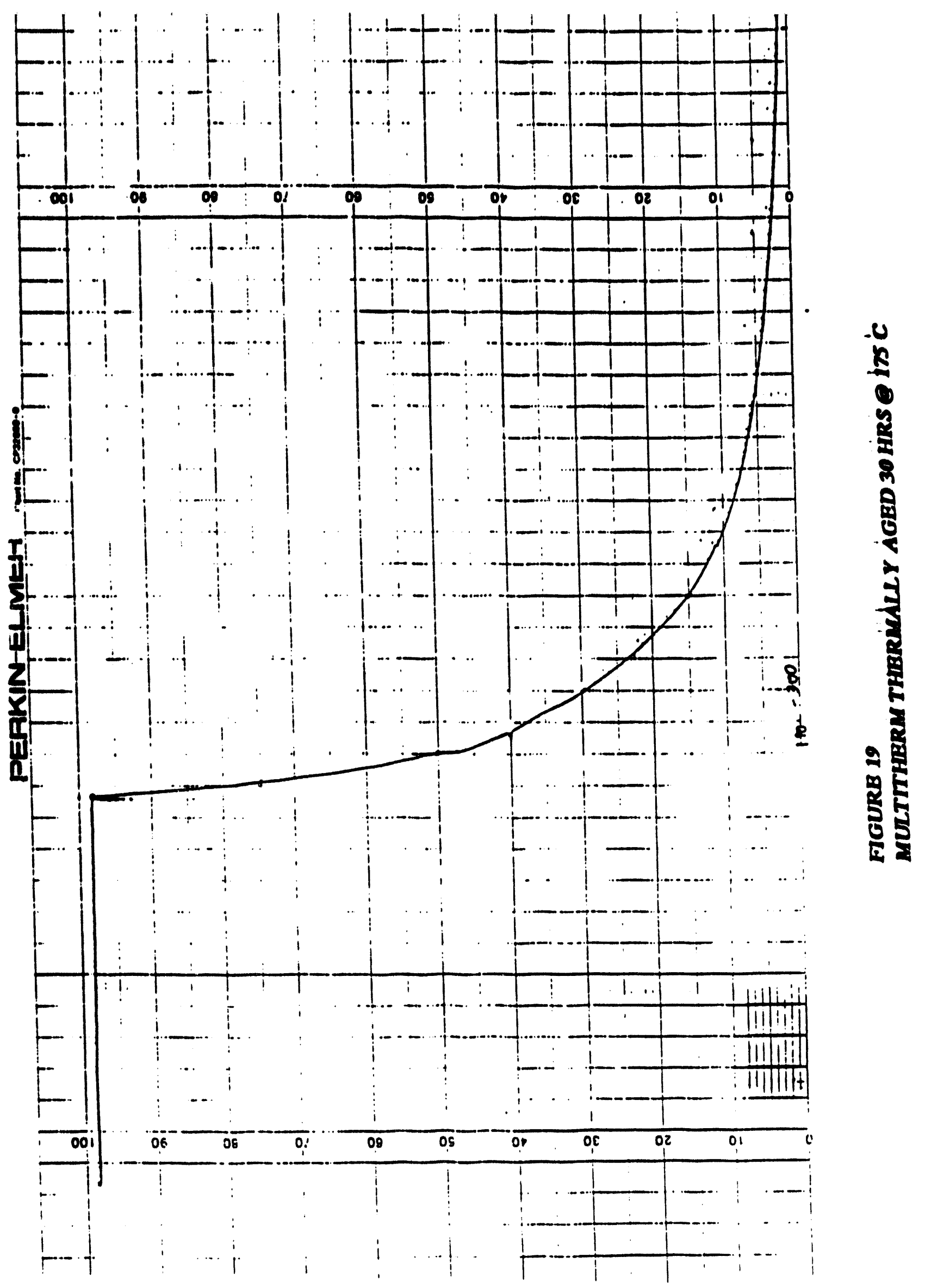




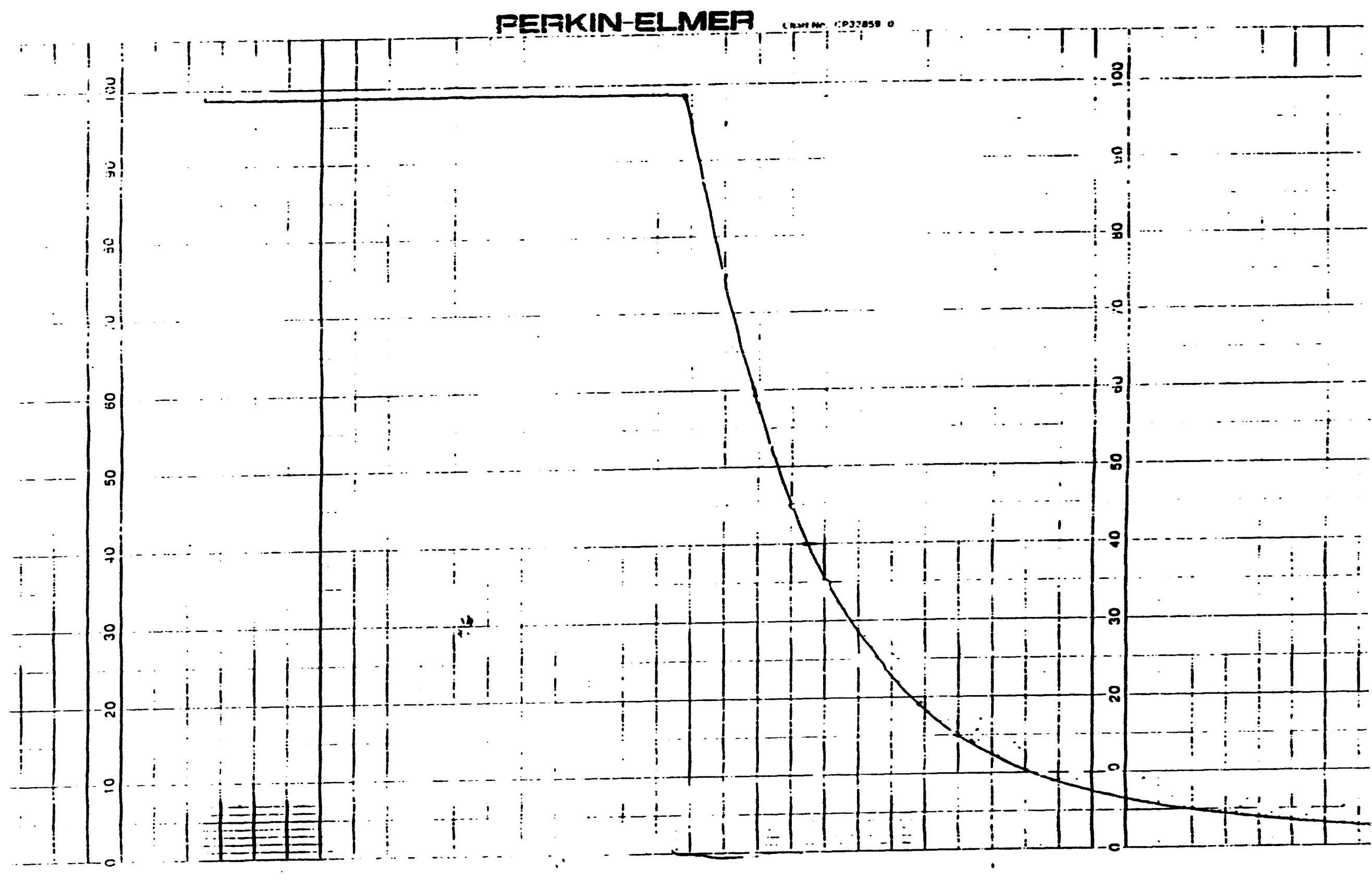




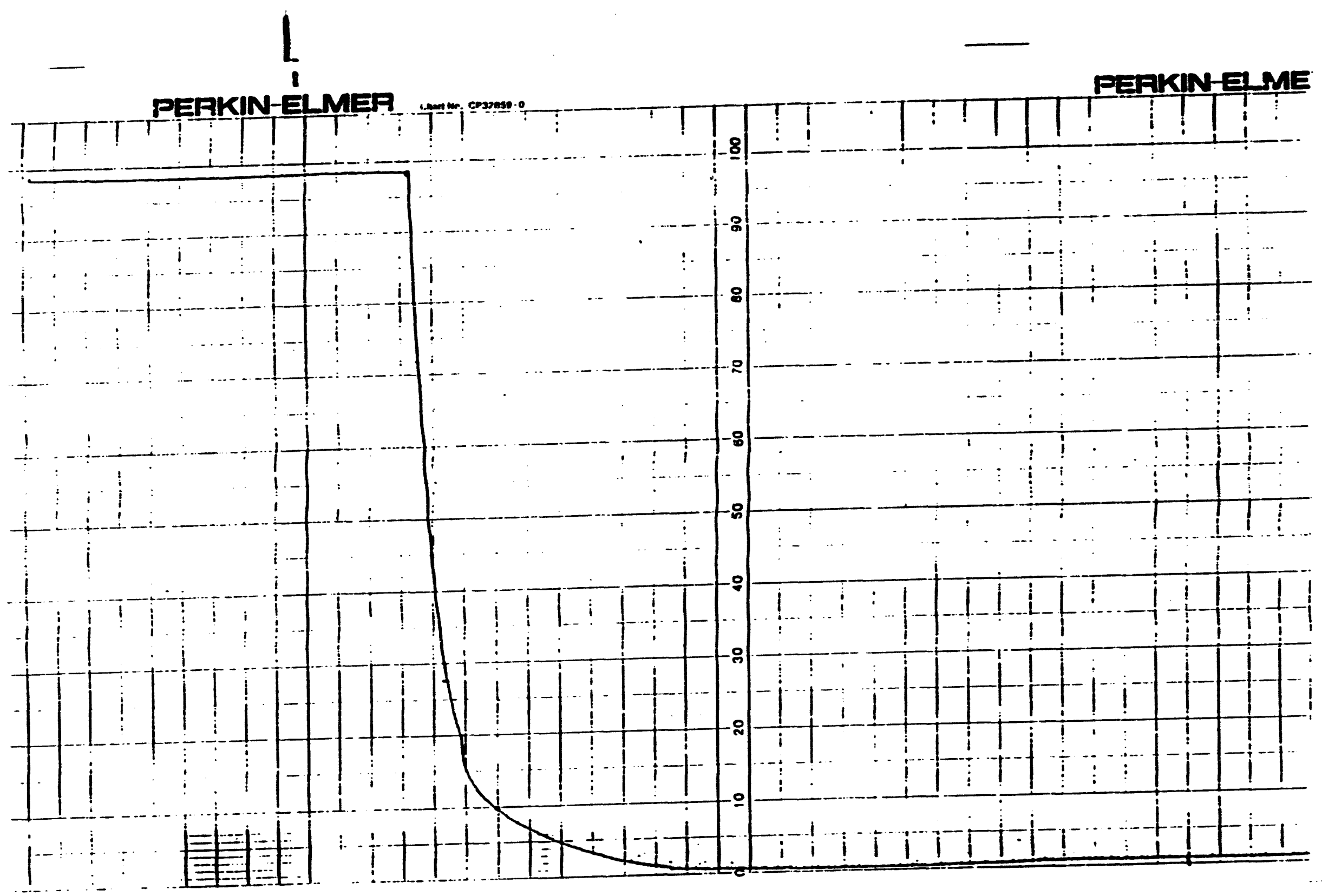

FGURB 21

MULTITFIRM THRRMALY AGBD 200 FRS O 200 C 


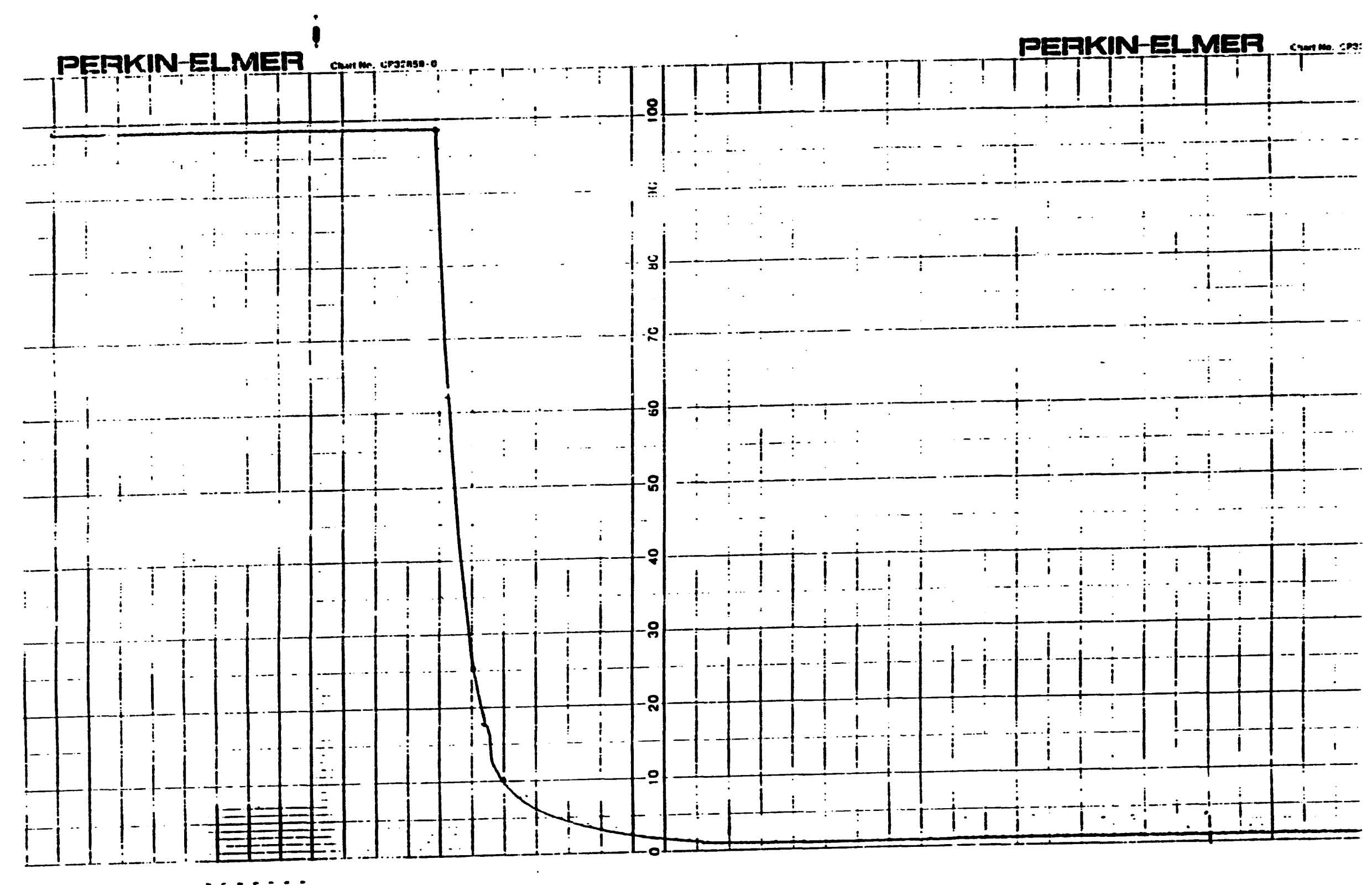



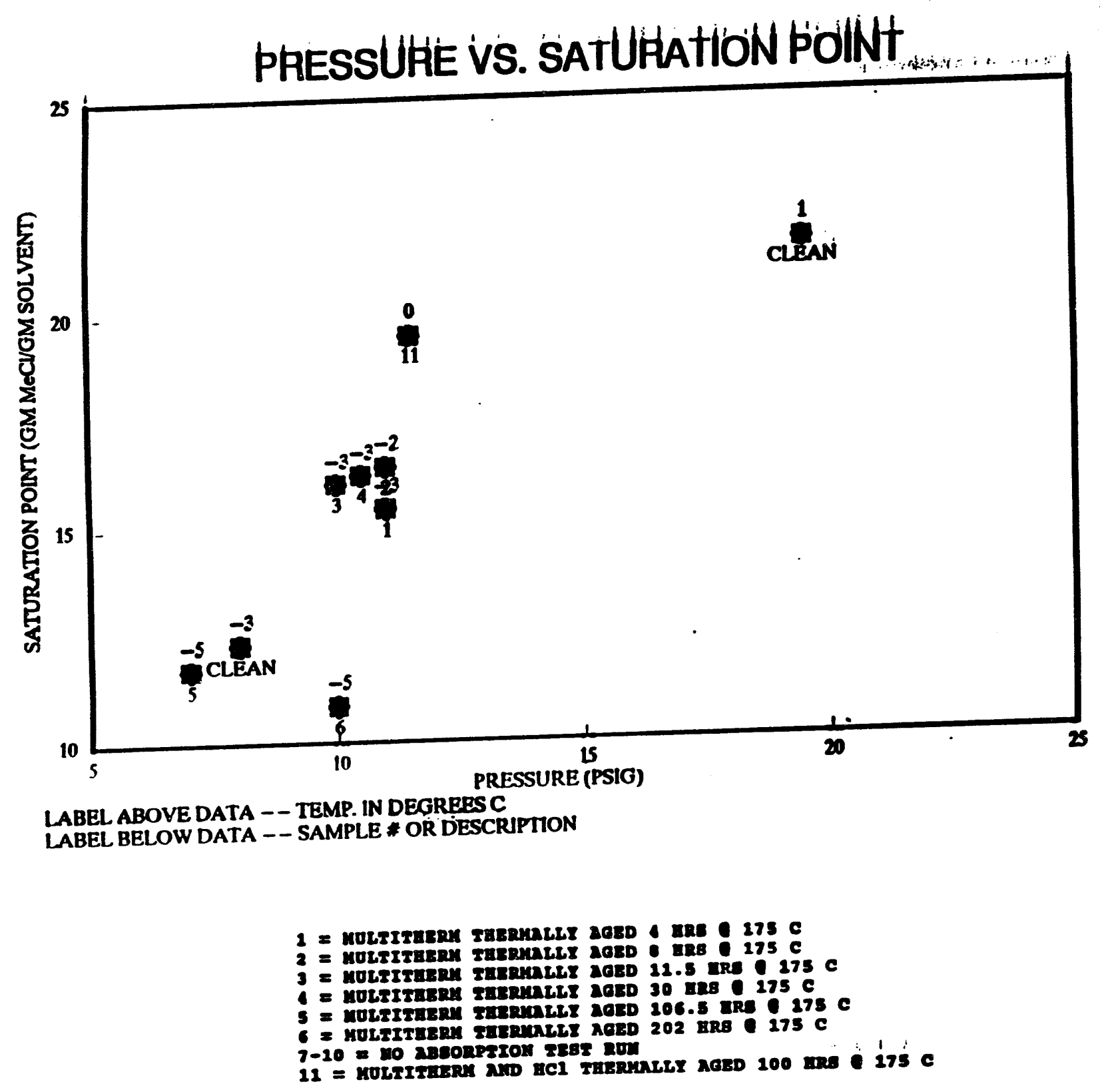

FIGURE 23 


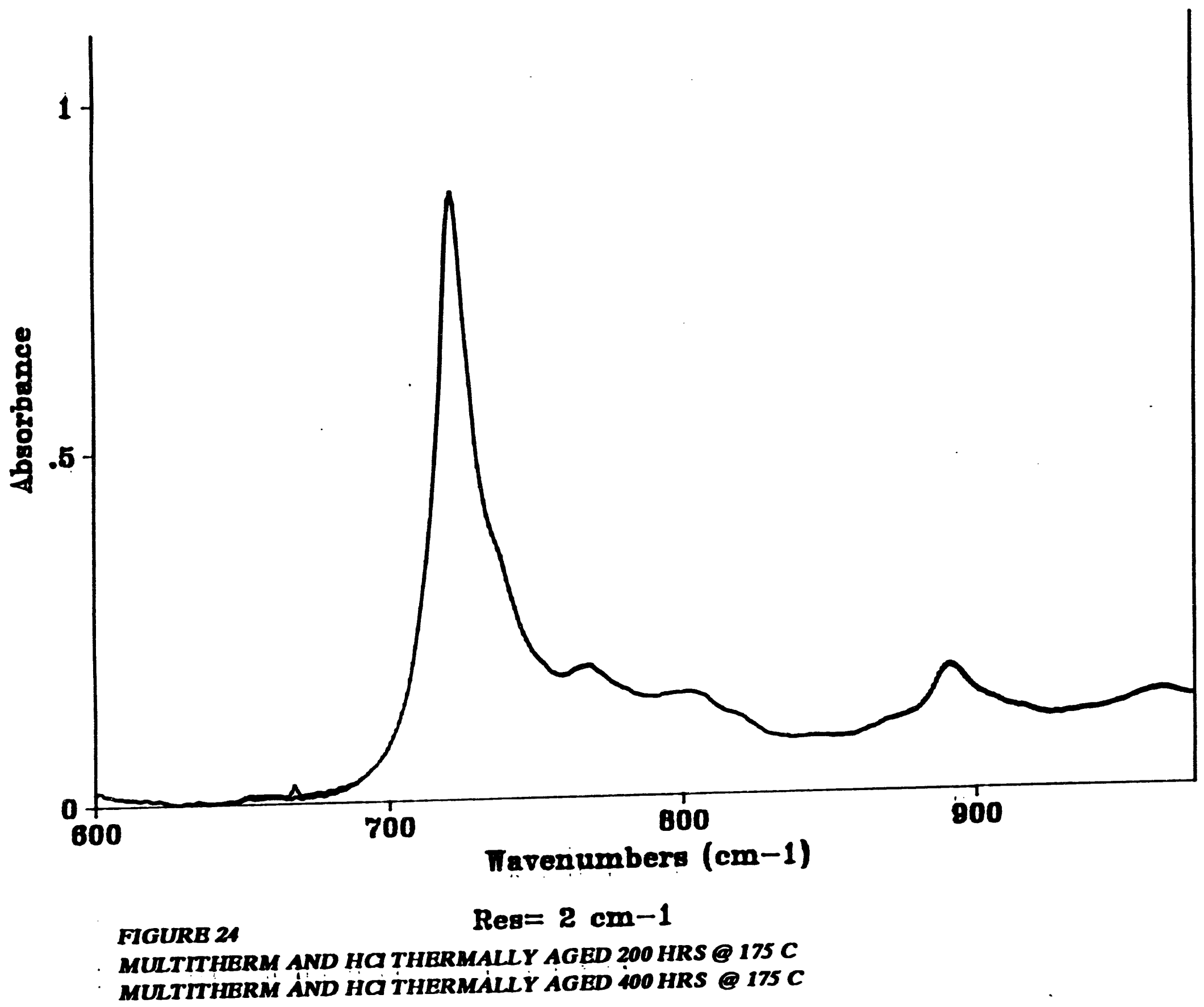




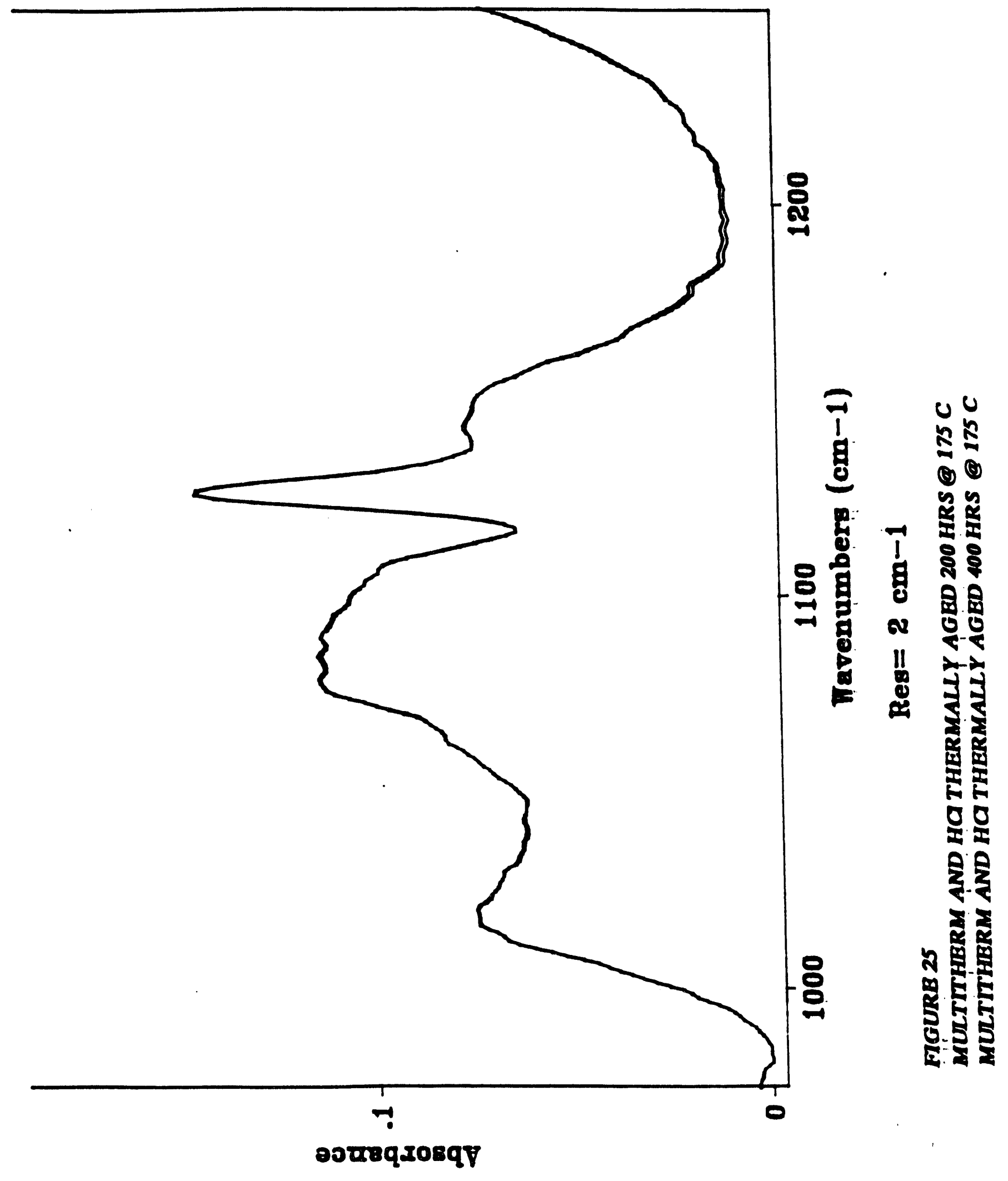




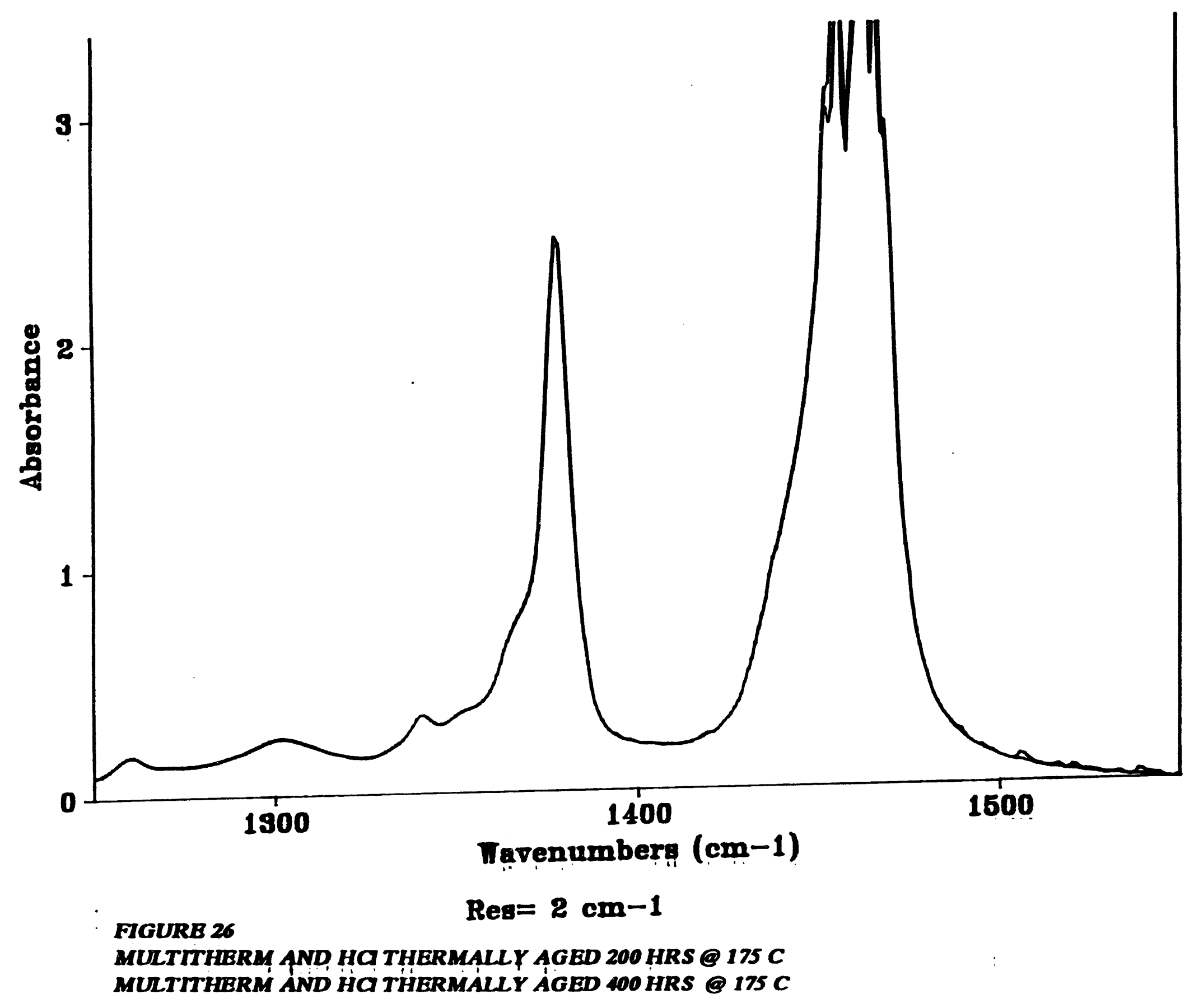




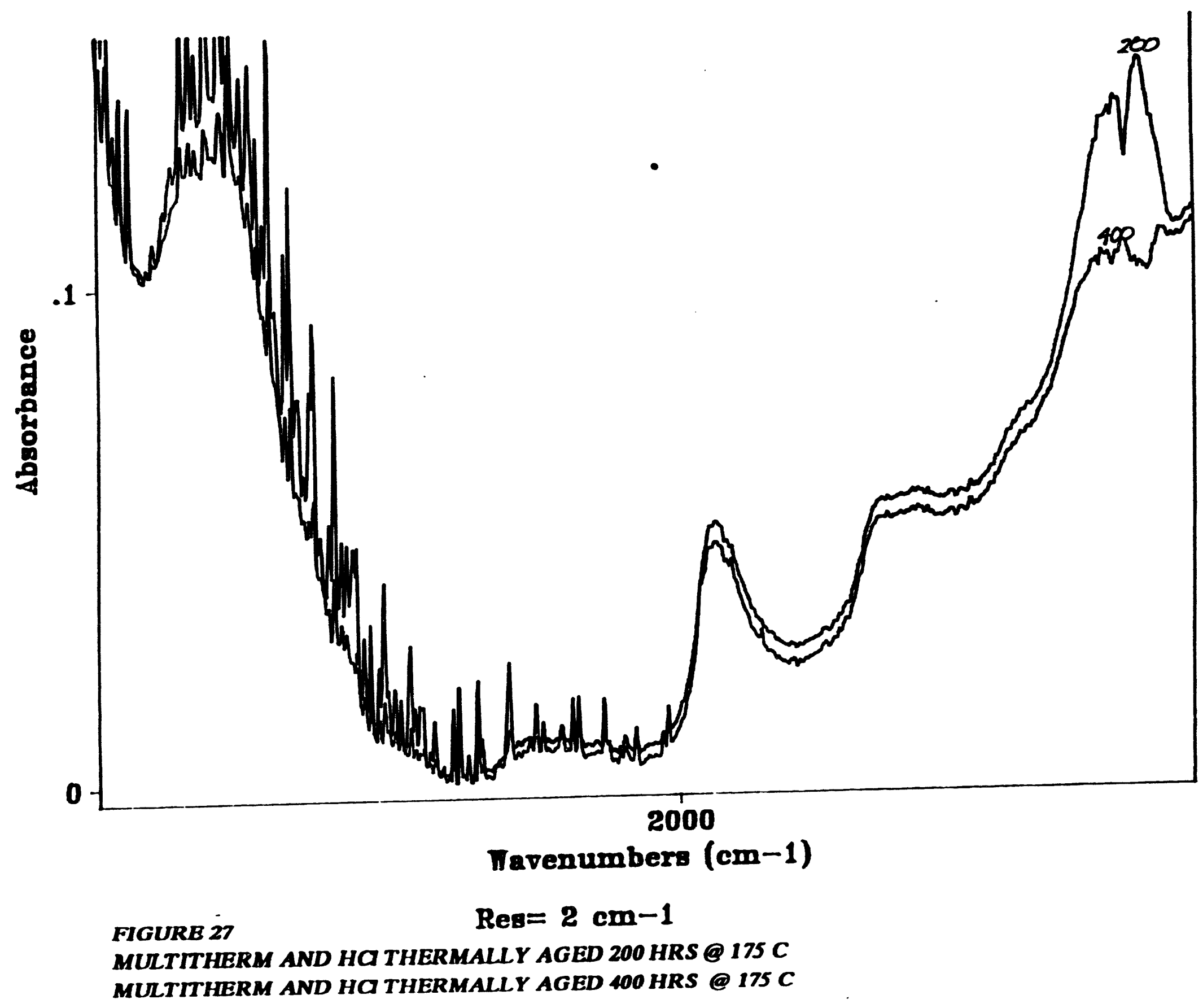




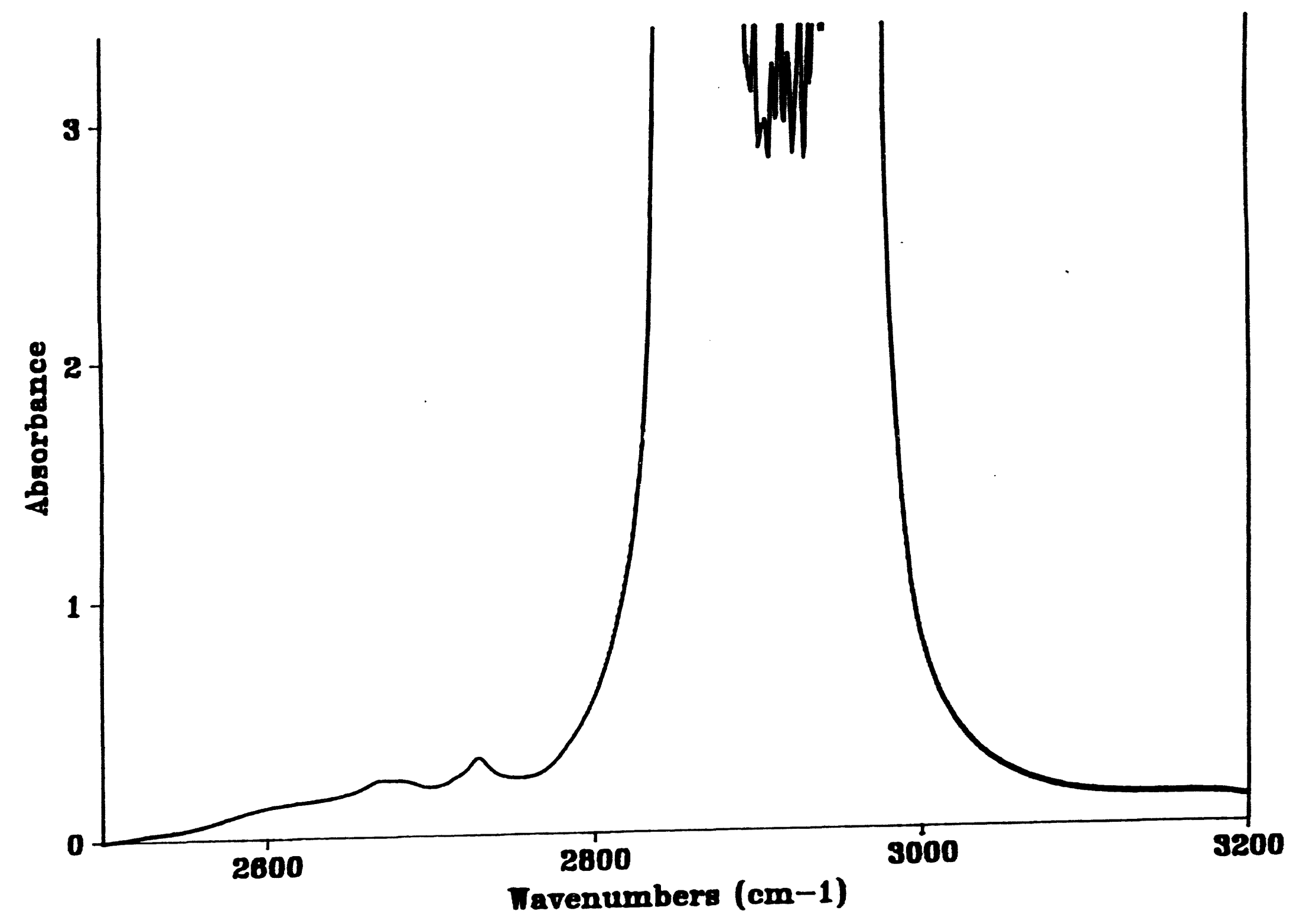

FIGURB 28

Res= $2 \mathrm{~cm}-1$

MUITITHERM AND HCT THERMALLY AGED 200 HRS @ 175 C MUITTHERM AND HOTHERMALLY AGED 400 HRS @ 175 C 


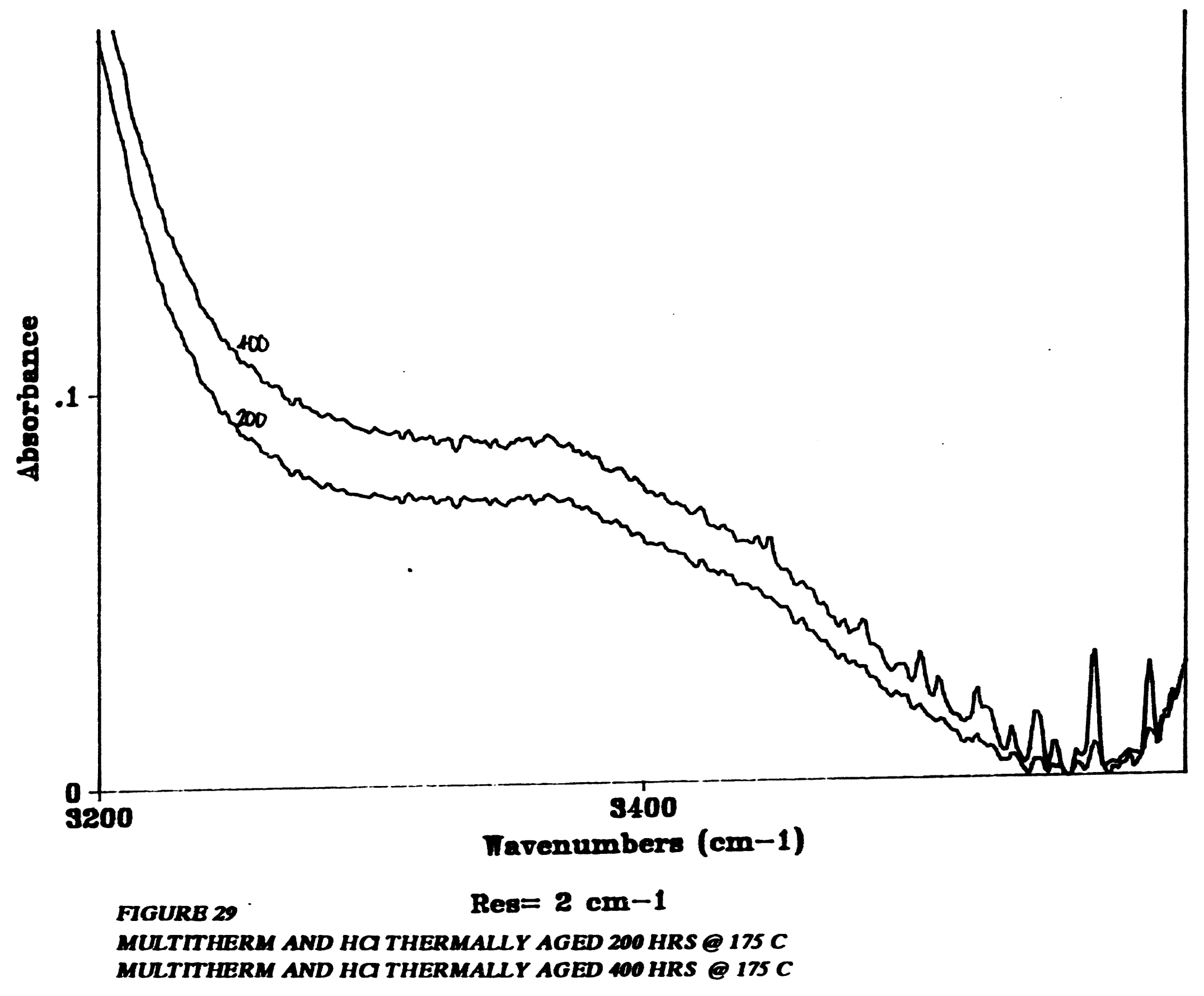




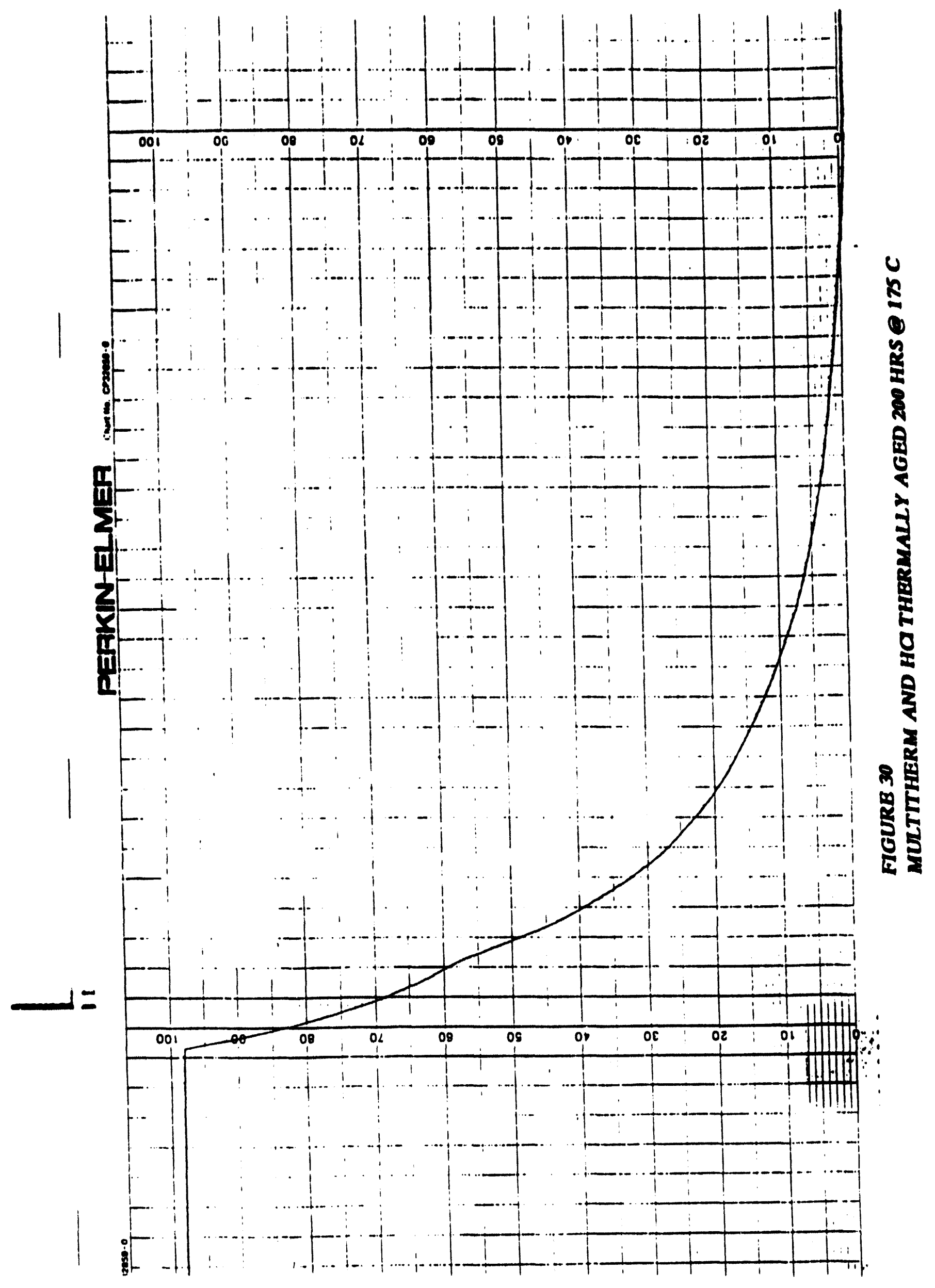




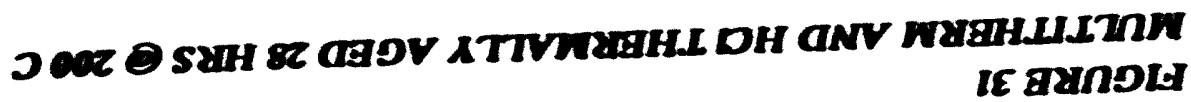

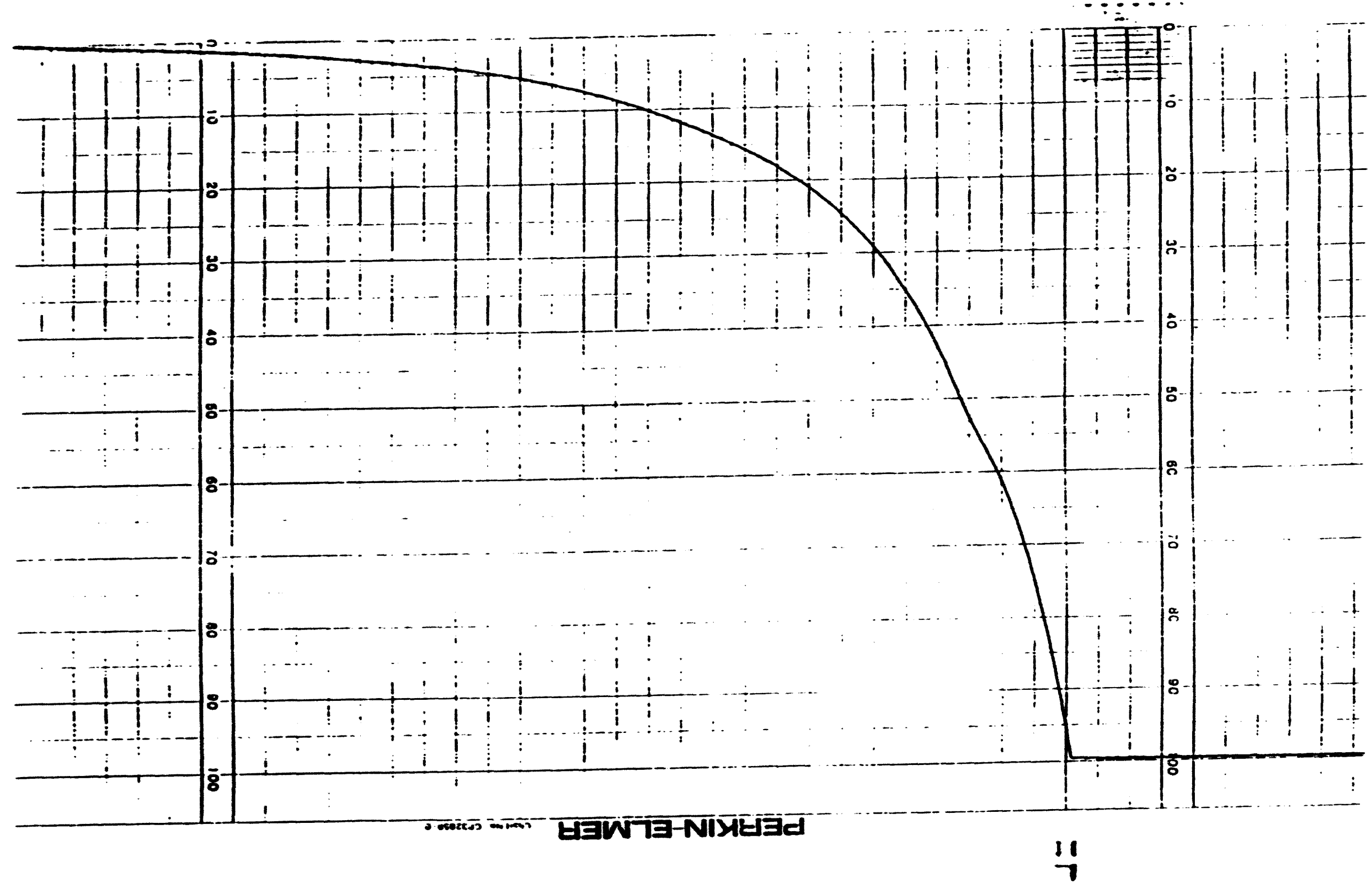




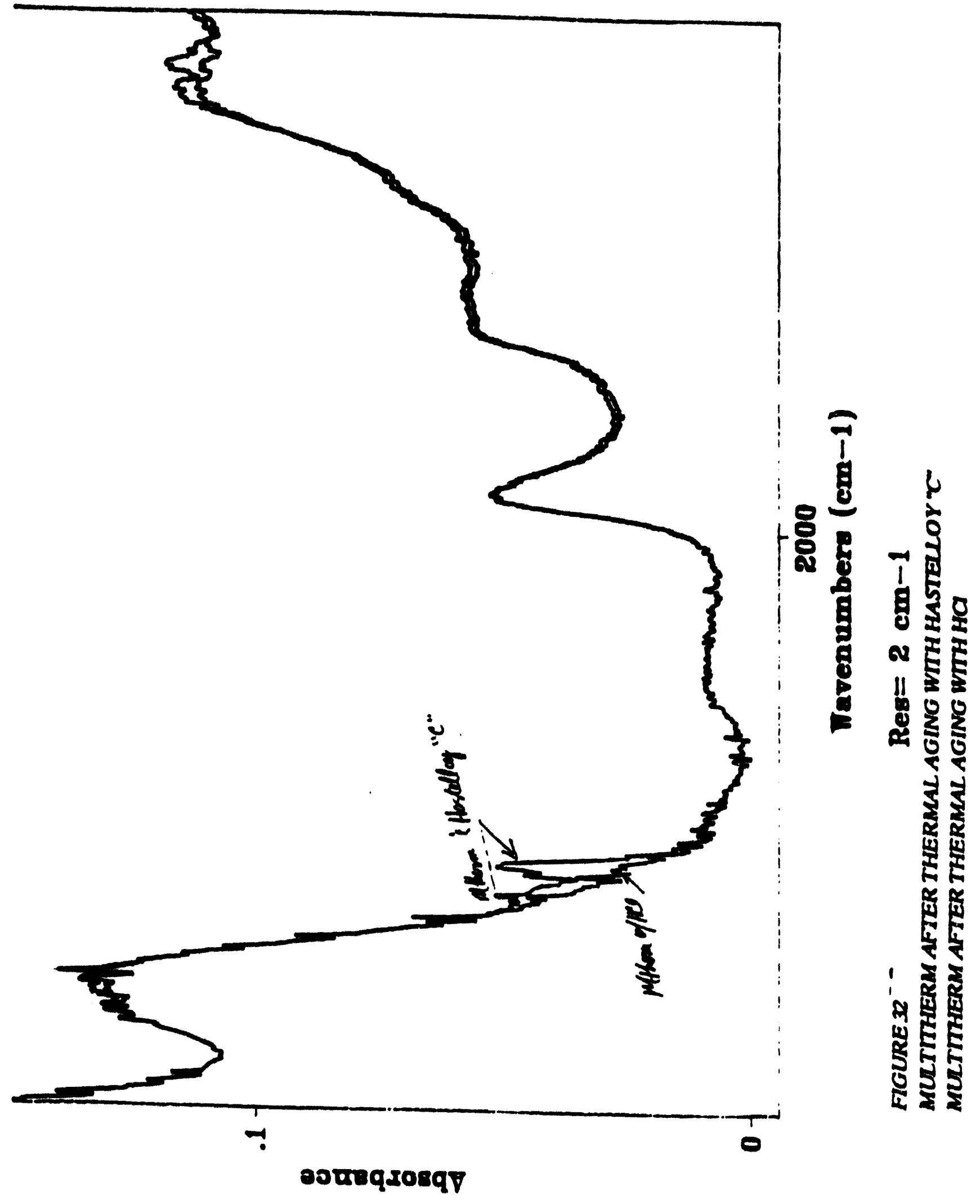


<smiles></smiles> 


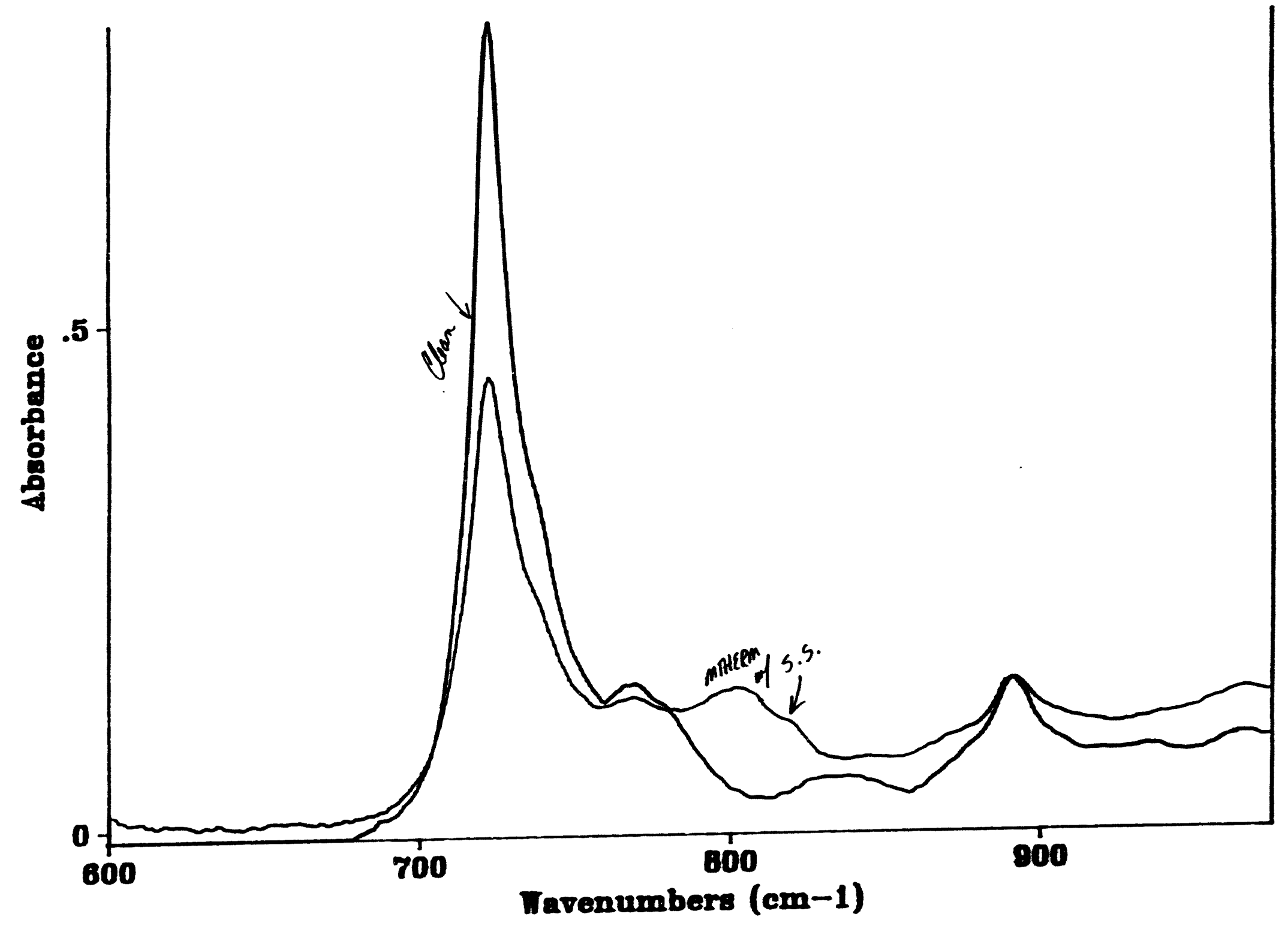

FIGURB 34

$\operatorname{Res}=2 \mathrm{~cm}-1$

CLEAN MULTITHERM

MULTITHERM AFTER THERMAL A GING WTH STANLESS STEEL 


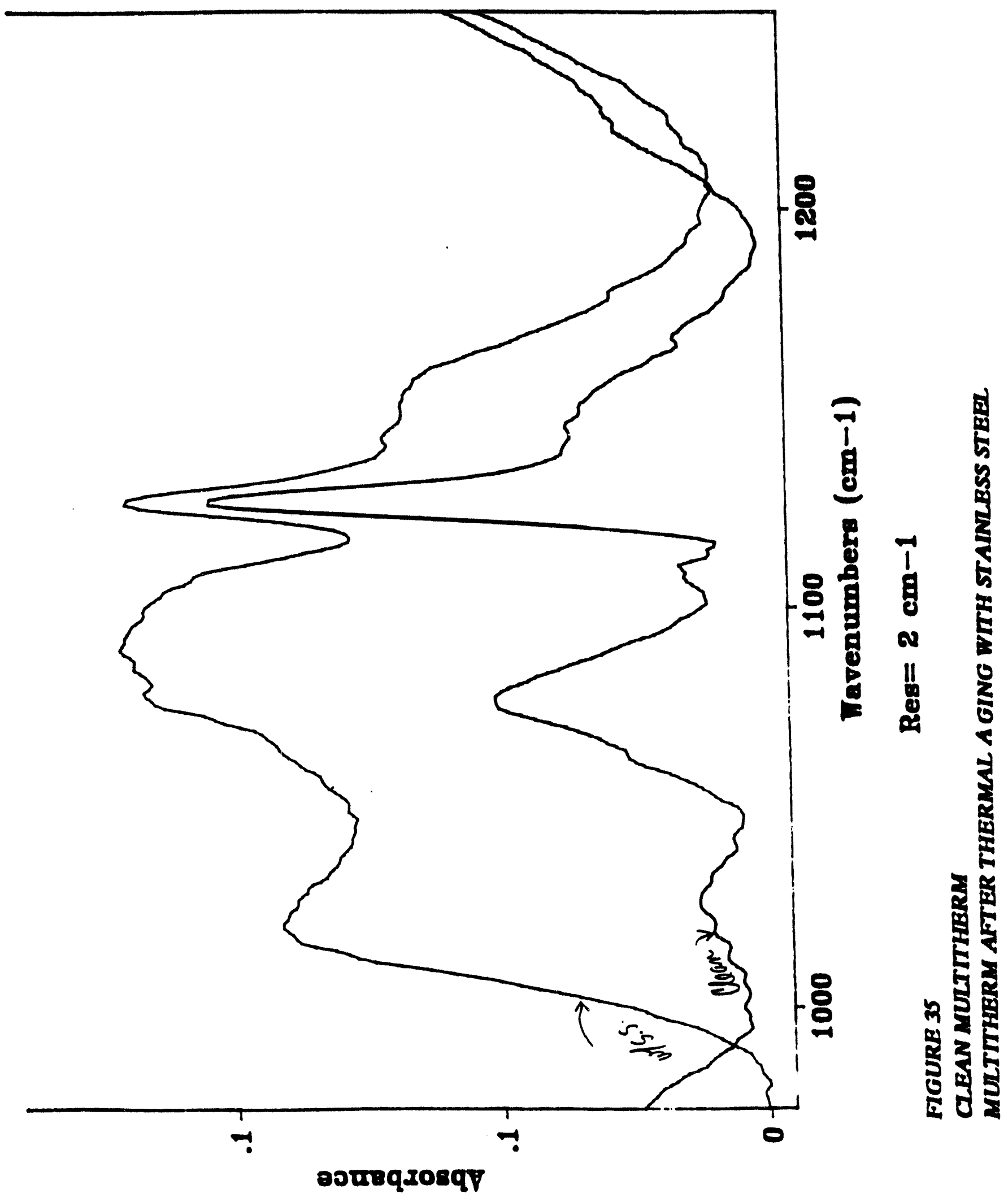




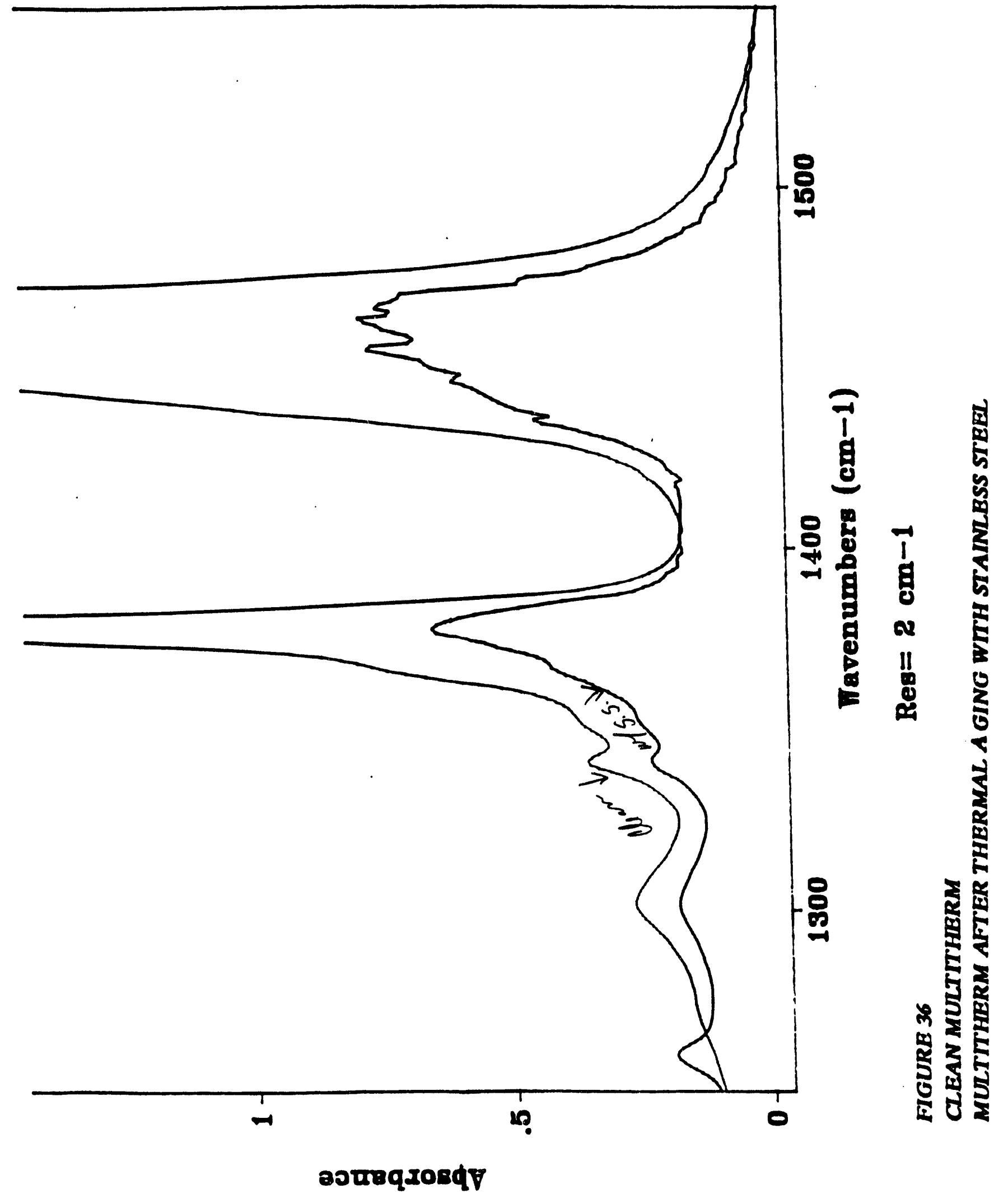




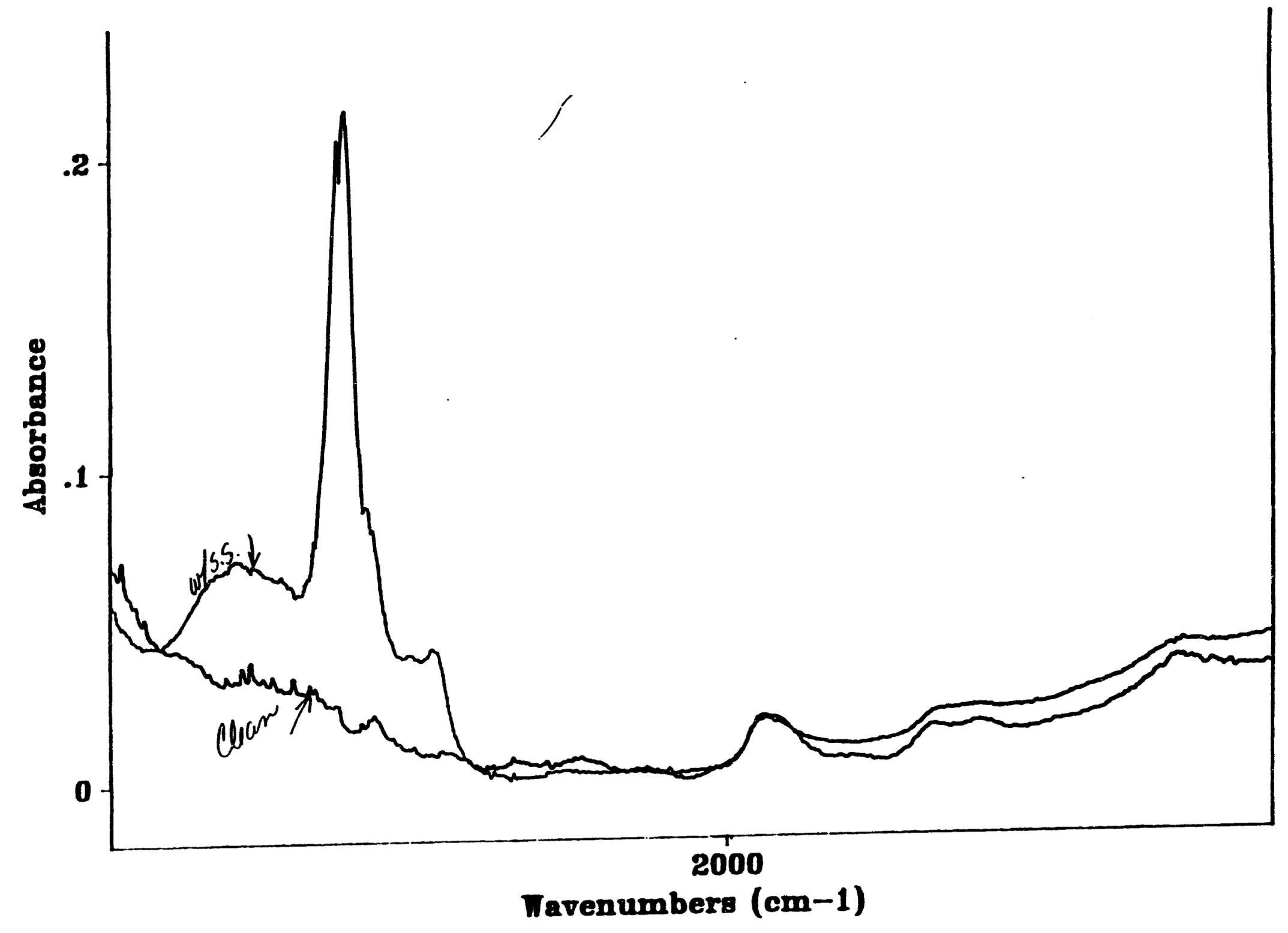

FIGURE 37

Reg $=2 \mathrm{~cm}-1$

CLEAN MULTITHERM

MULTTHERM AFTER THERMAL A GING WTH STAINLESS STEEL 


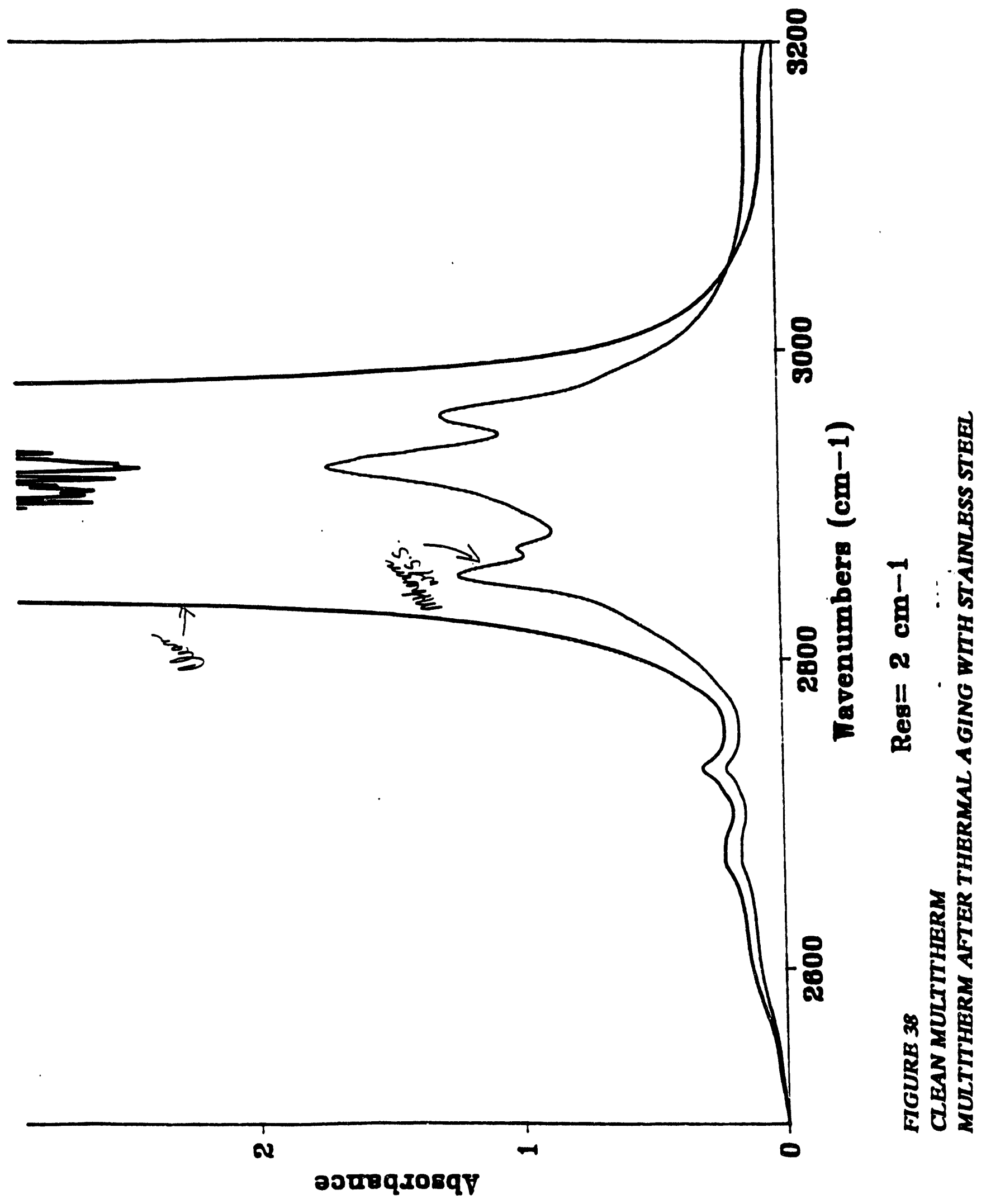




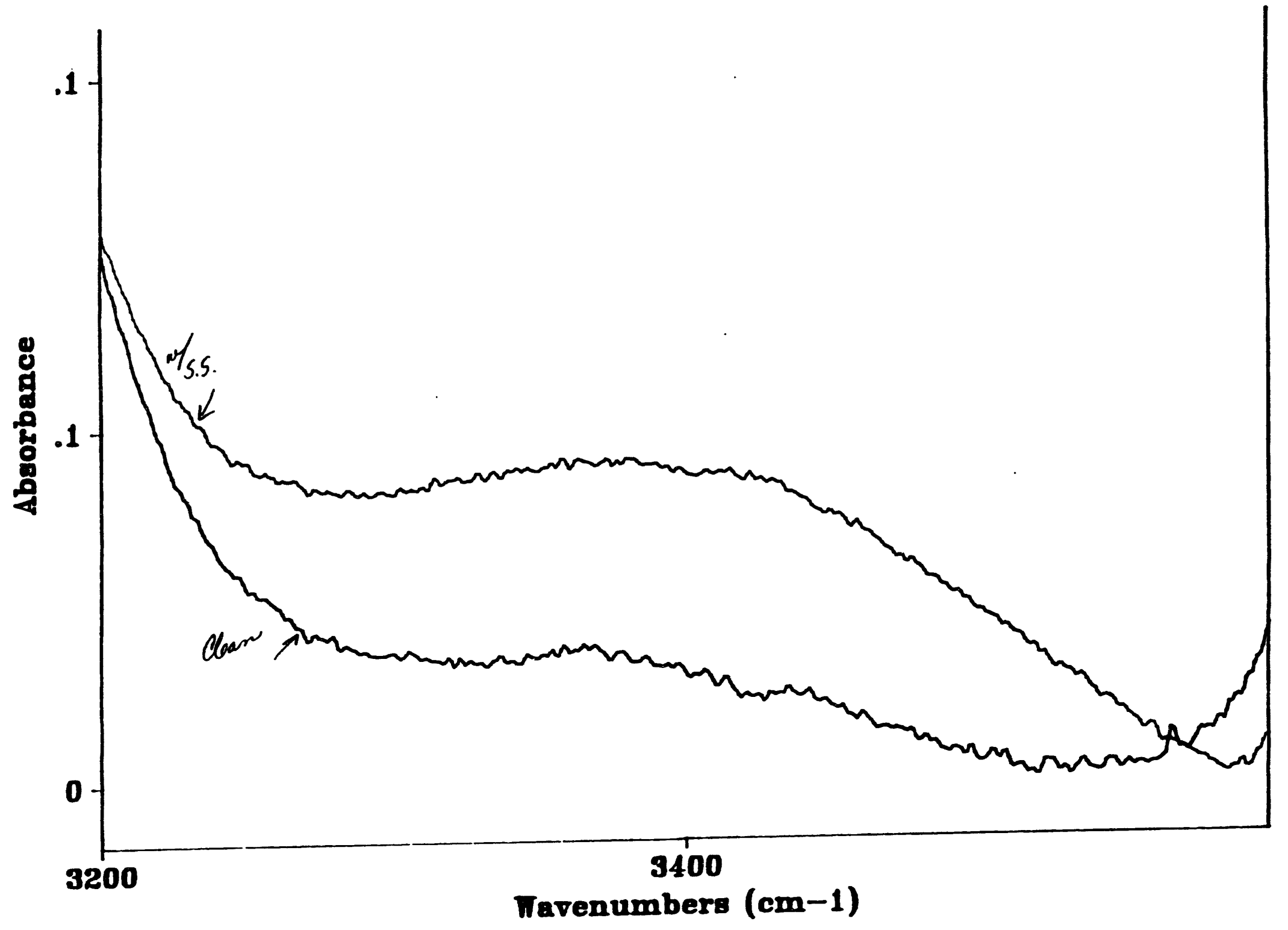

FIGURB 39

Reg $=2 \mathrm{~cm}-1$

CLEAN MULTITHERM

MULTITHERM AFTER THERMAL A GING WTHH STAINLESS STEEL 


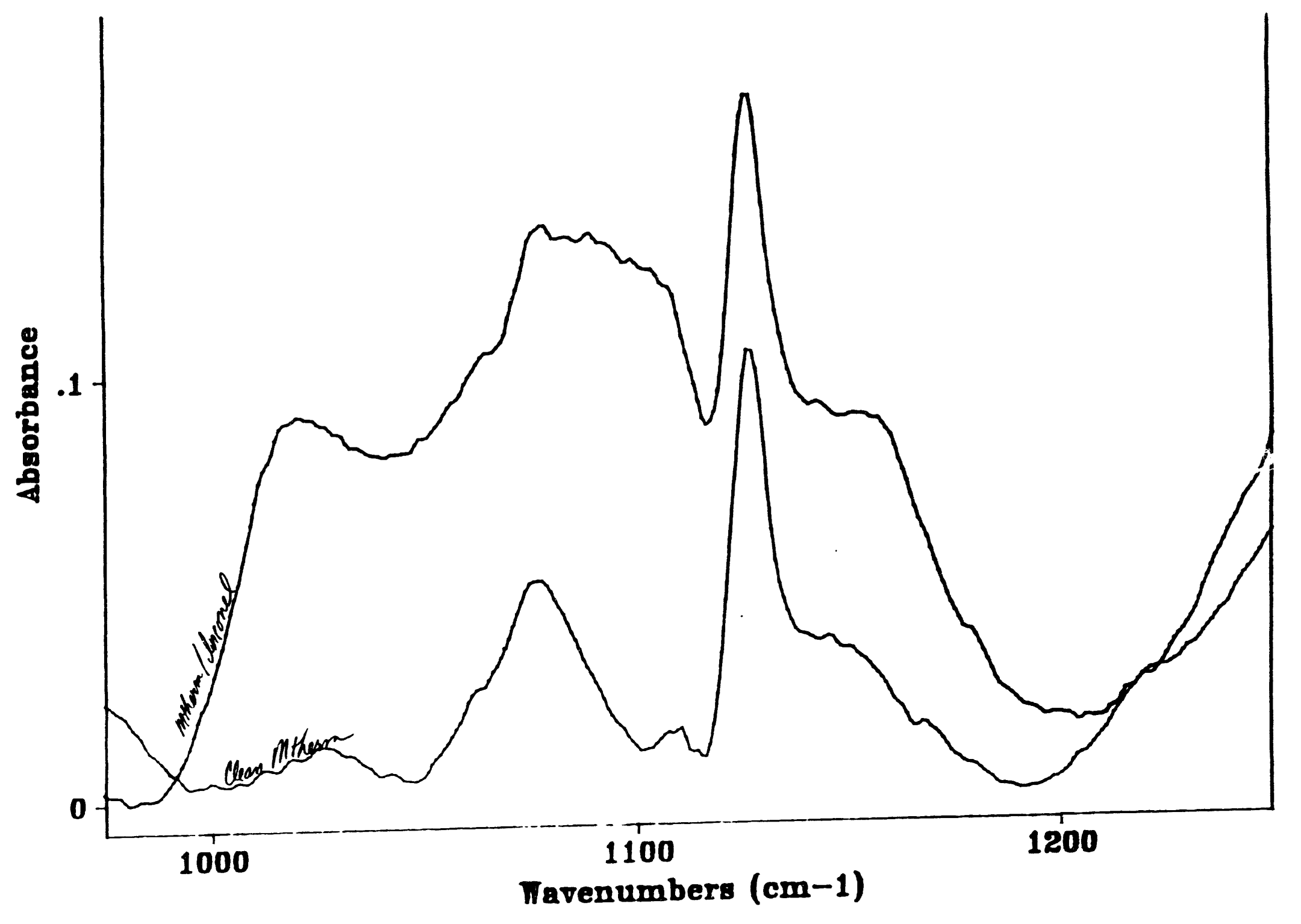

FIGURR 40

Reg $=2 \mathrm{~cm}-1$

CLEAN MULTTTHERM

MULTITHERM AFTER THERMAL AGING WTTH INCONEL 


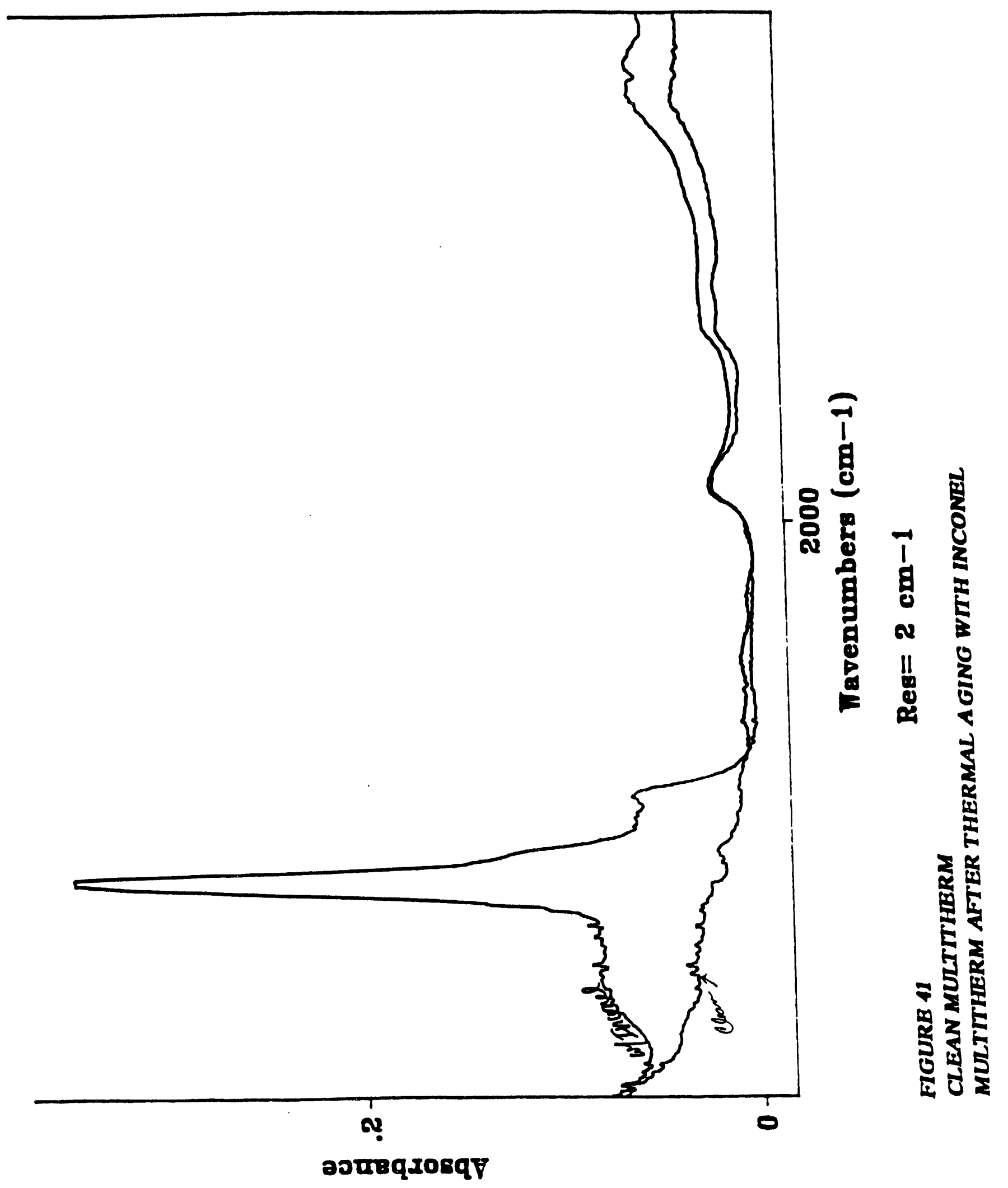




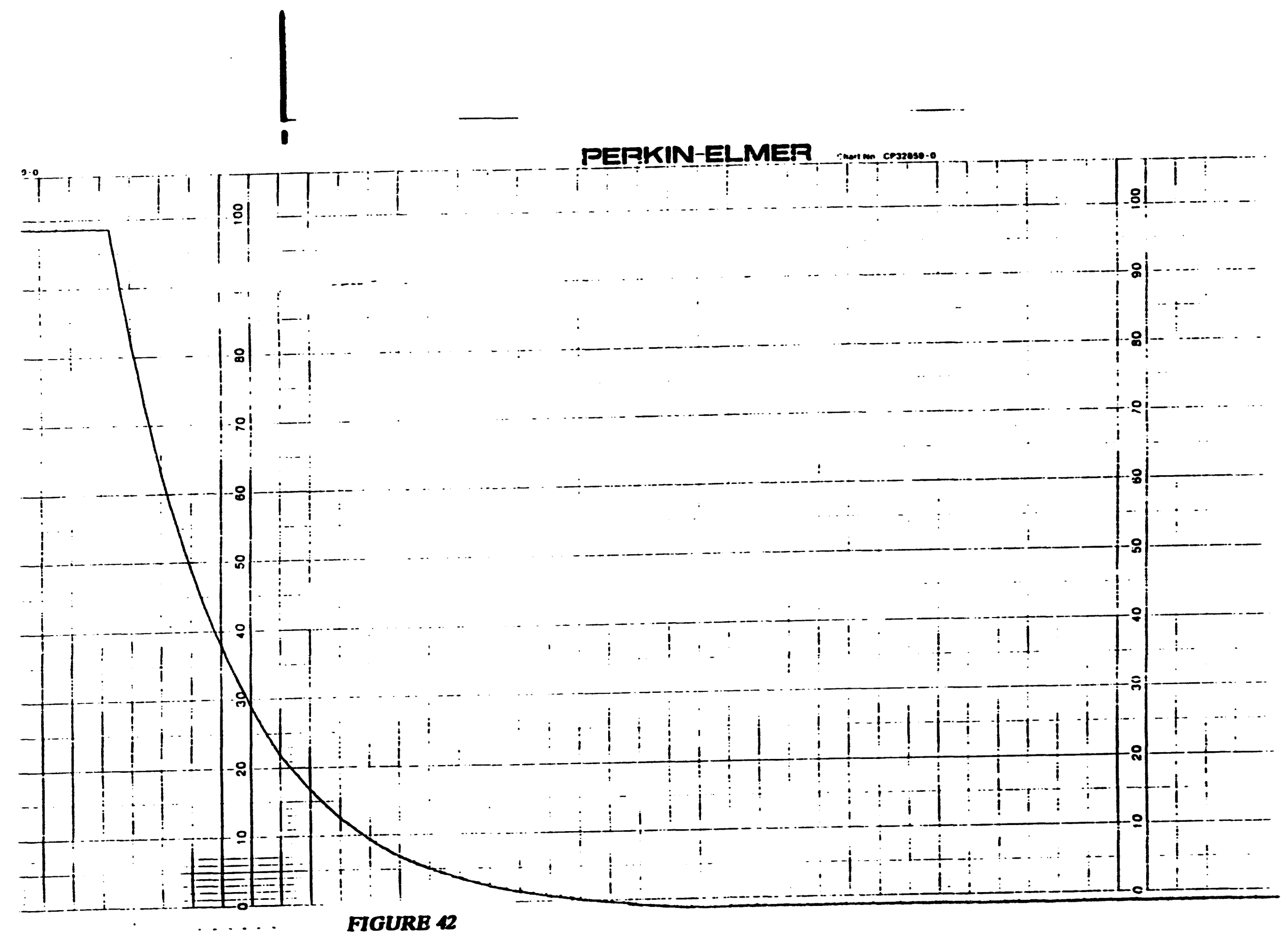




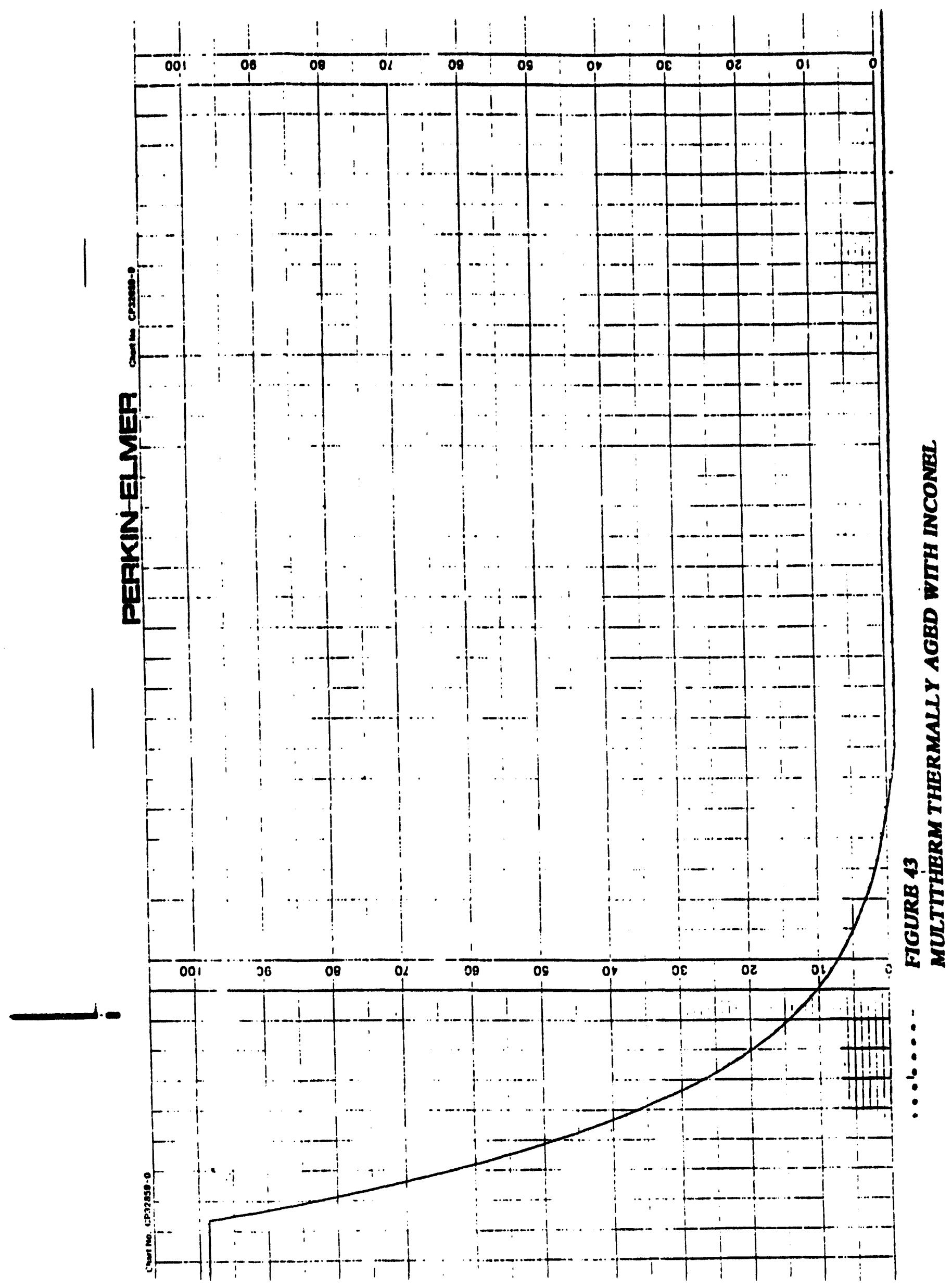









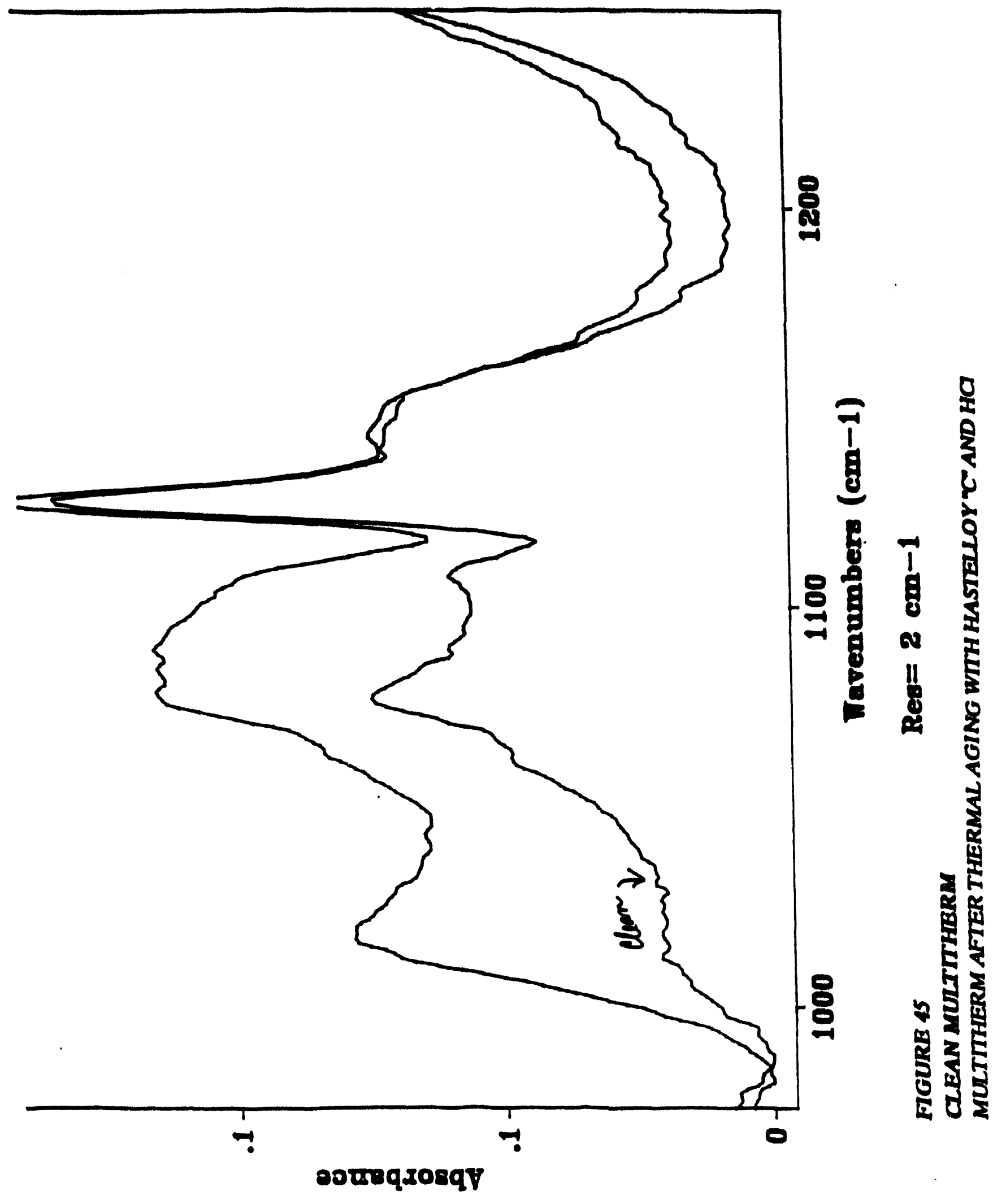




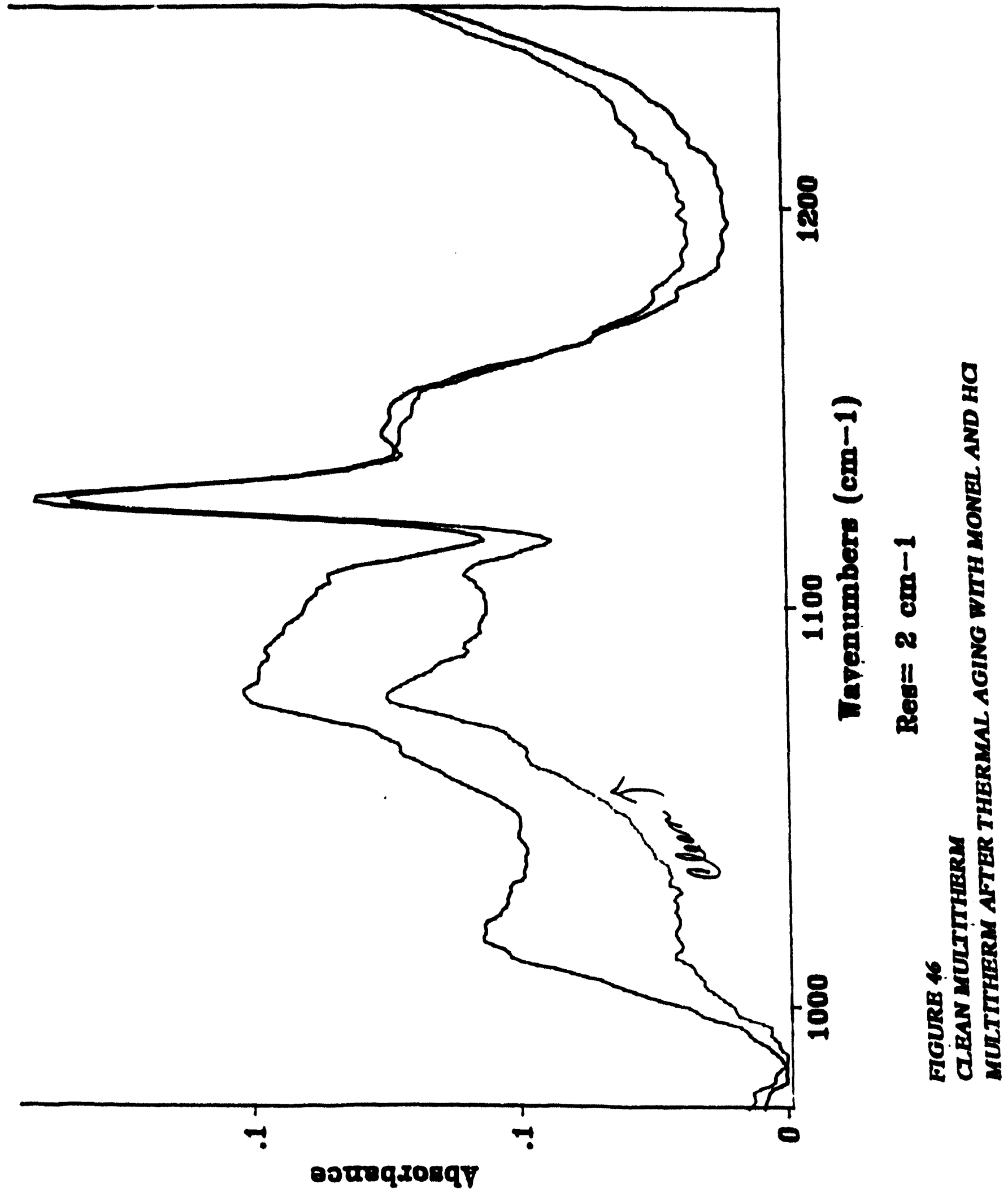




$$
\sum
$$




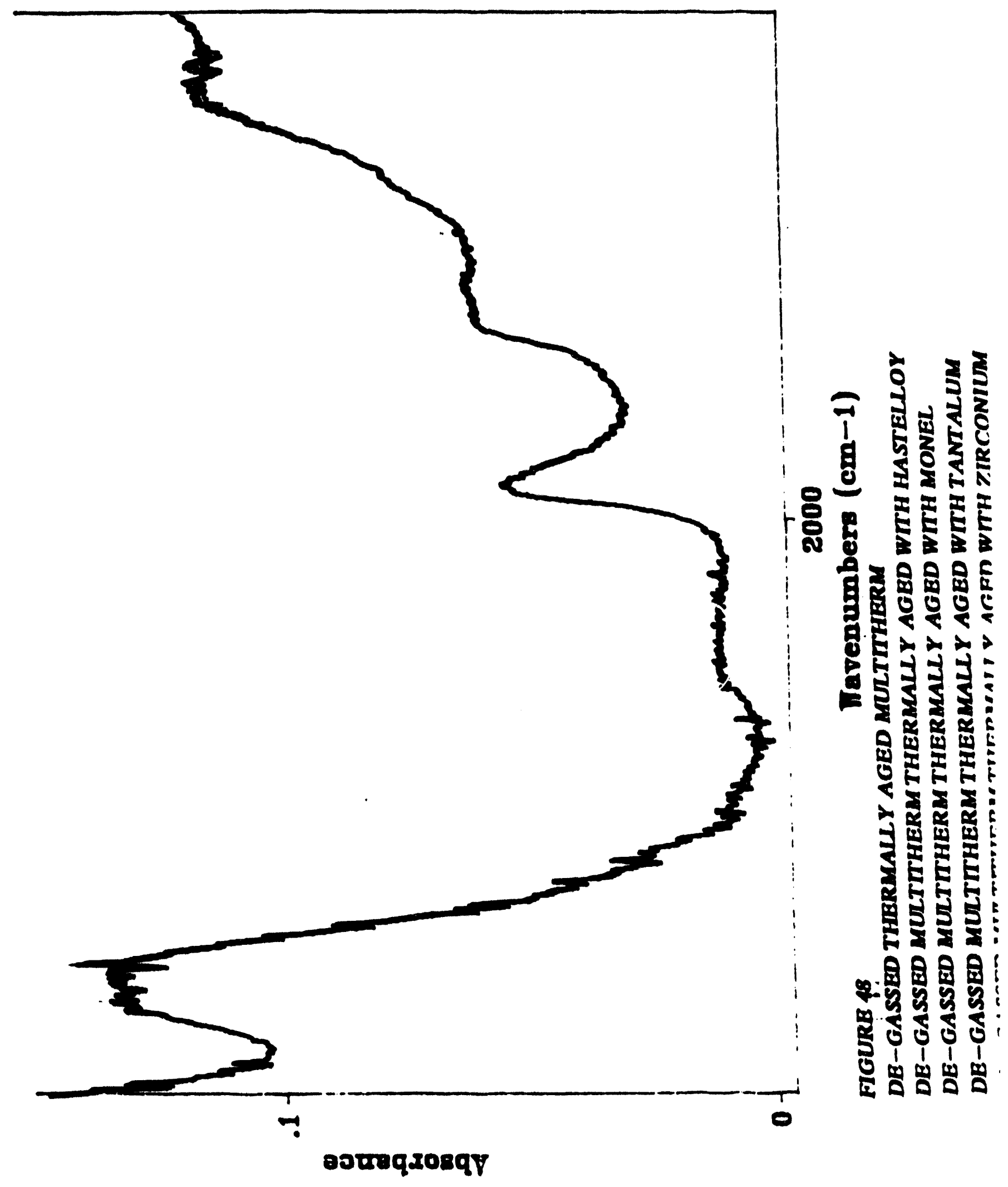




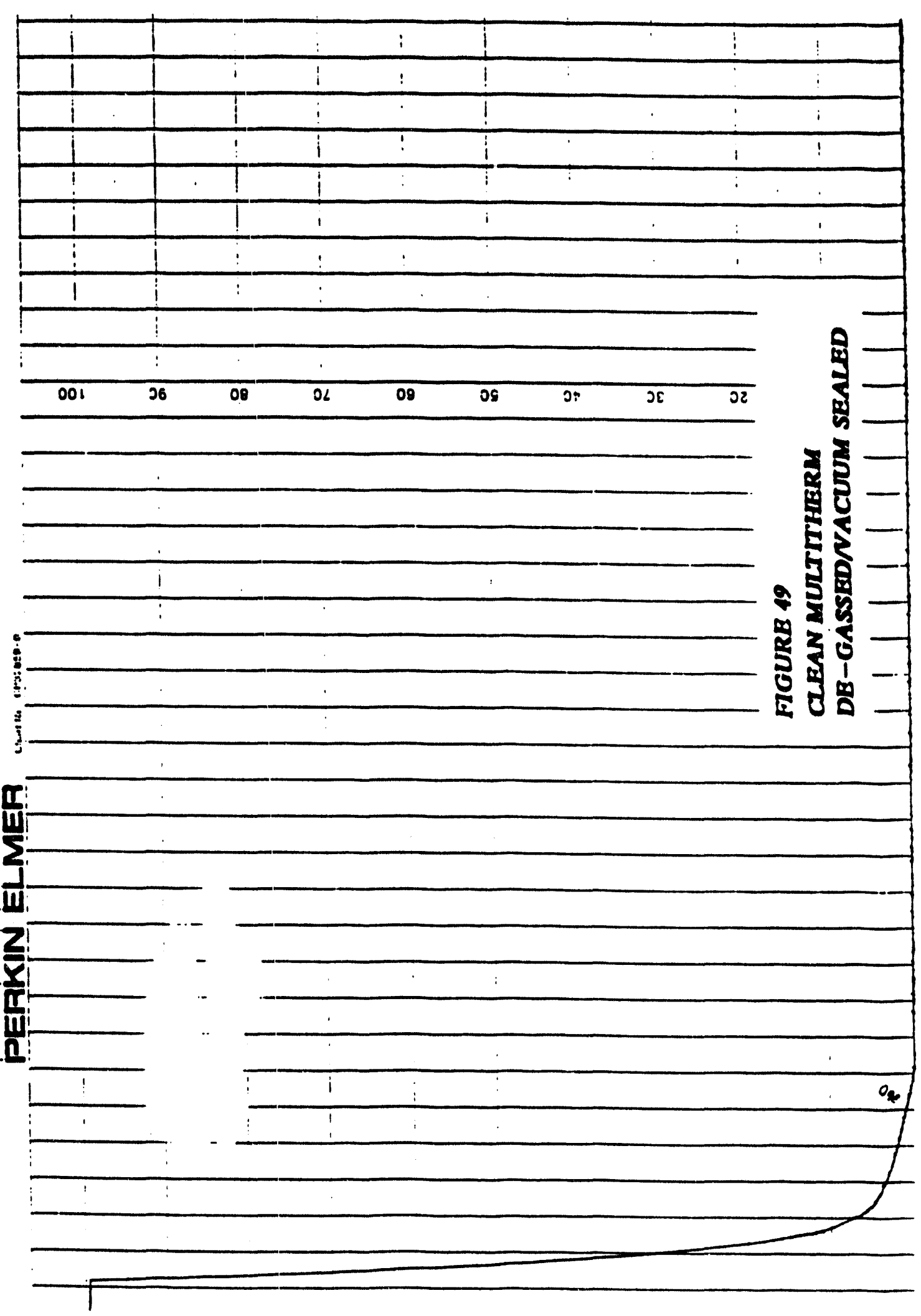




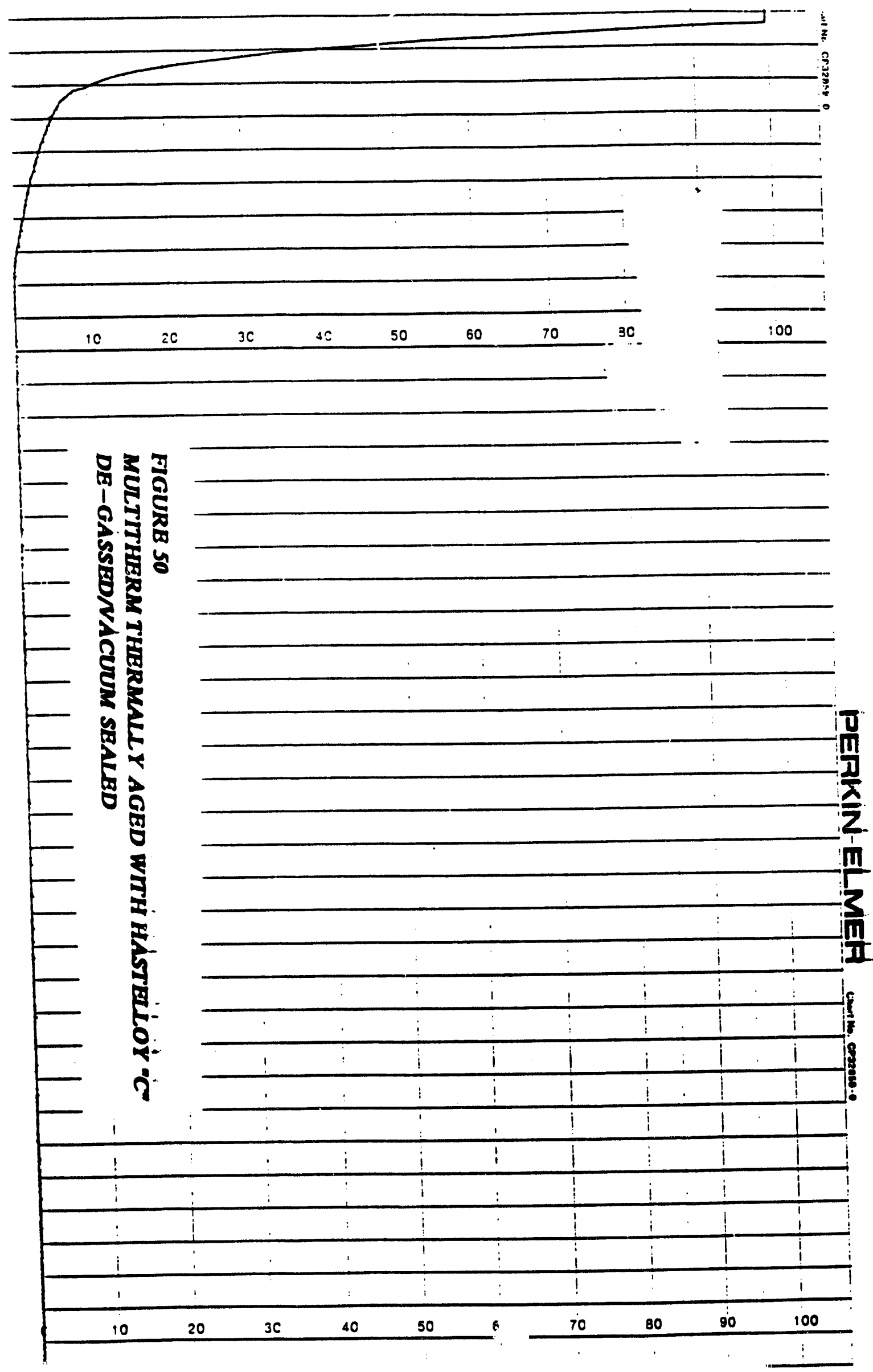




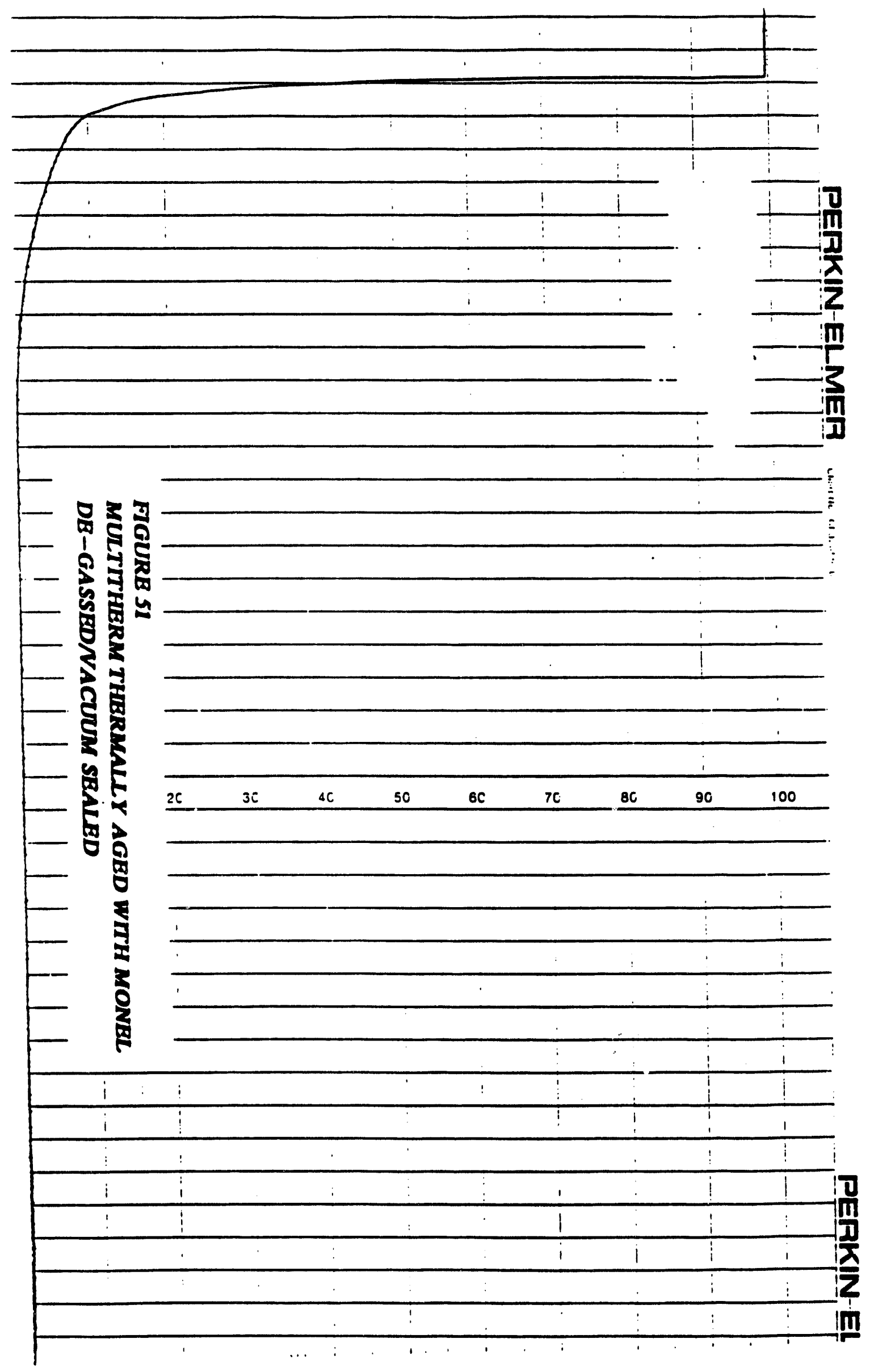




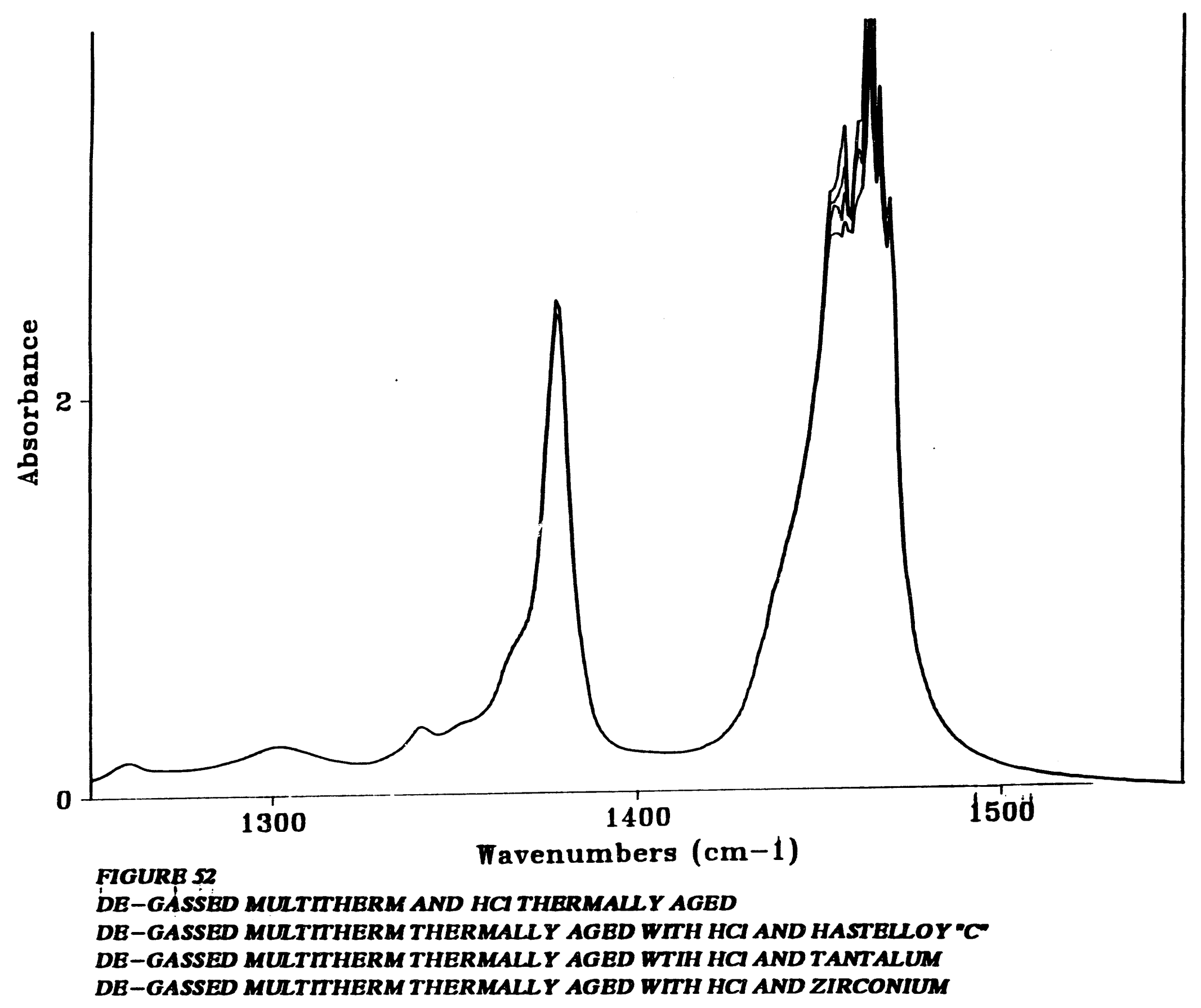




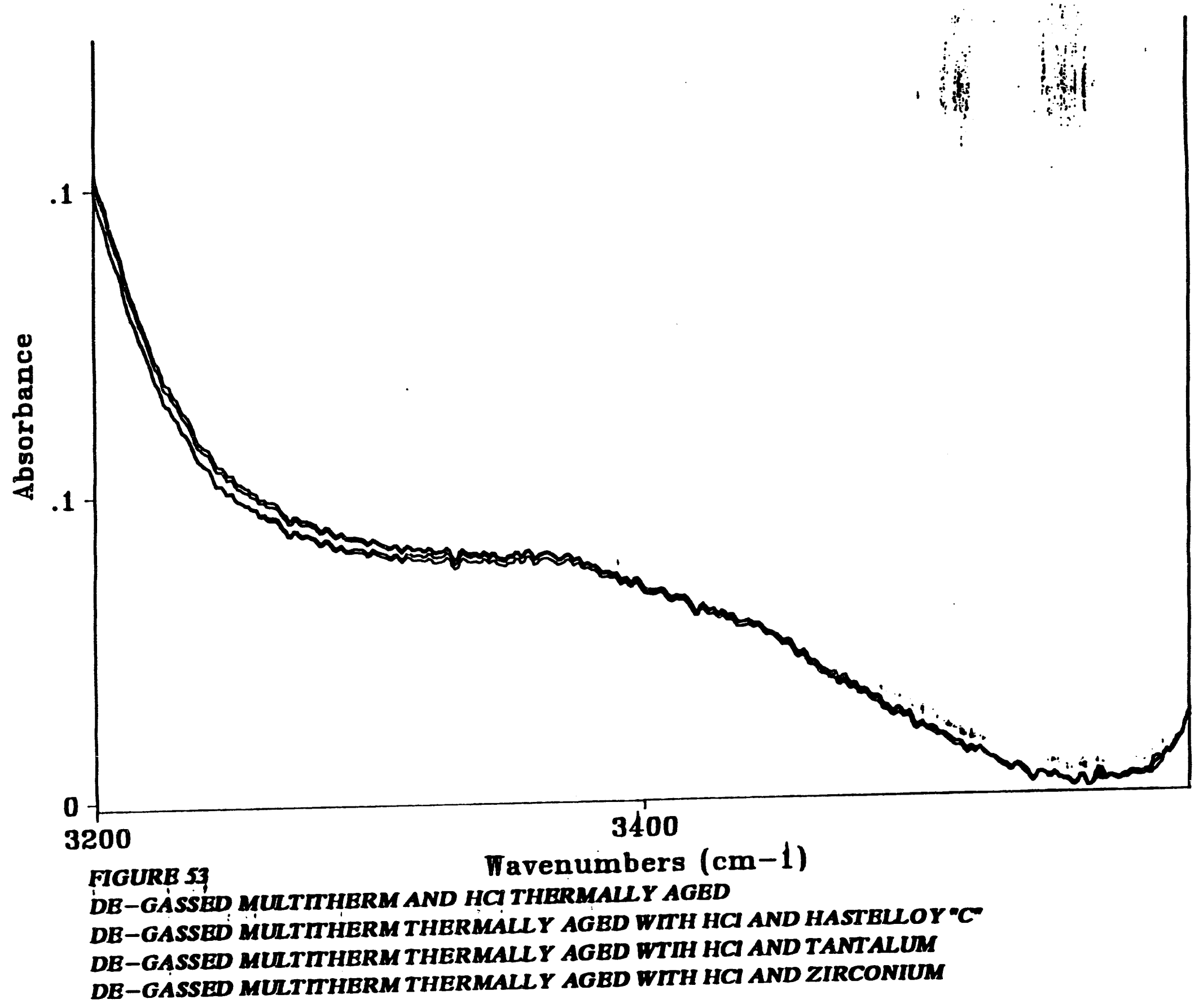


Data Appendix A

Experimental Data Sets 


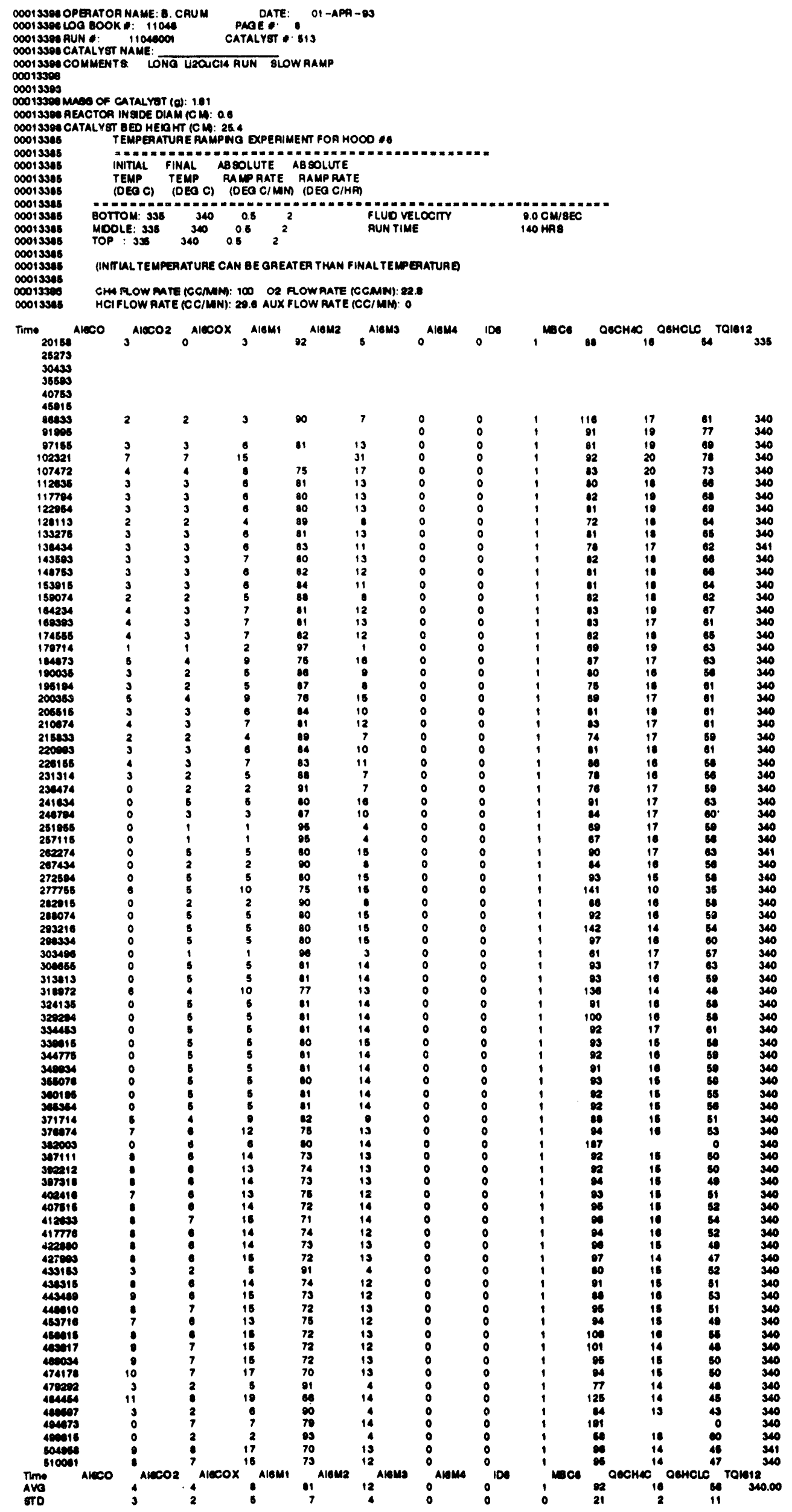




\section{RUN 11046001}

CATALYST 513

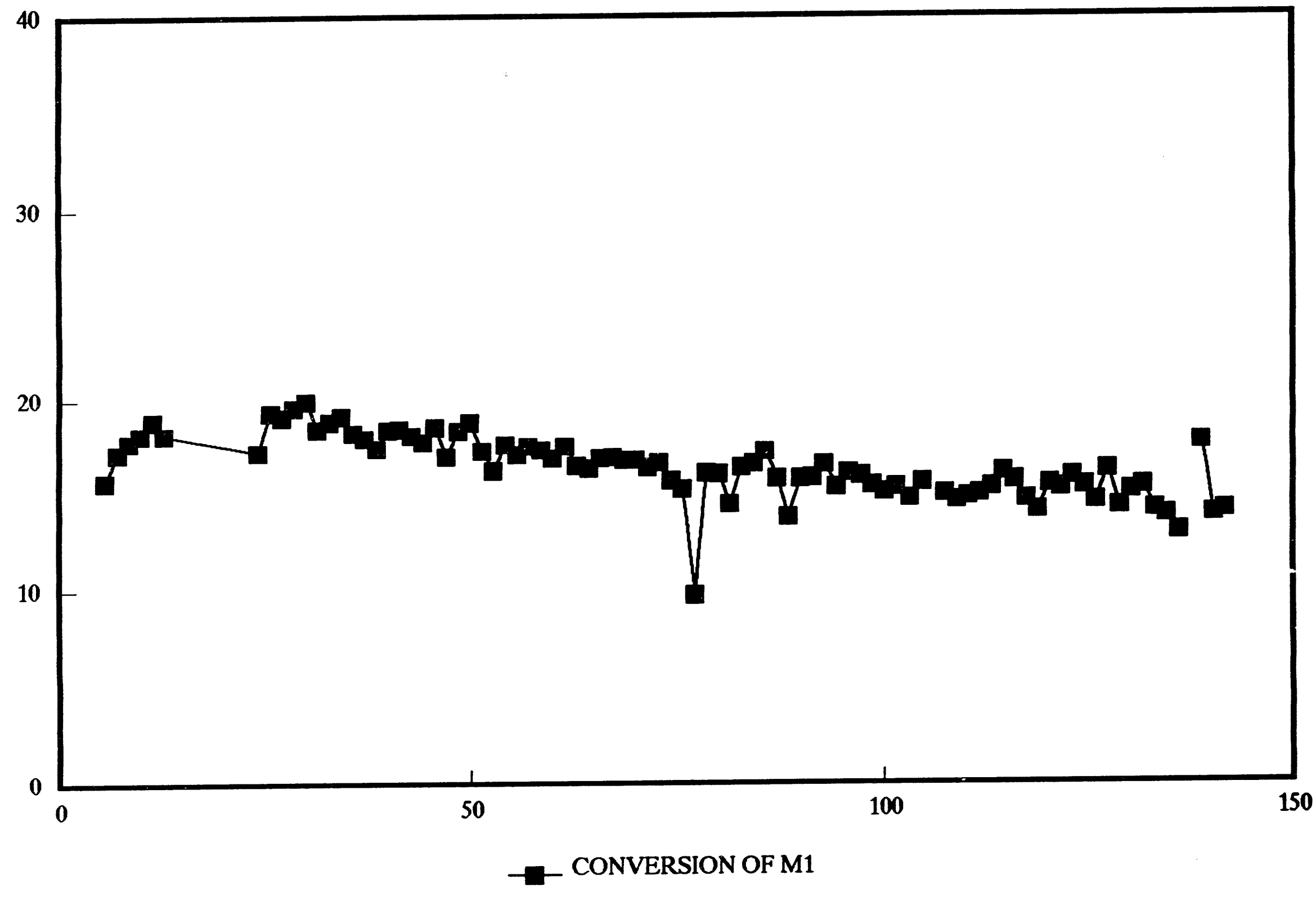




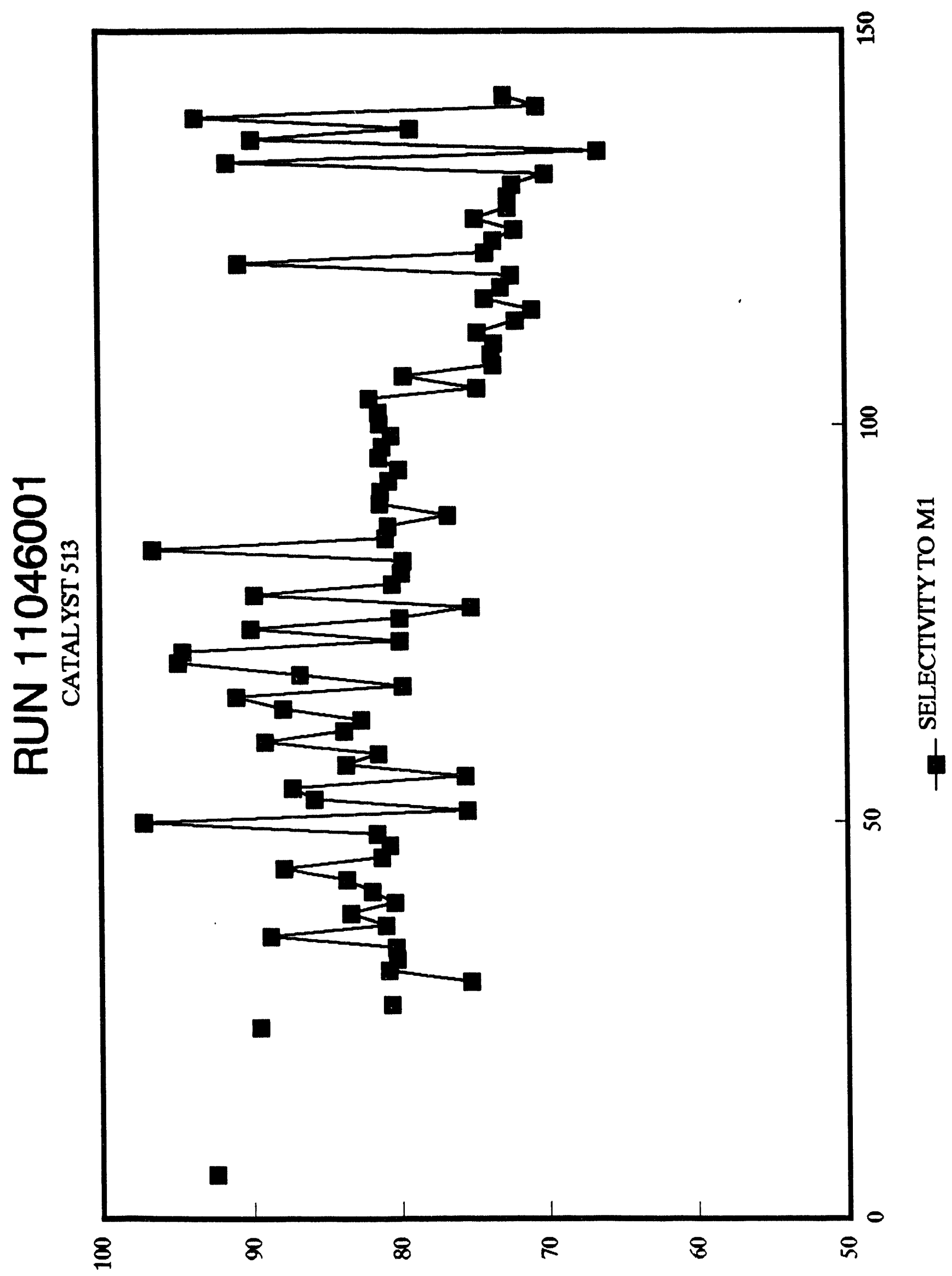




\section{RUN 11046001}

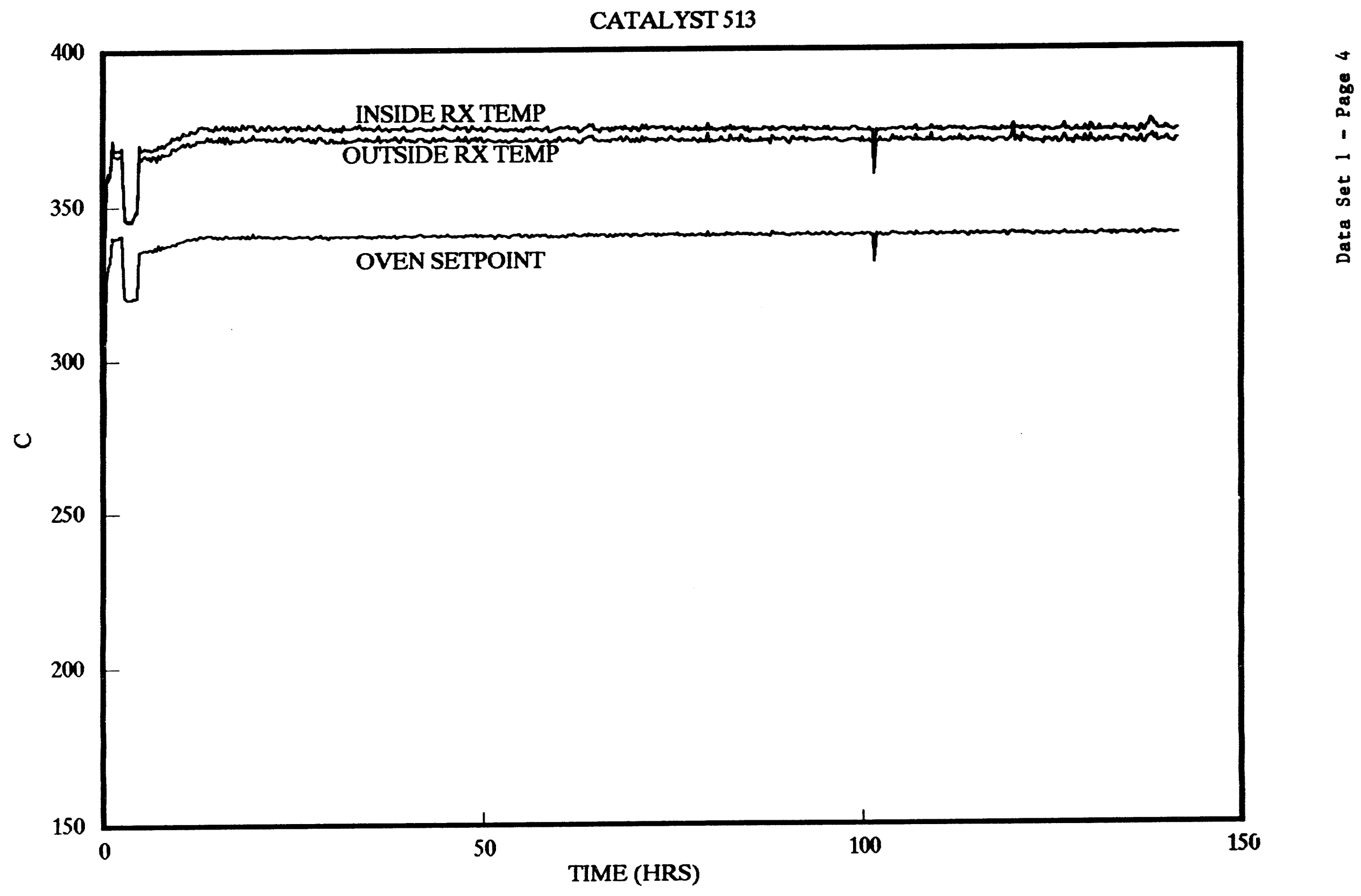




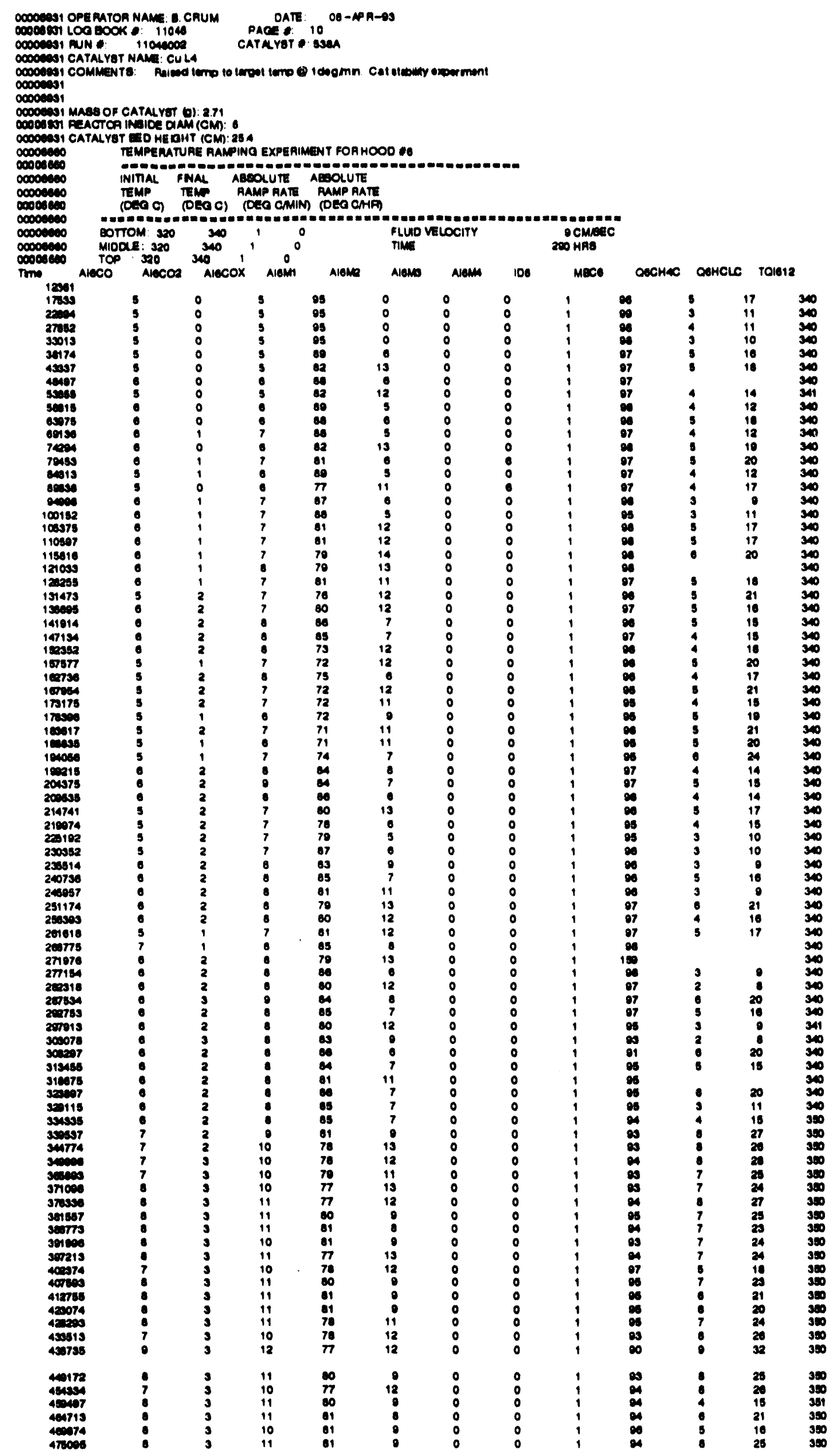




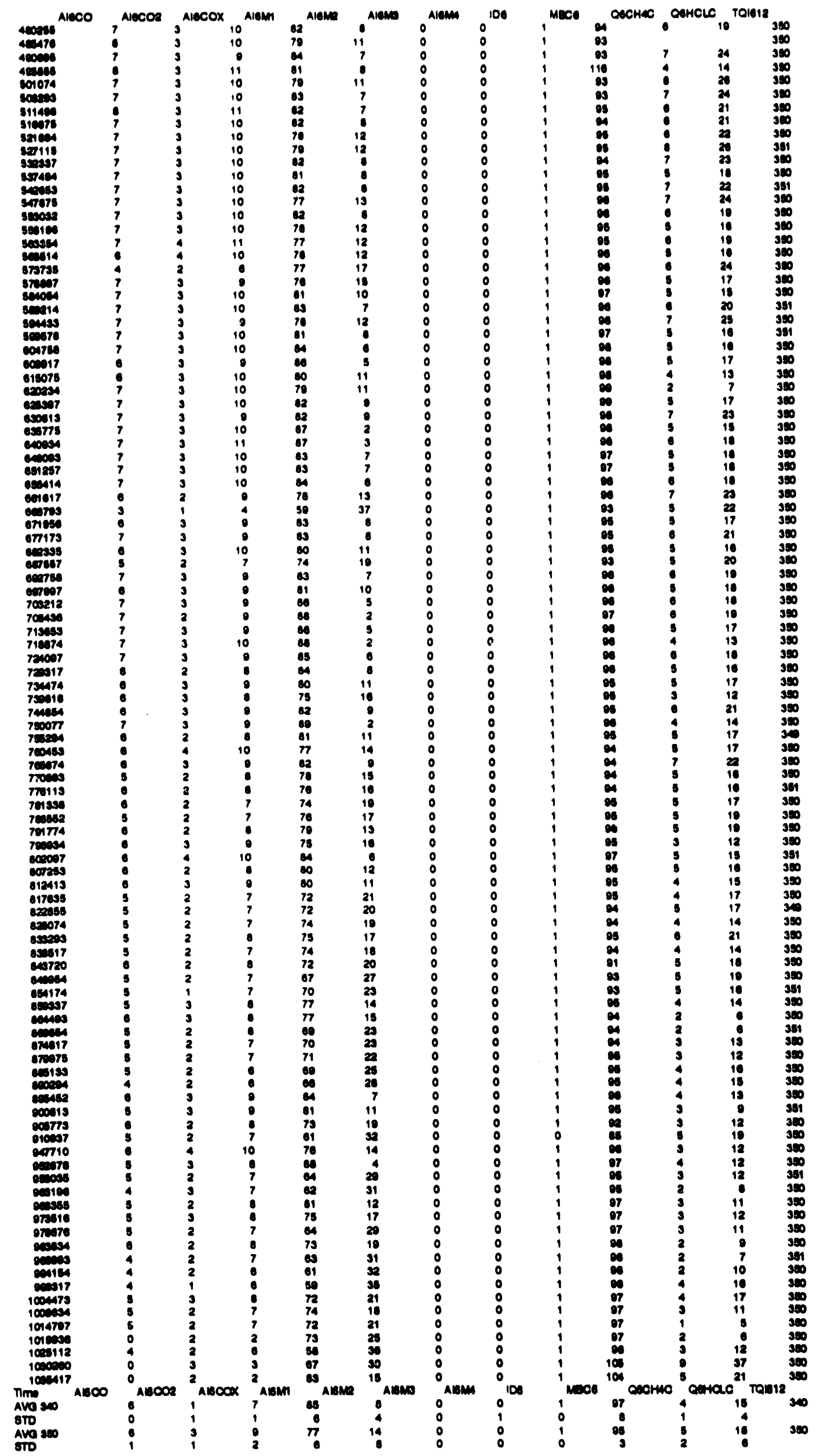

Data Set 2 - Page 2 


\section{RUN 11046002}

CATALYST 538A

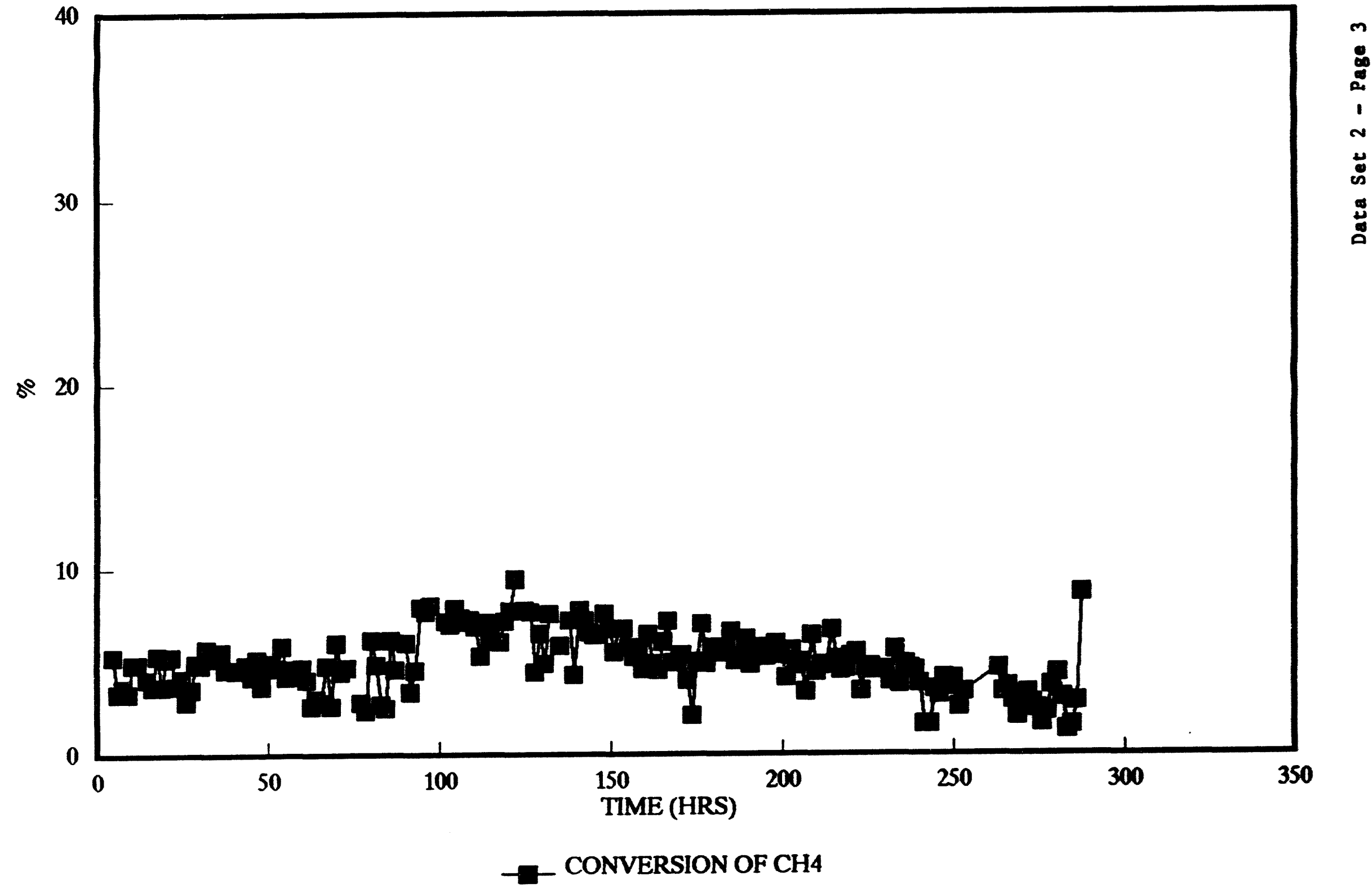




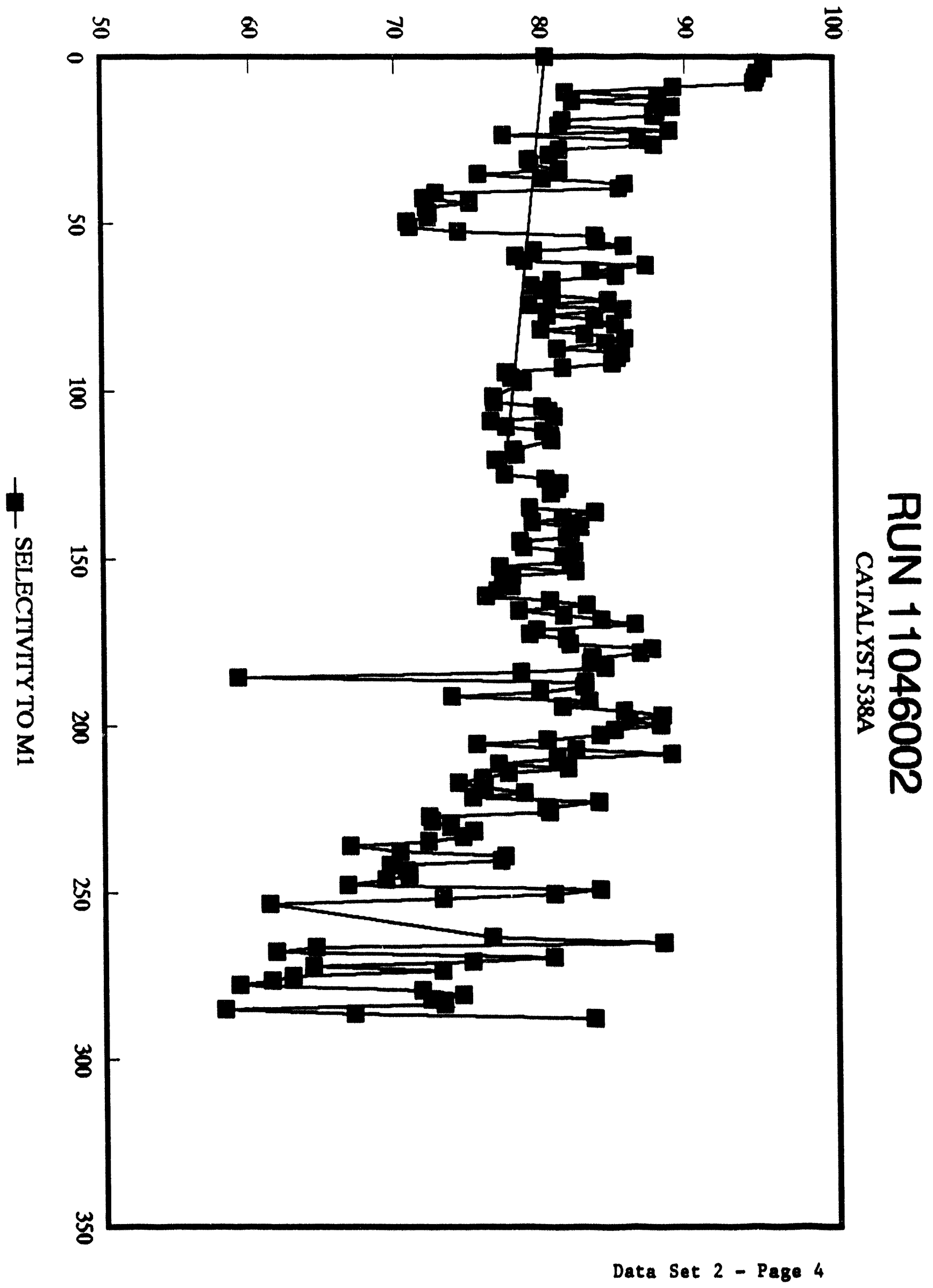




\section{RUN 11046002}

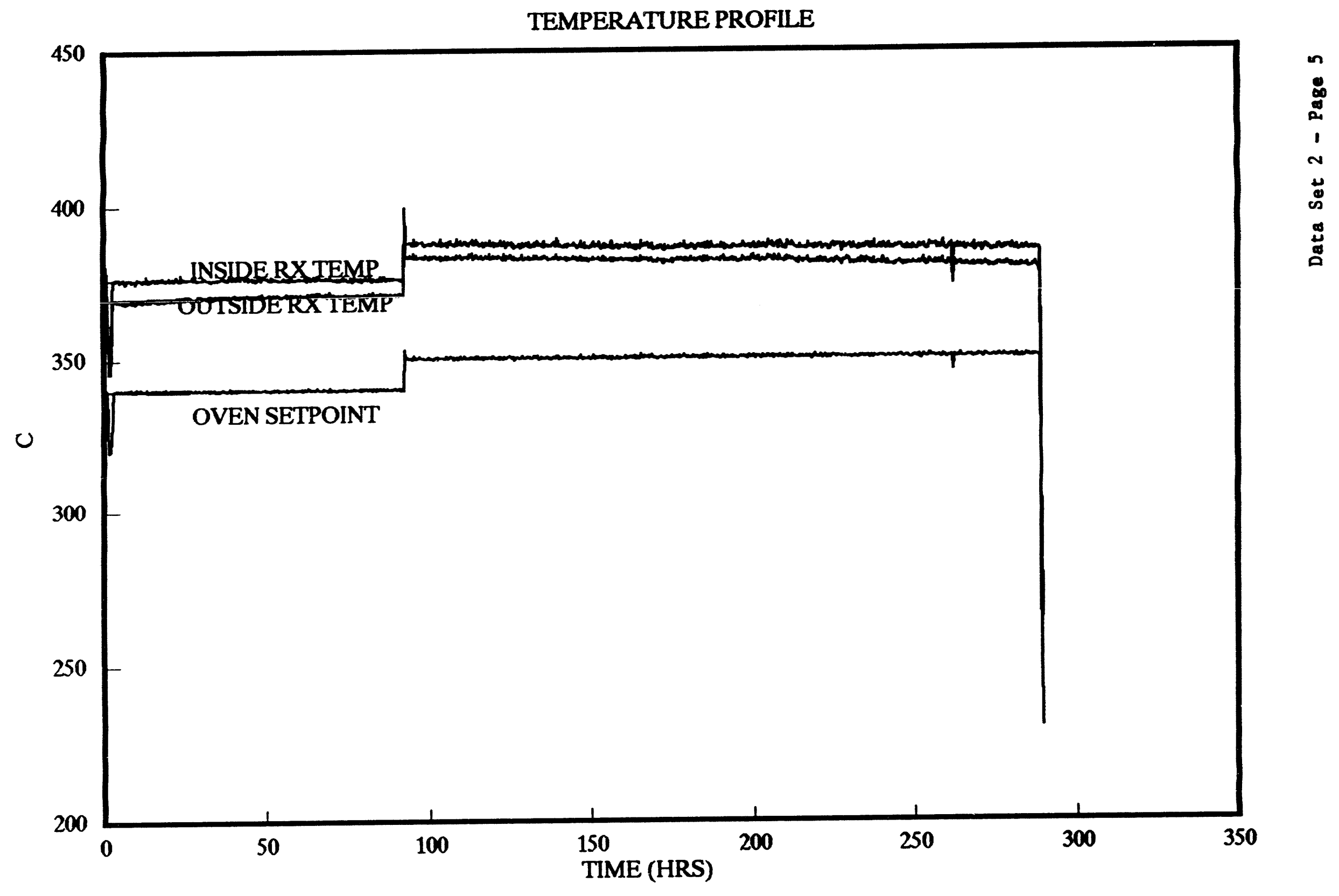




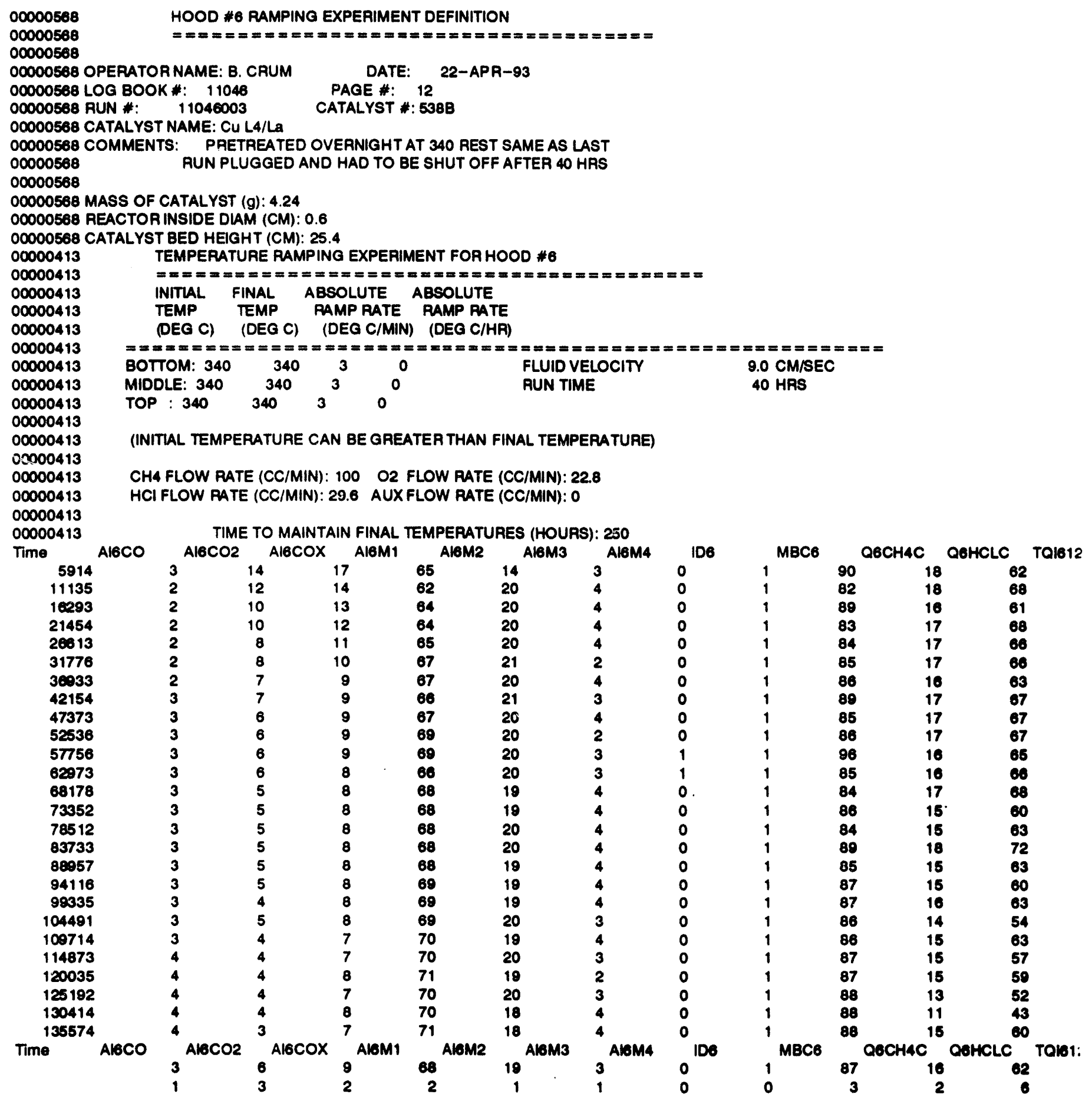




\section{RUN 11046003}

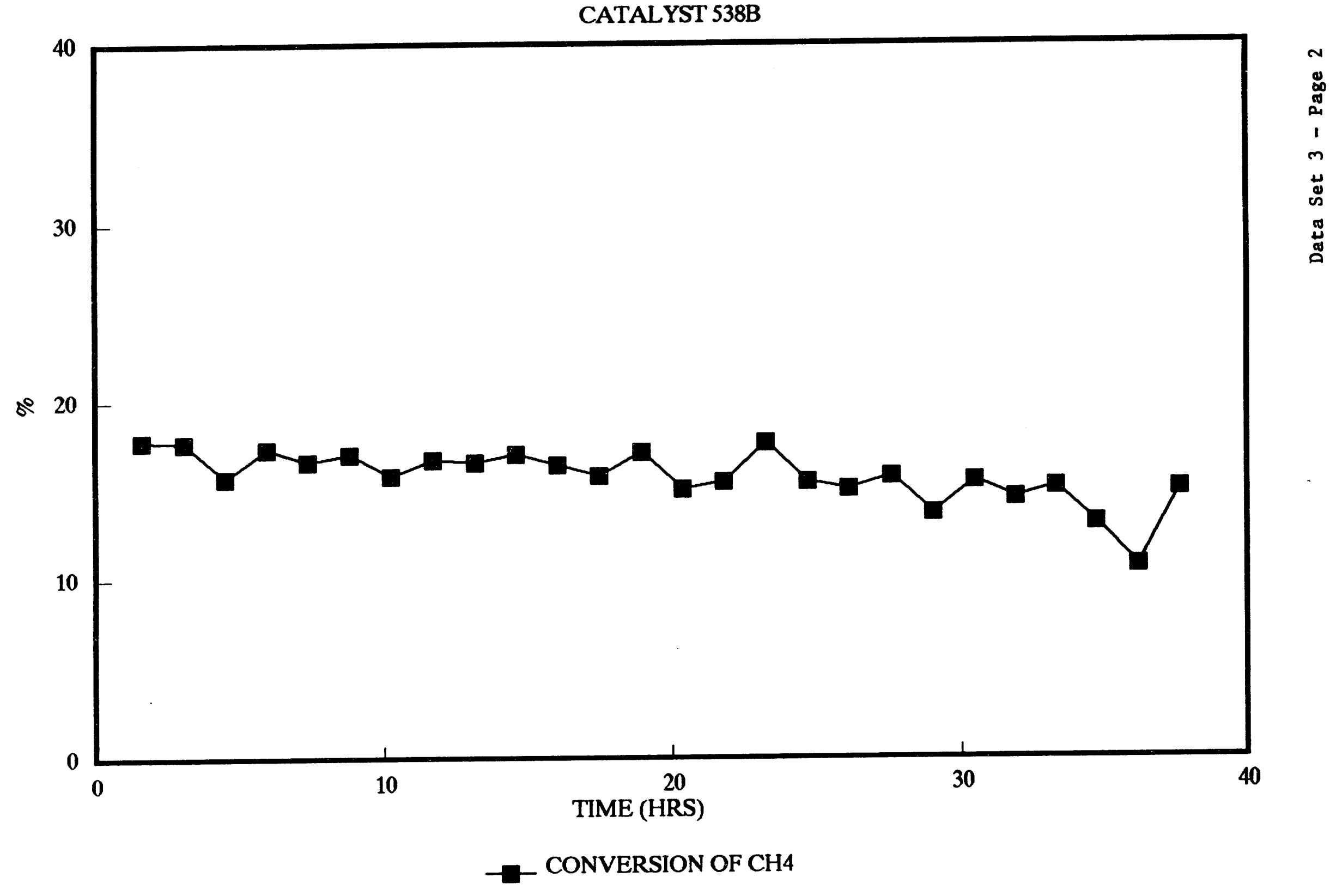




\section{RUN 11046003}

CATALYST 538B

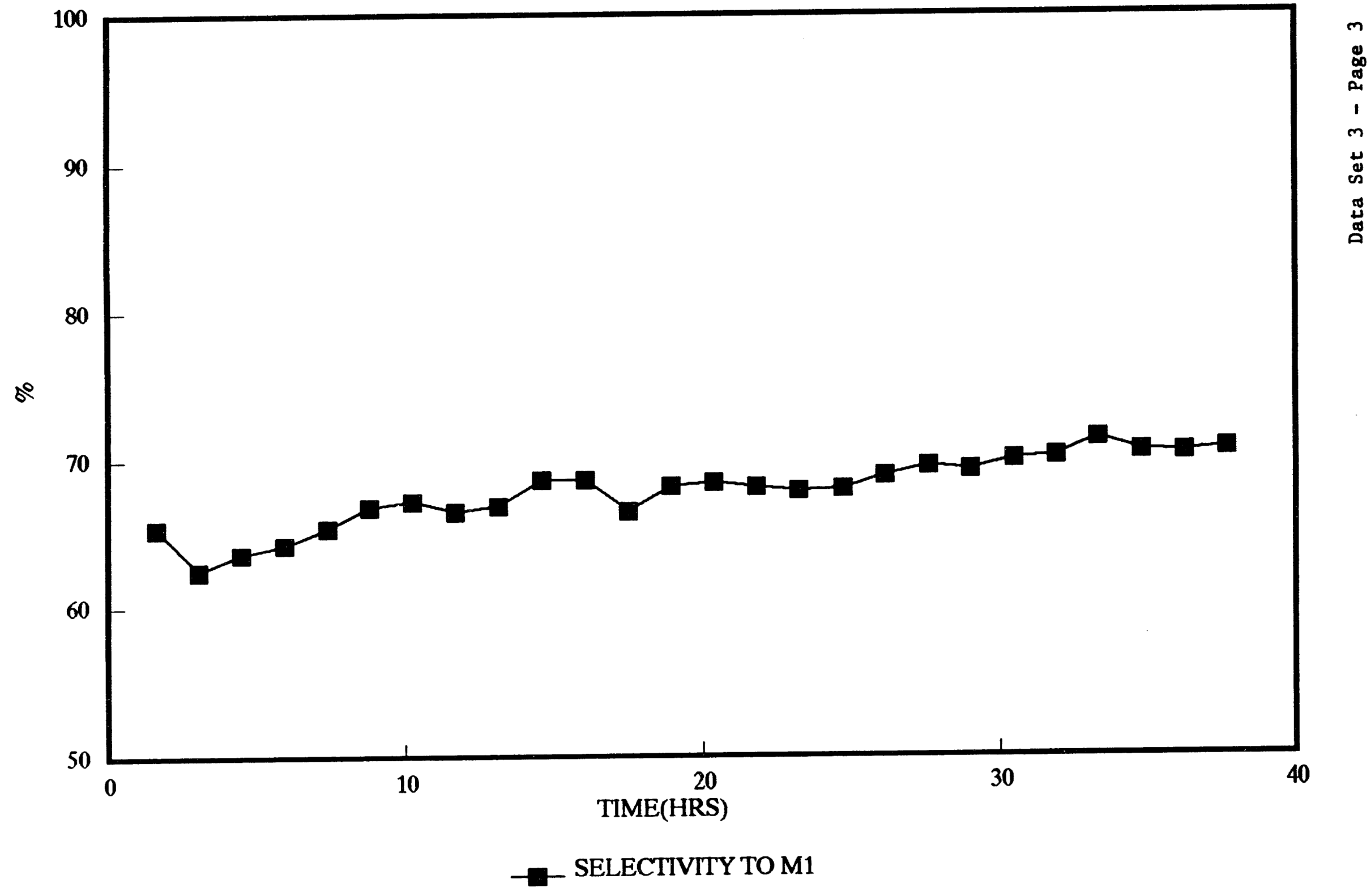




\section{RUN11046003}

CATALYST 538B

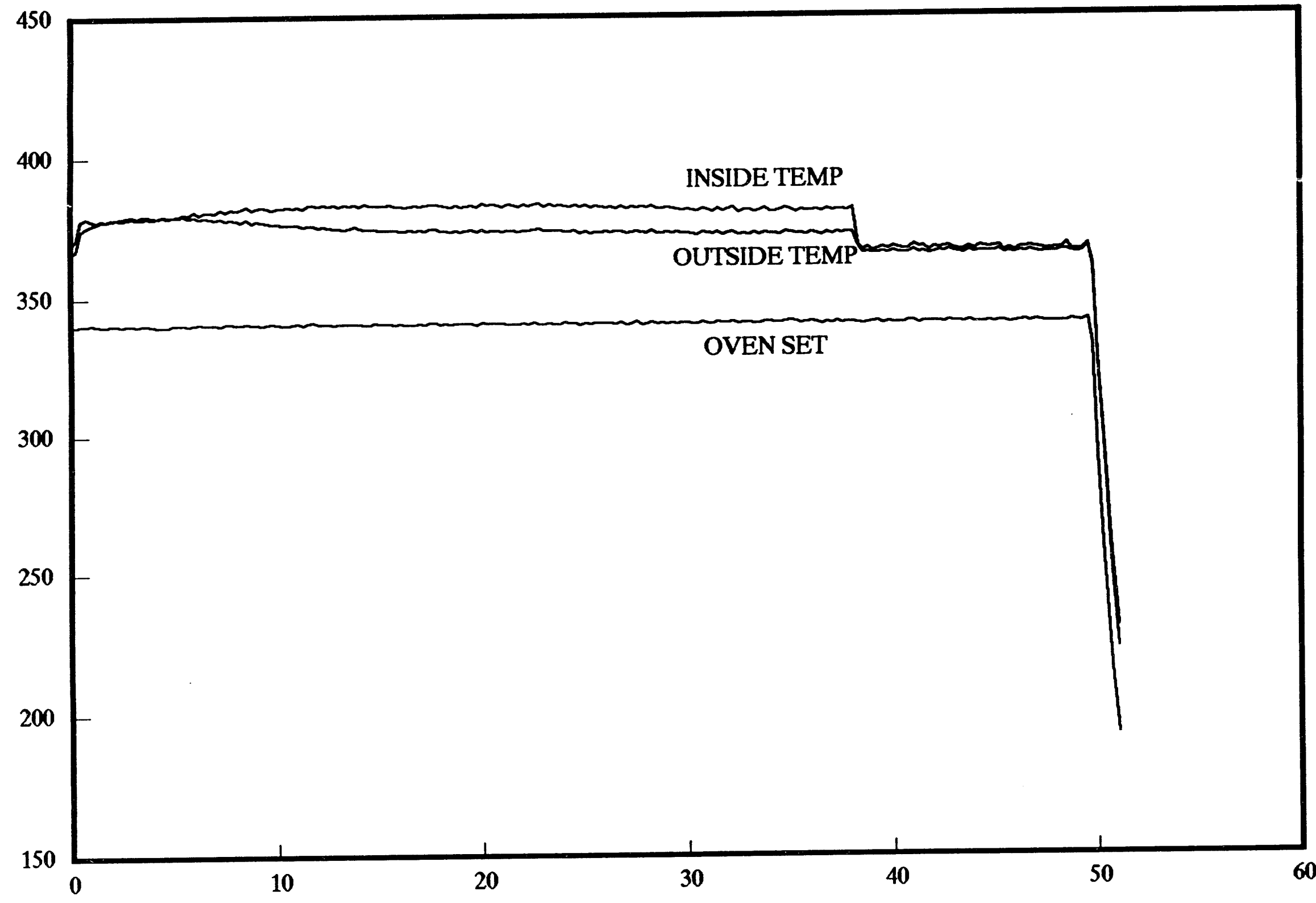




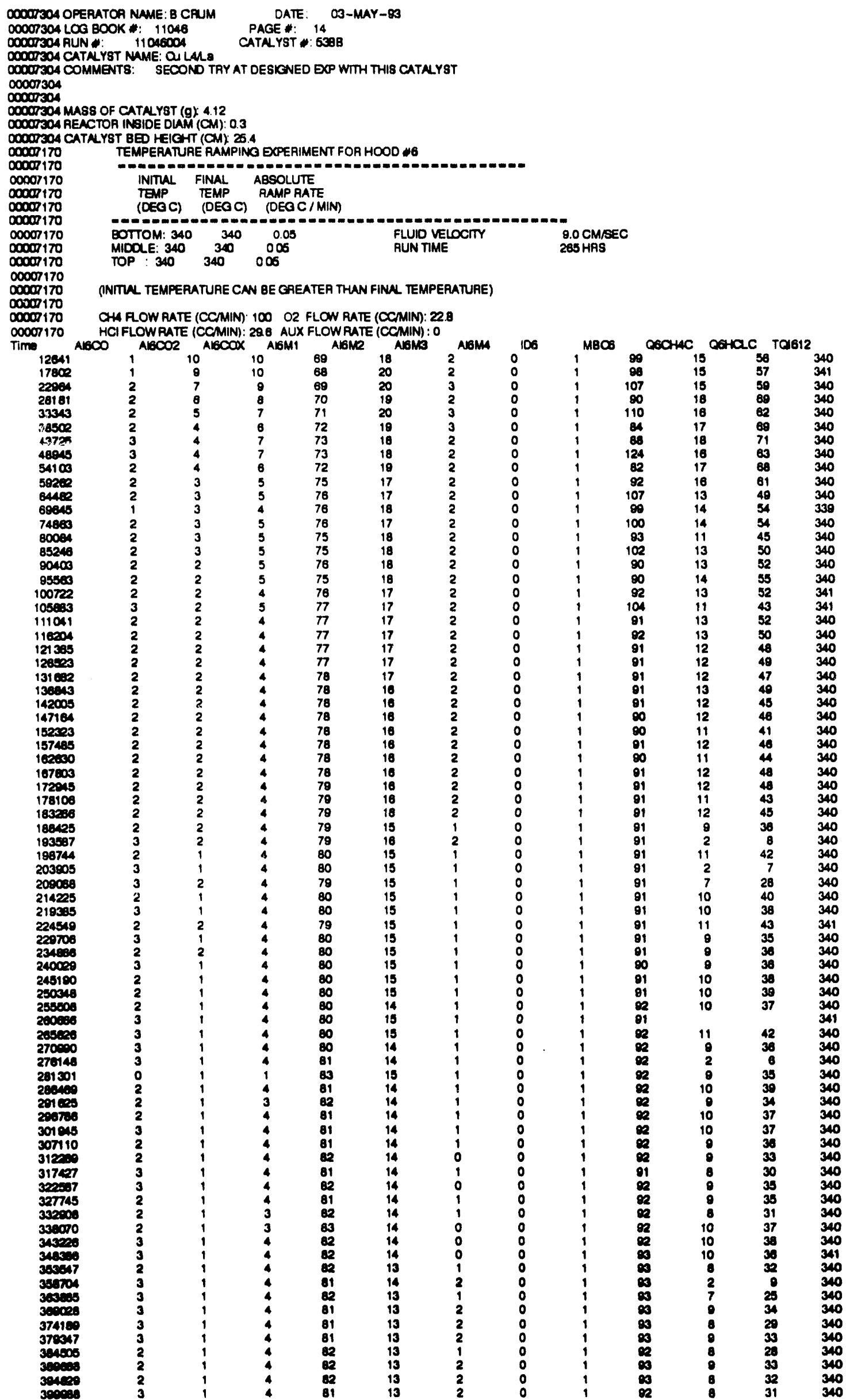




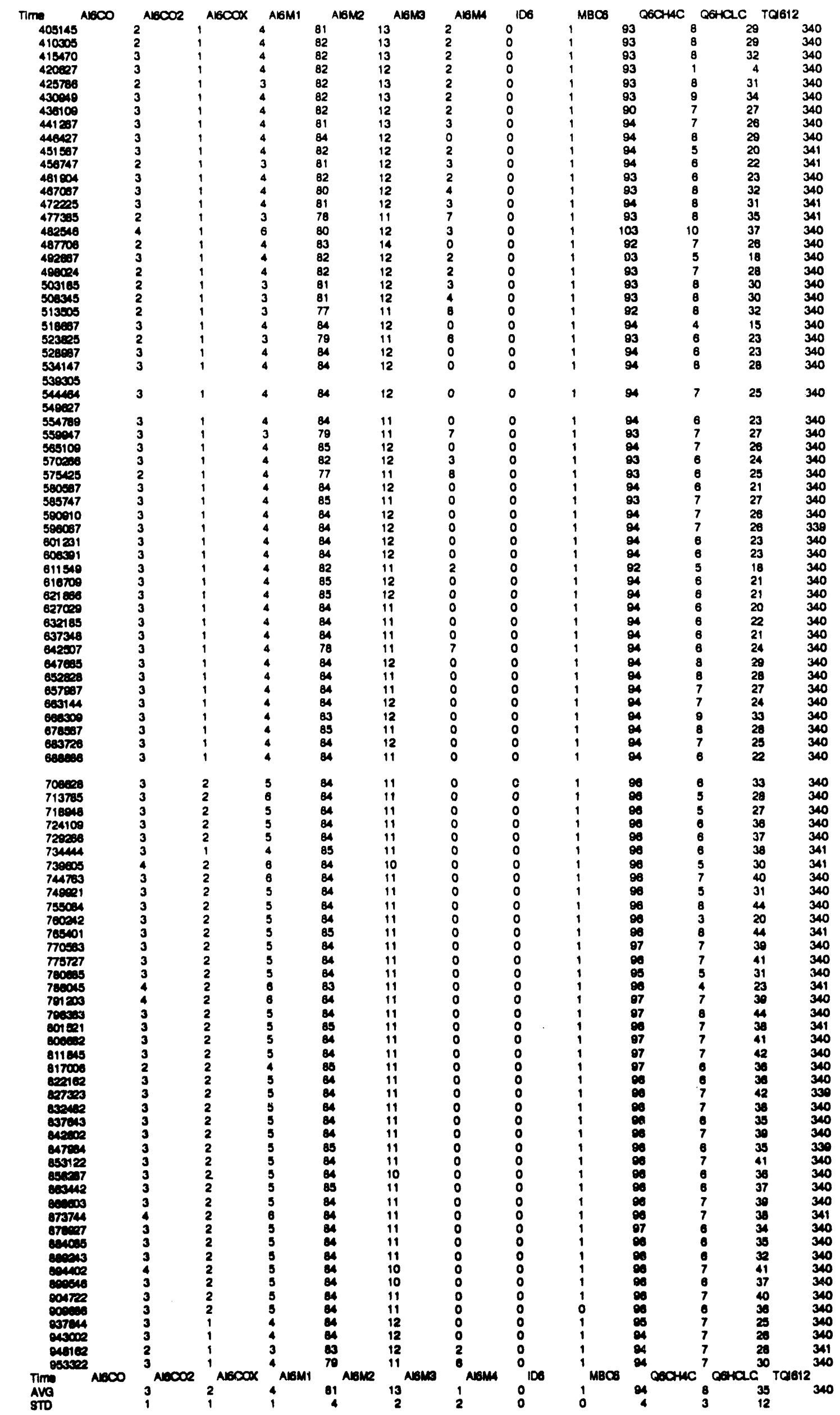


RUN 11046004

CATALYST 538B

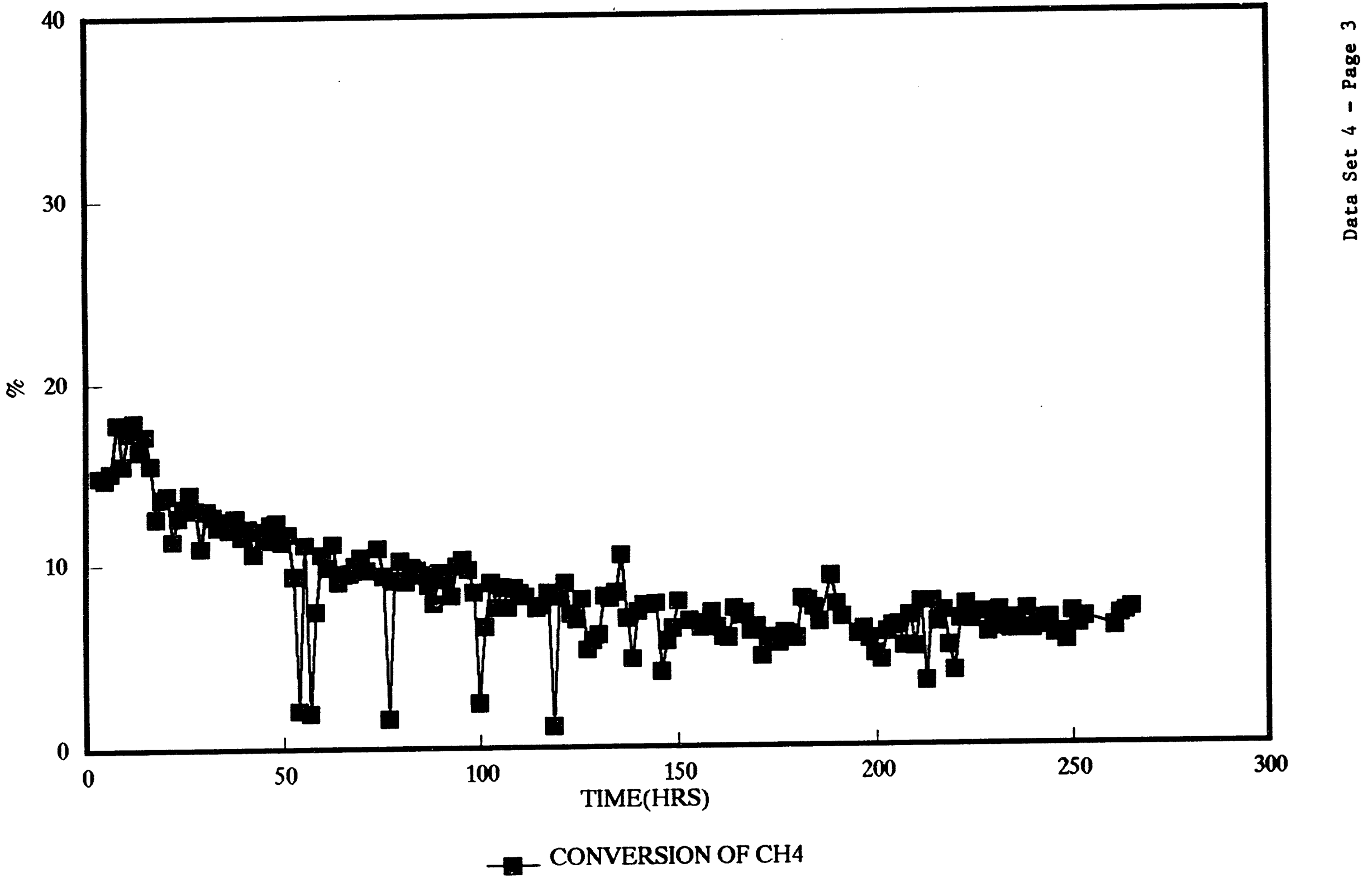




\section{RUN 11046004}

CATALYST 538B

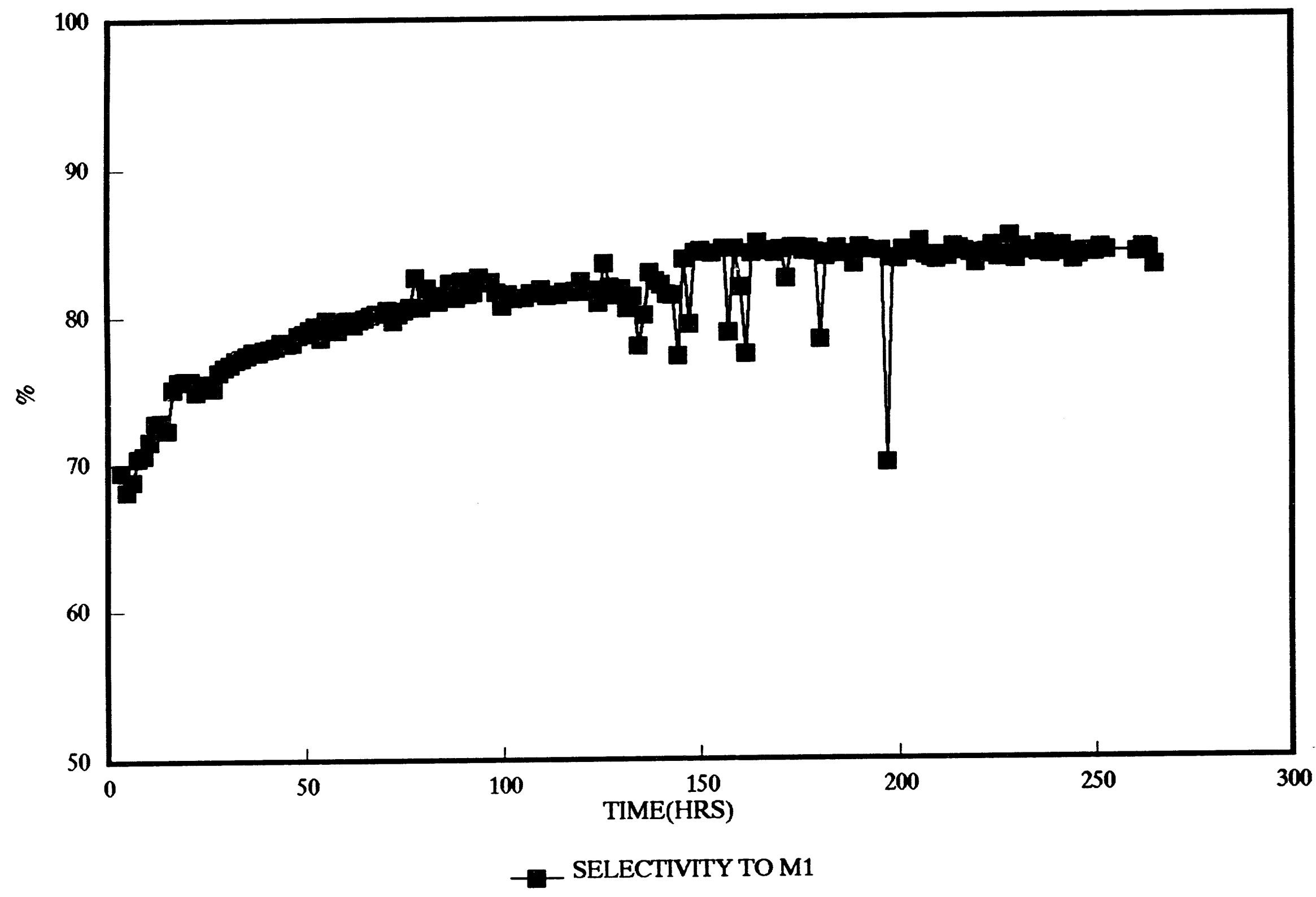




\title{
RUN 11046004
}

\author{
CATALYST 538B
}

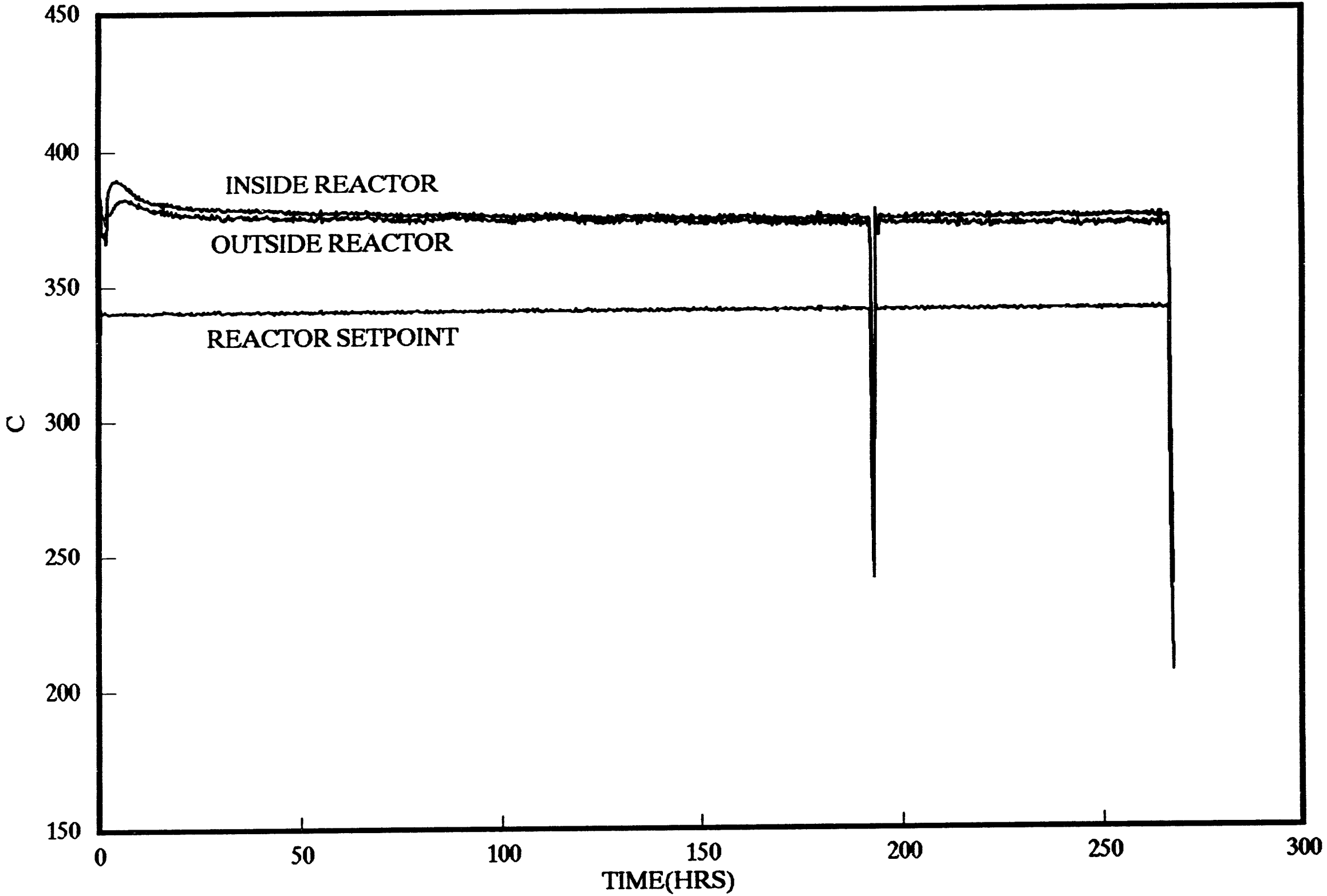




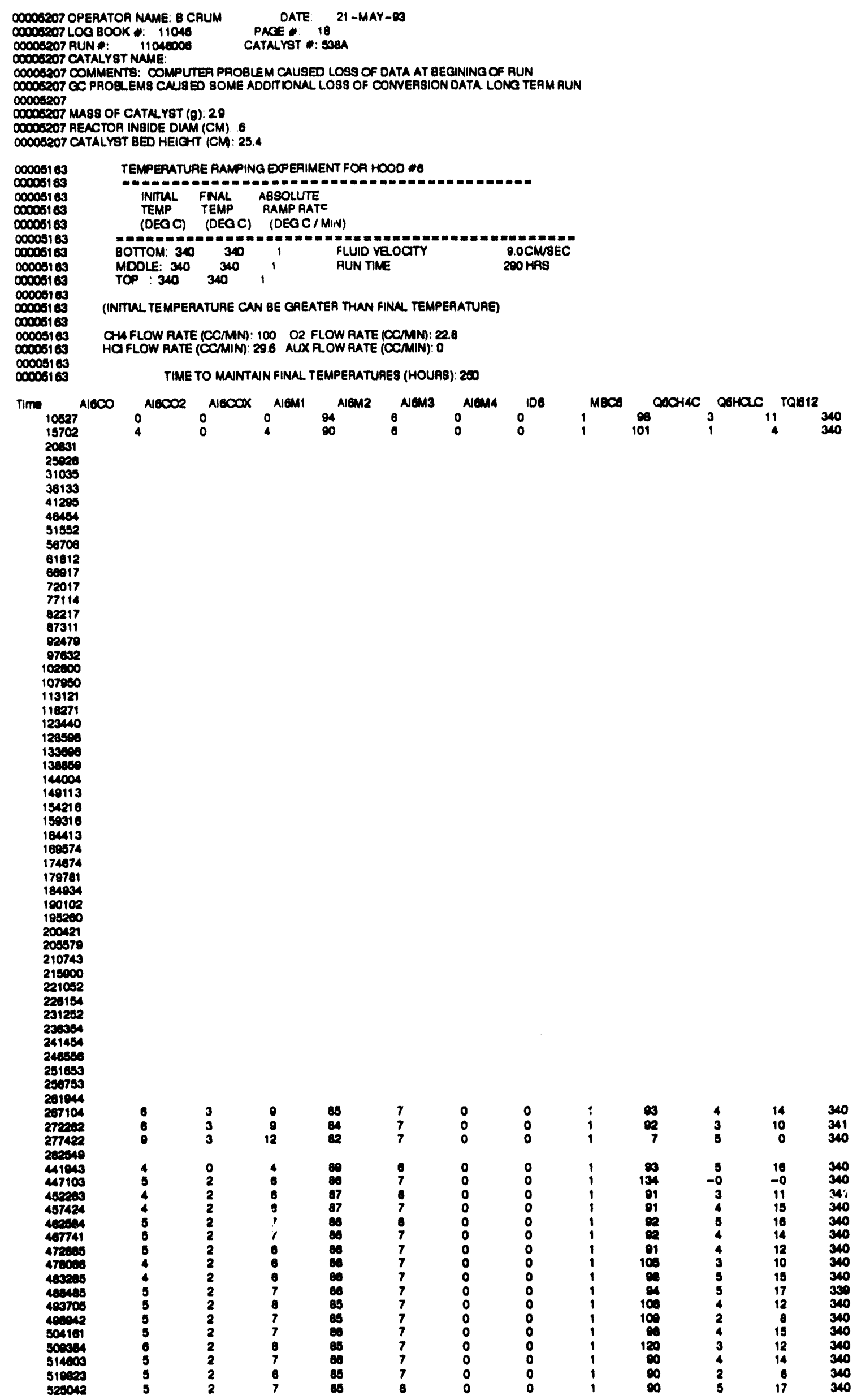




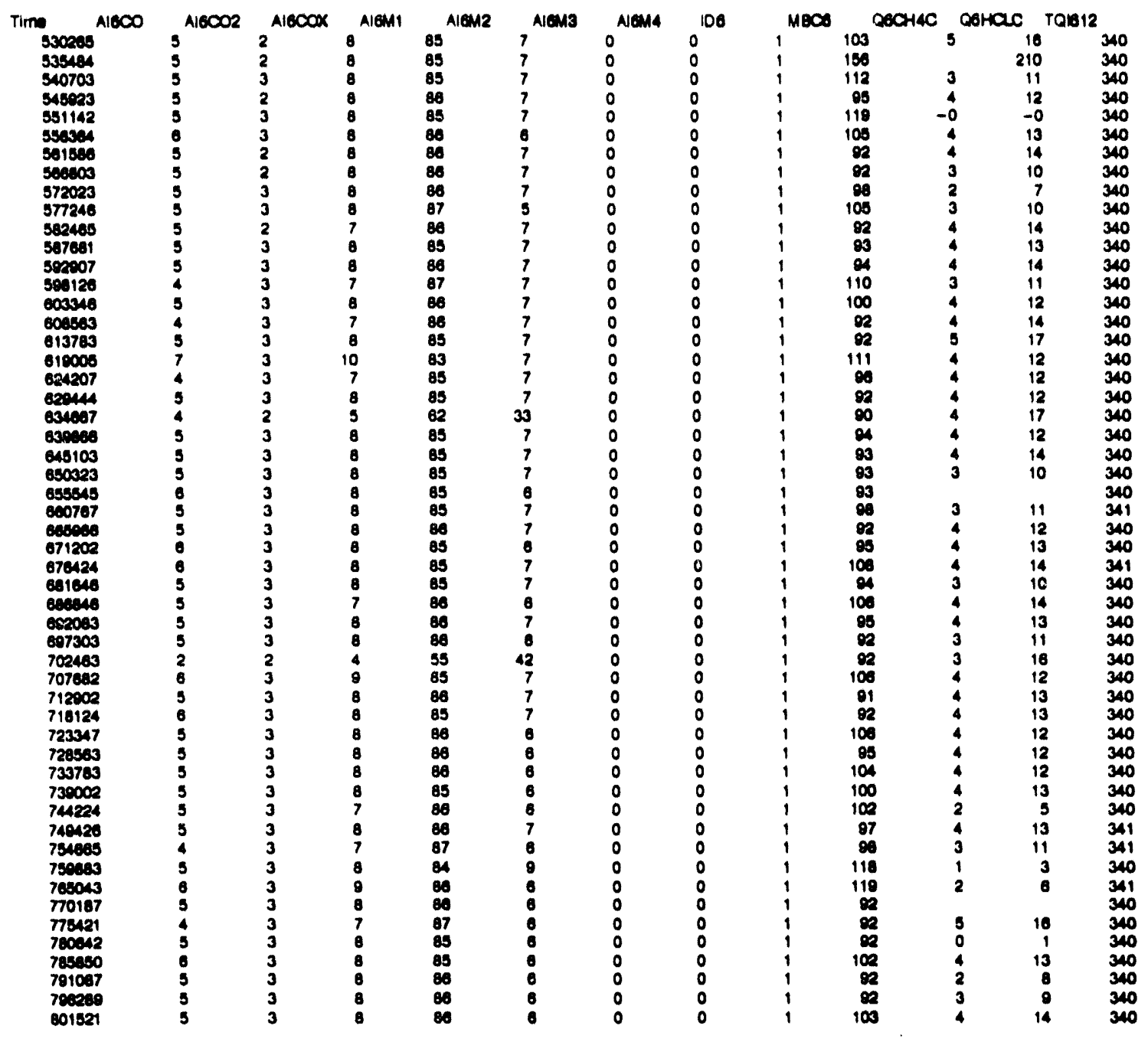

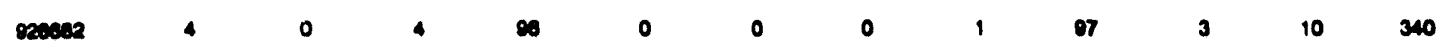

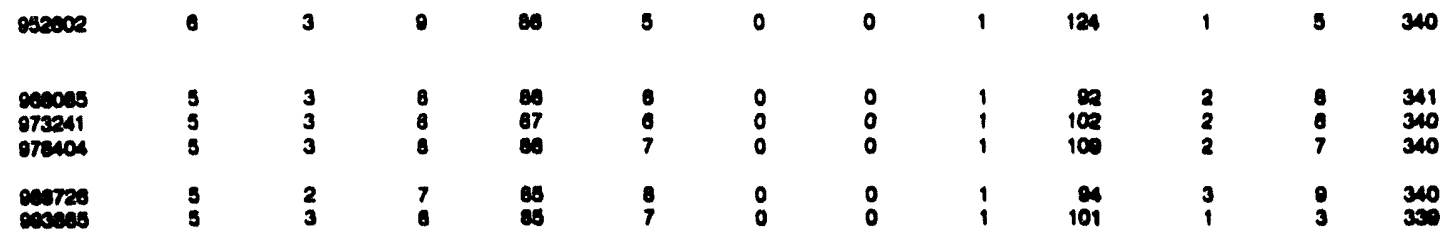

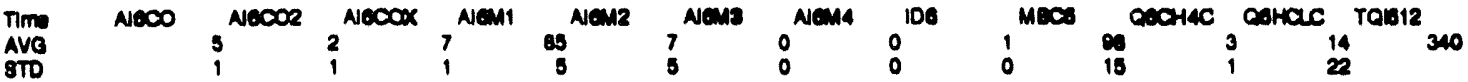




\section{RUN 11046006}

CATALYST 538A

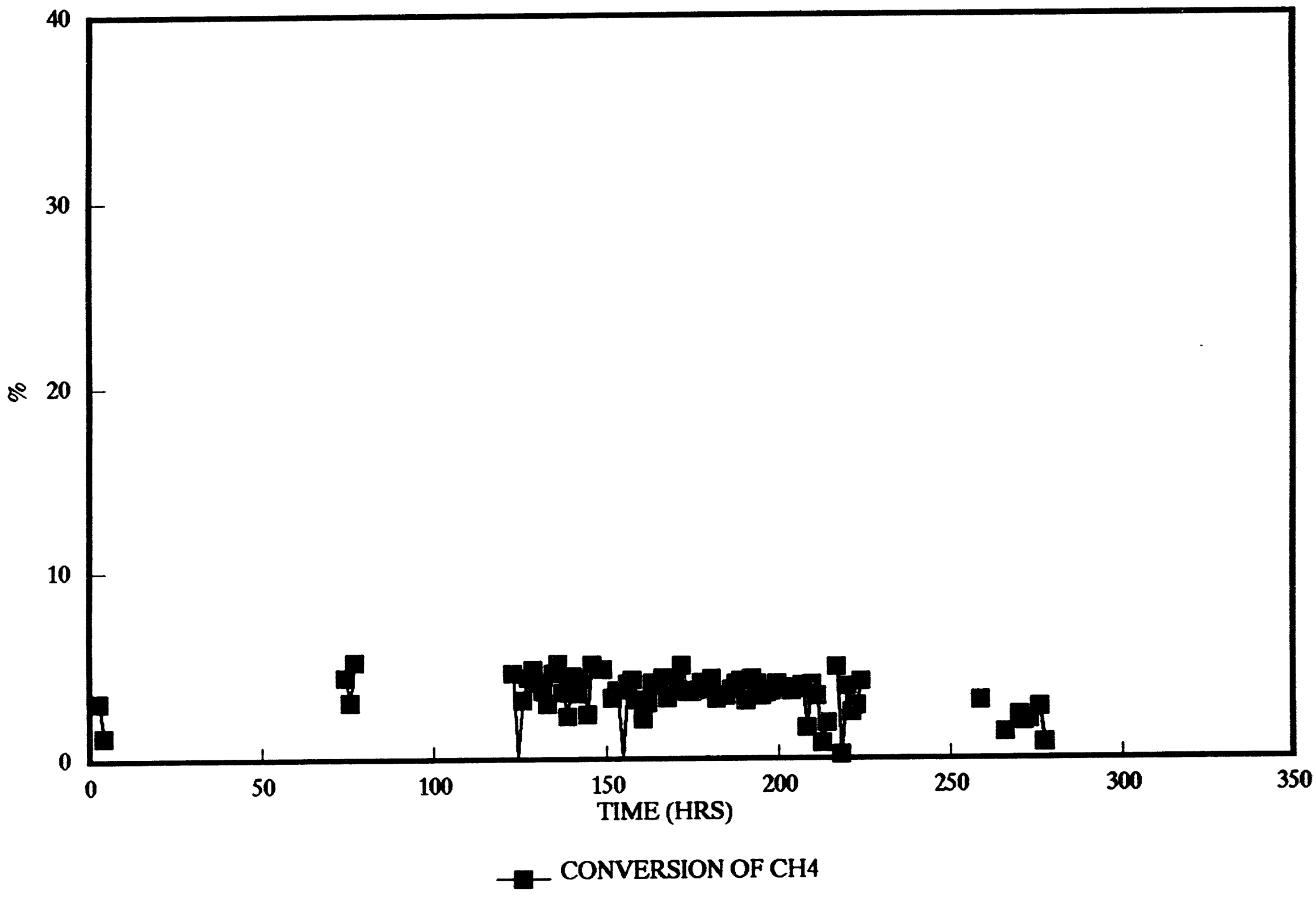


RUN 11046006

CATALYST 538A

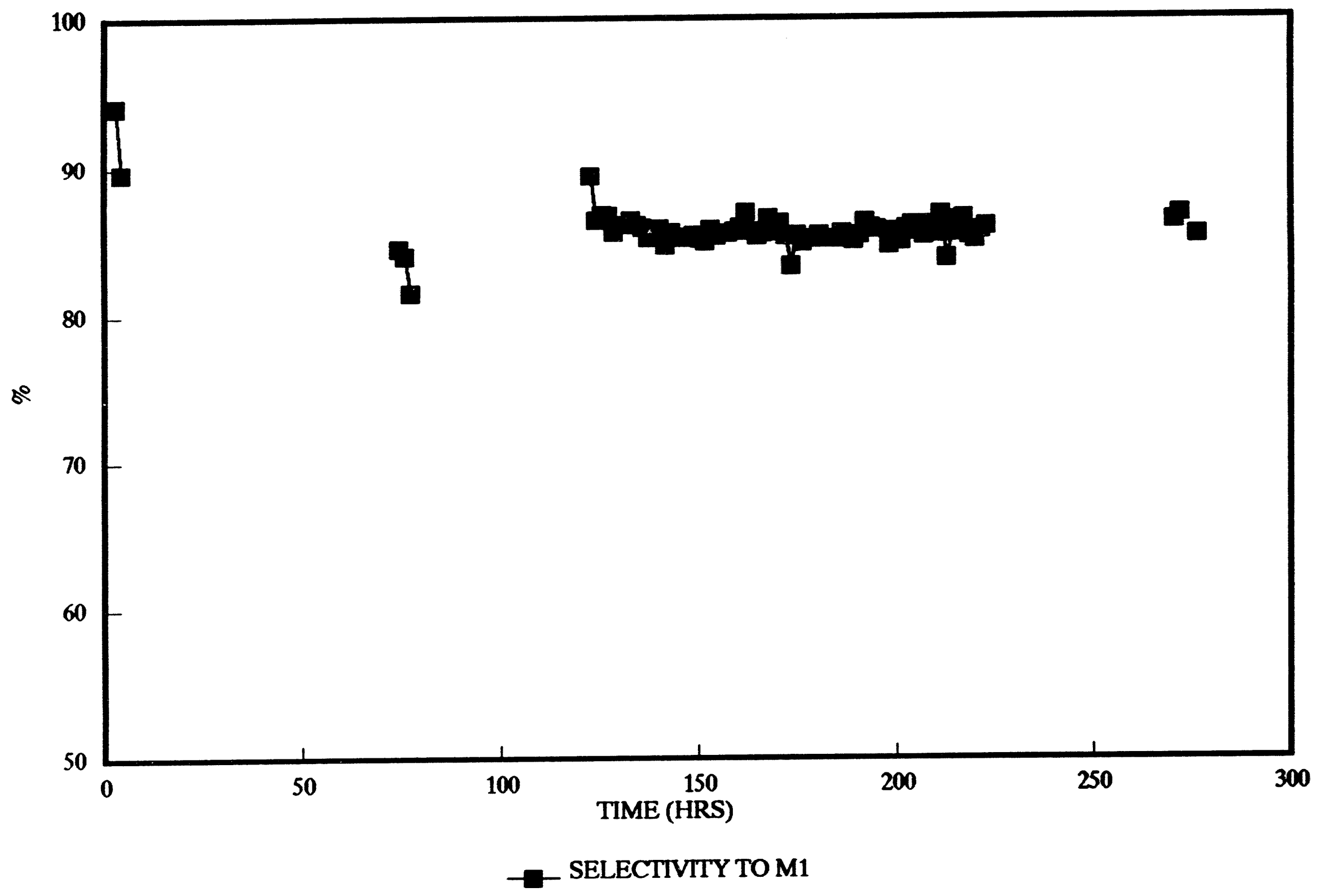




\section{Run 11046006}

Catalyst 538A

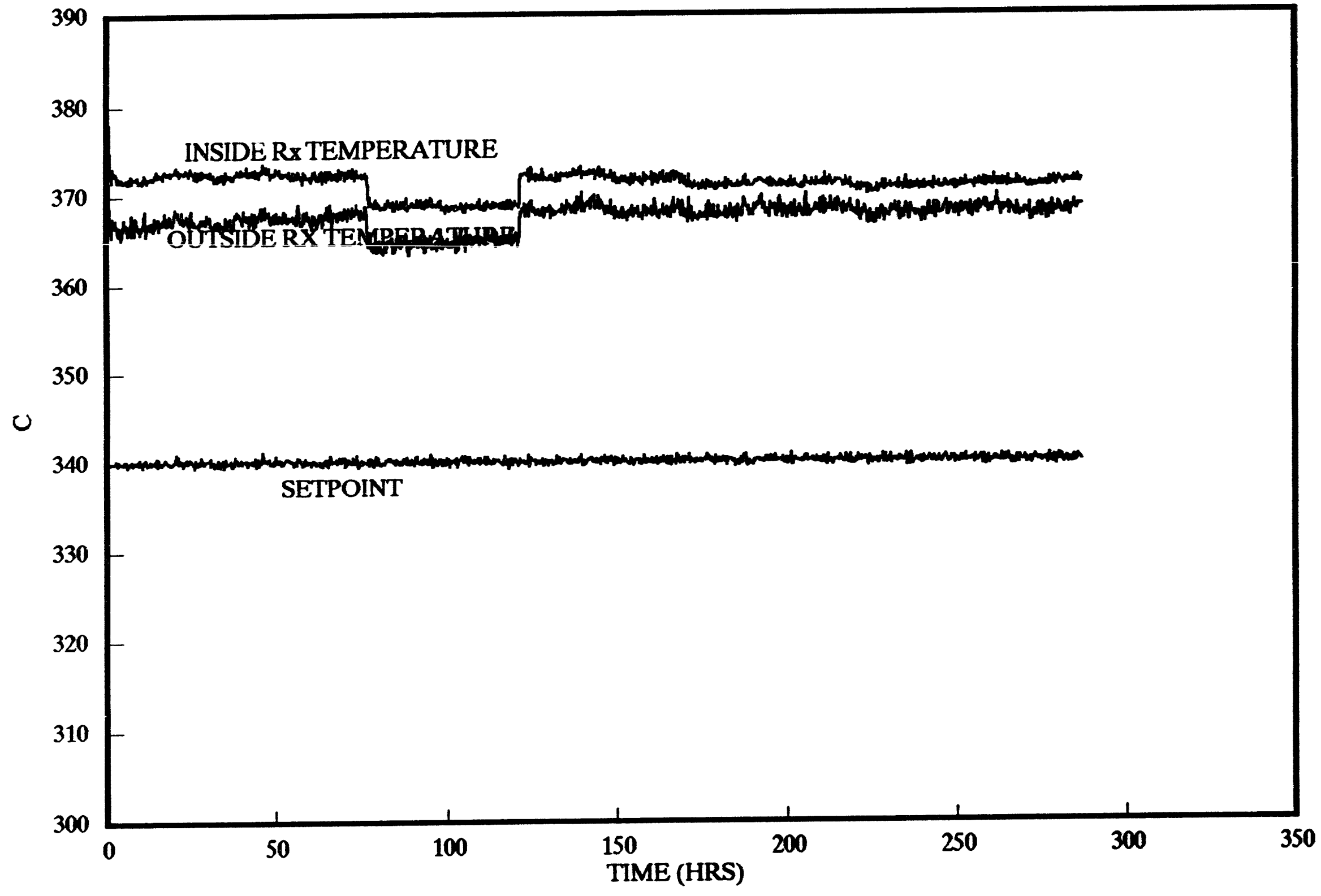




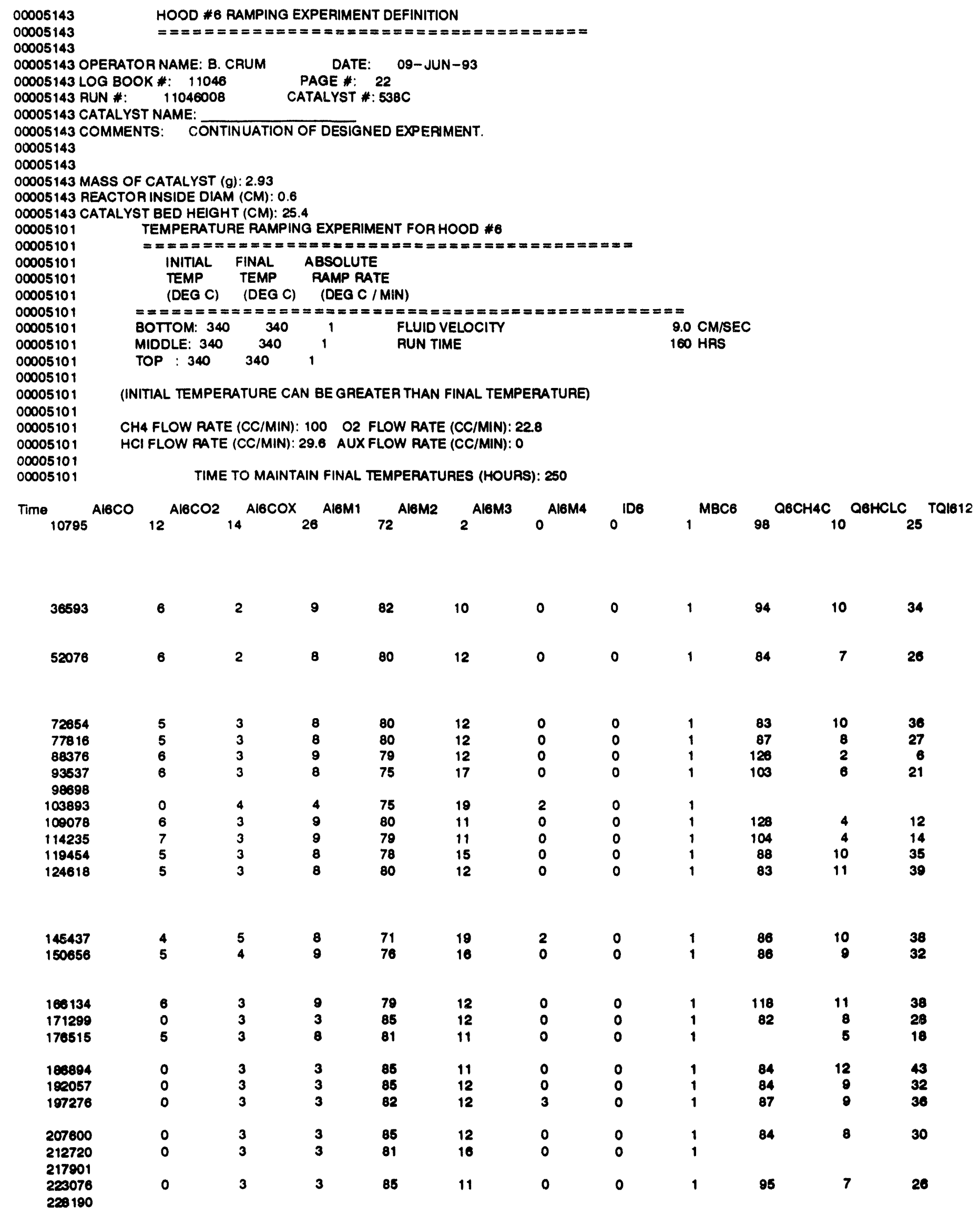




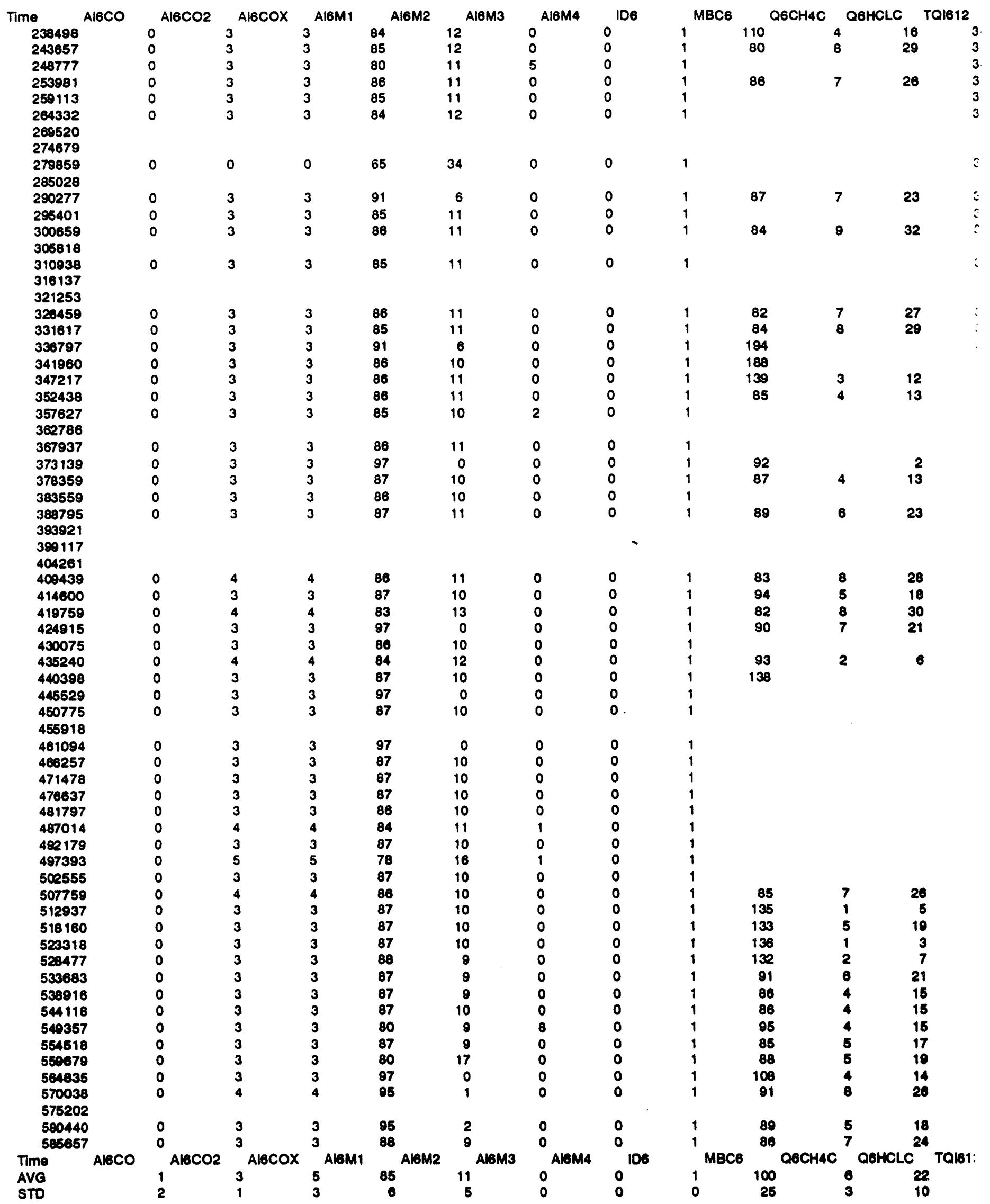




\section{RUN 11046008}

\section{CATALYST 538C}

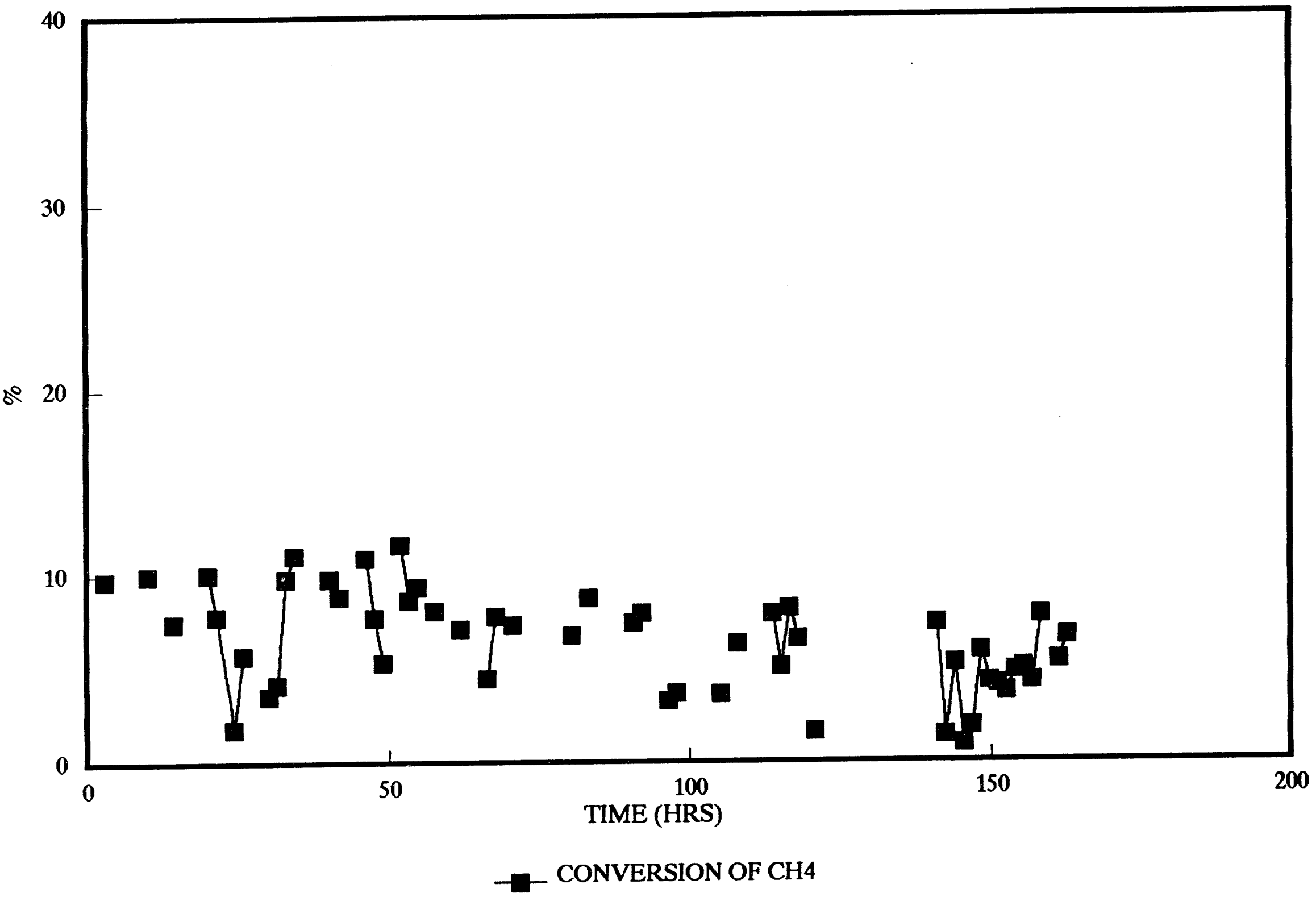




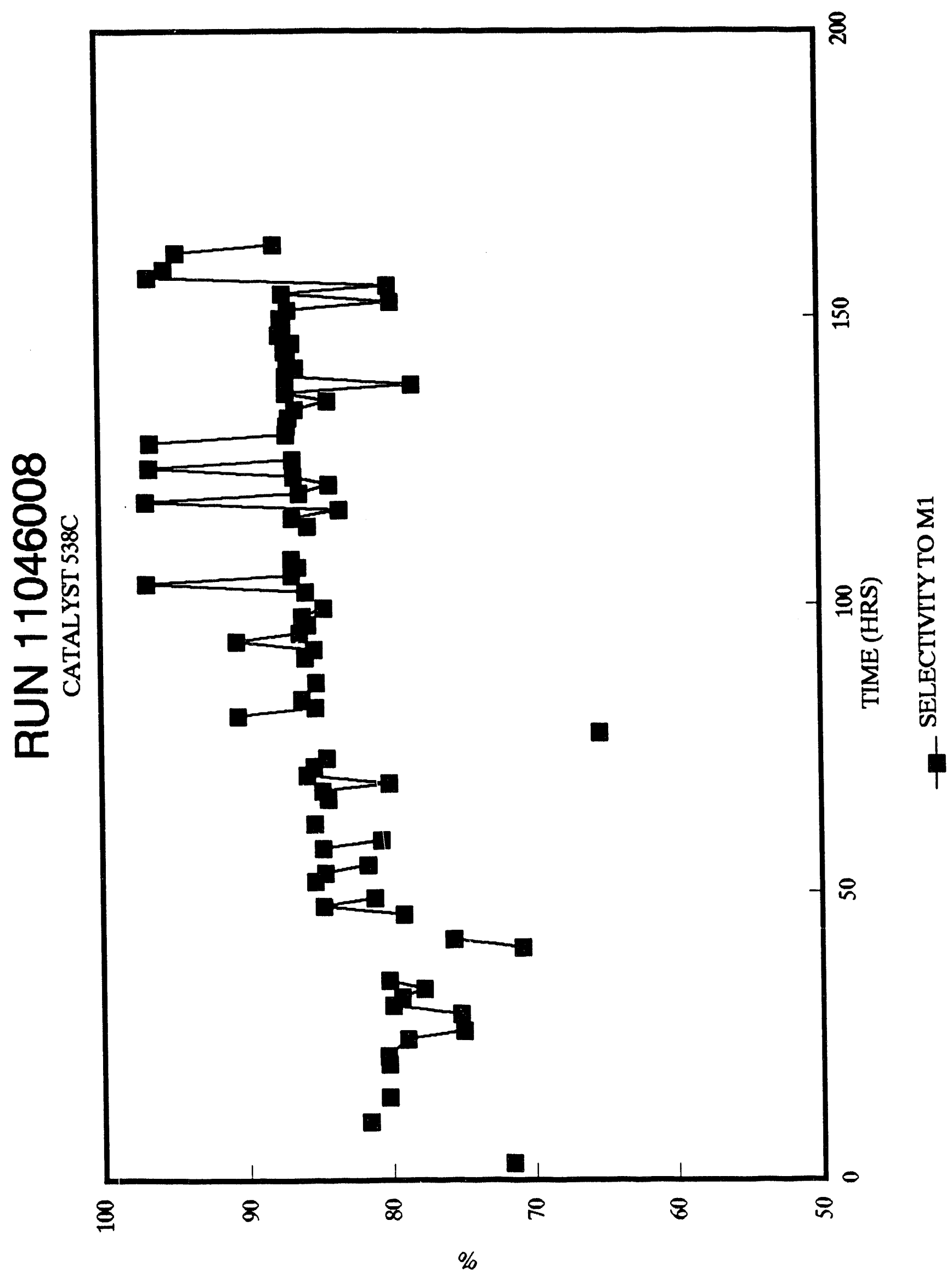




\section{RUN 11046008}

\section{CATALYST 538C}

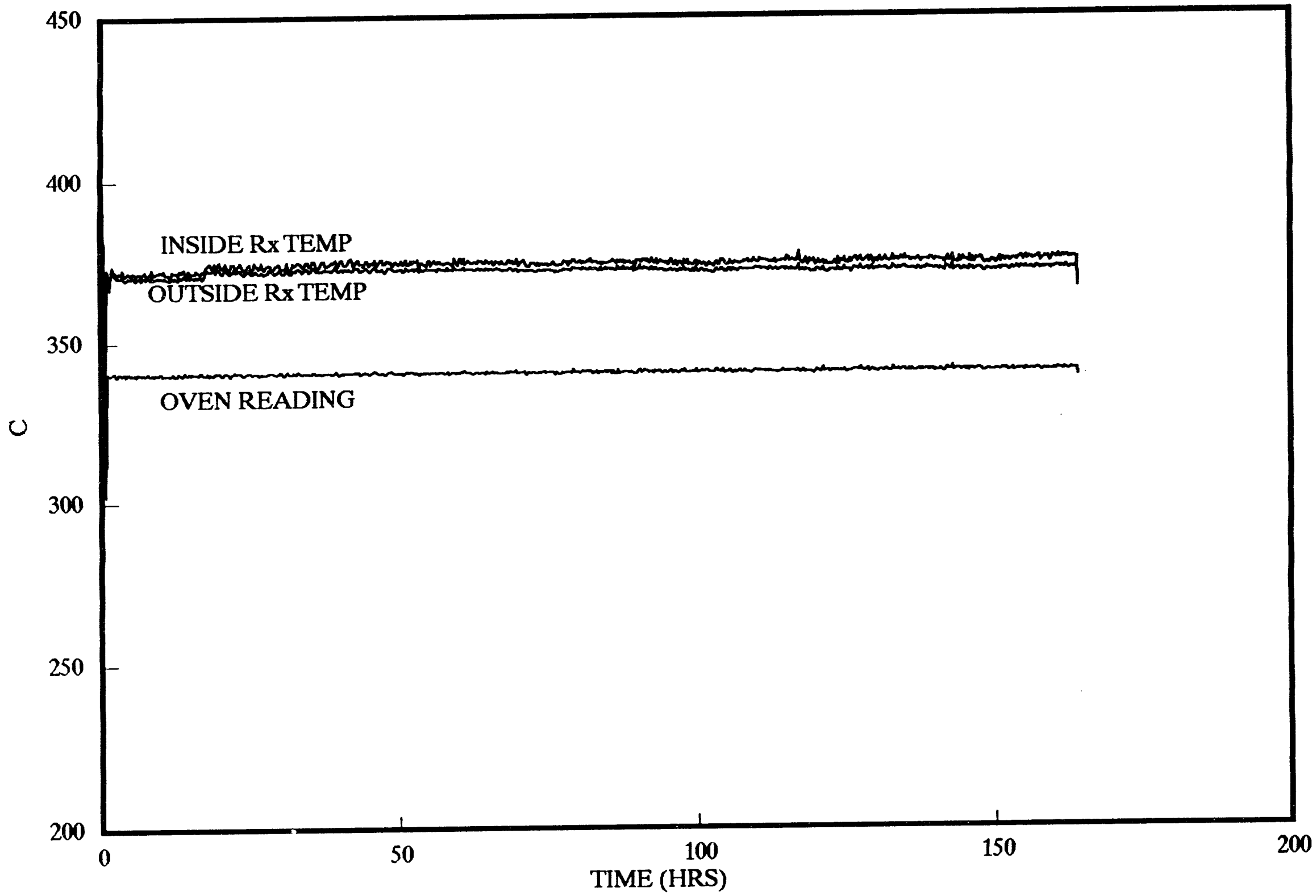




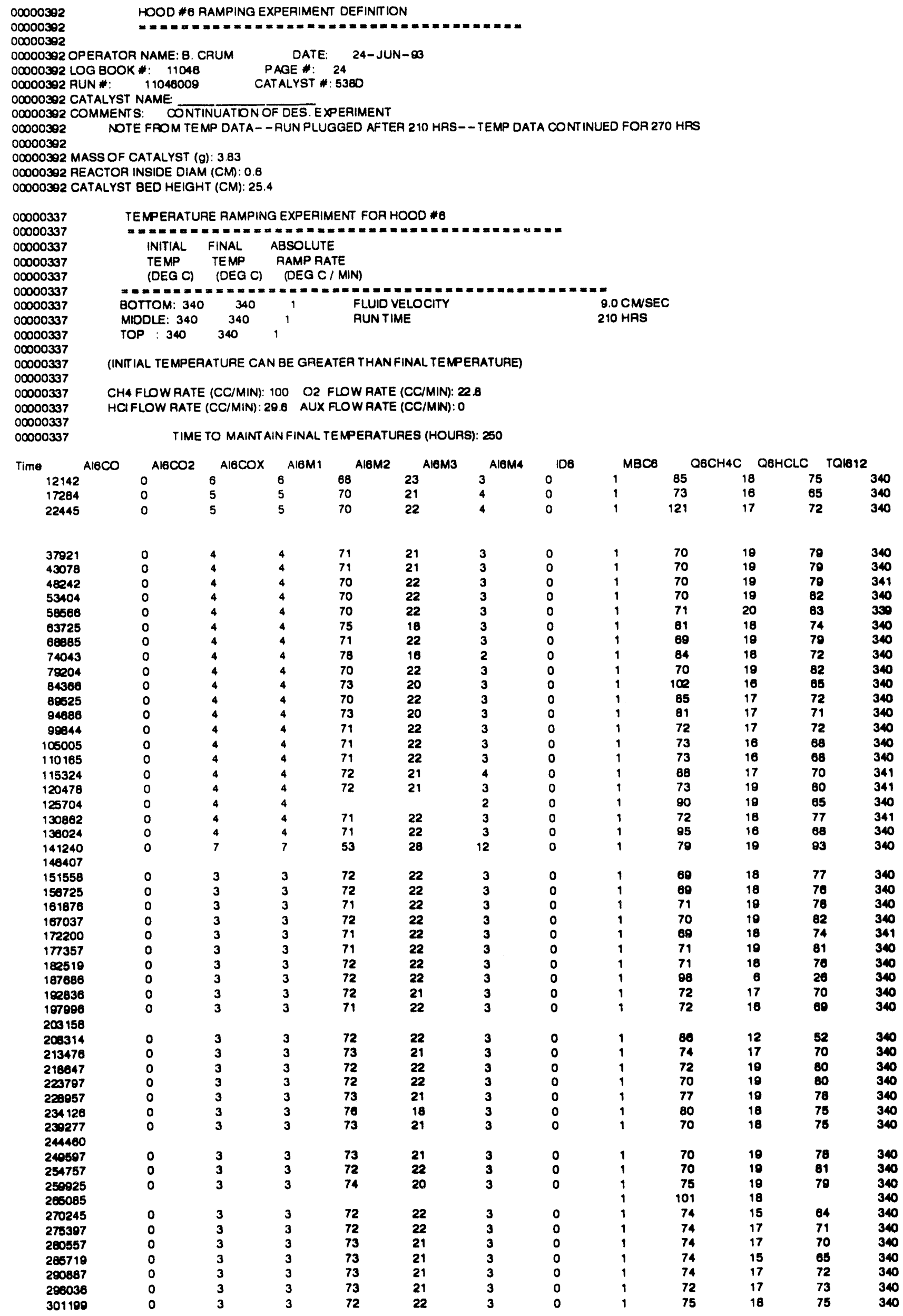




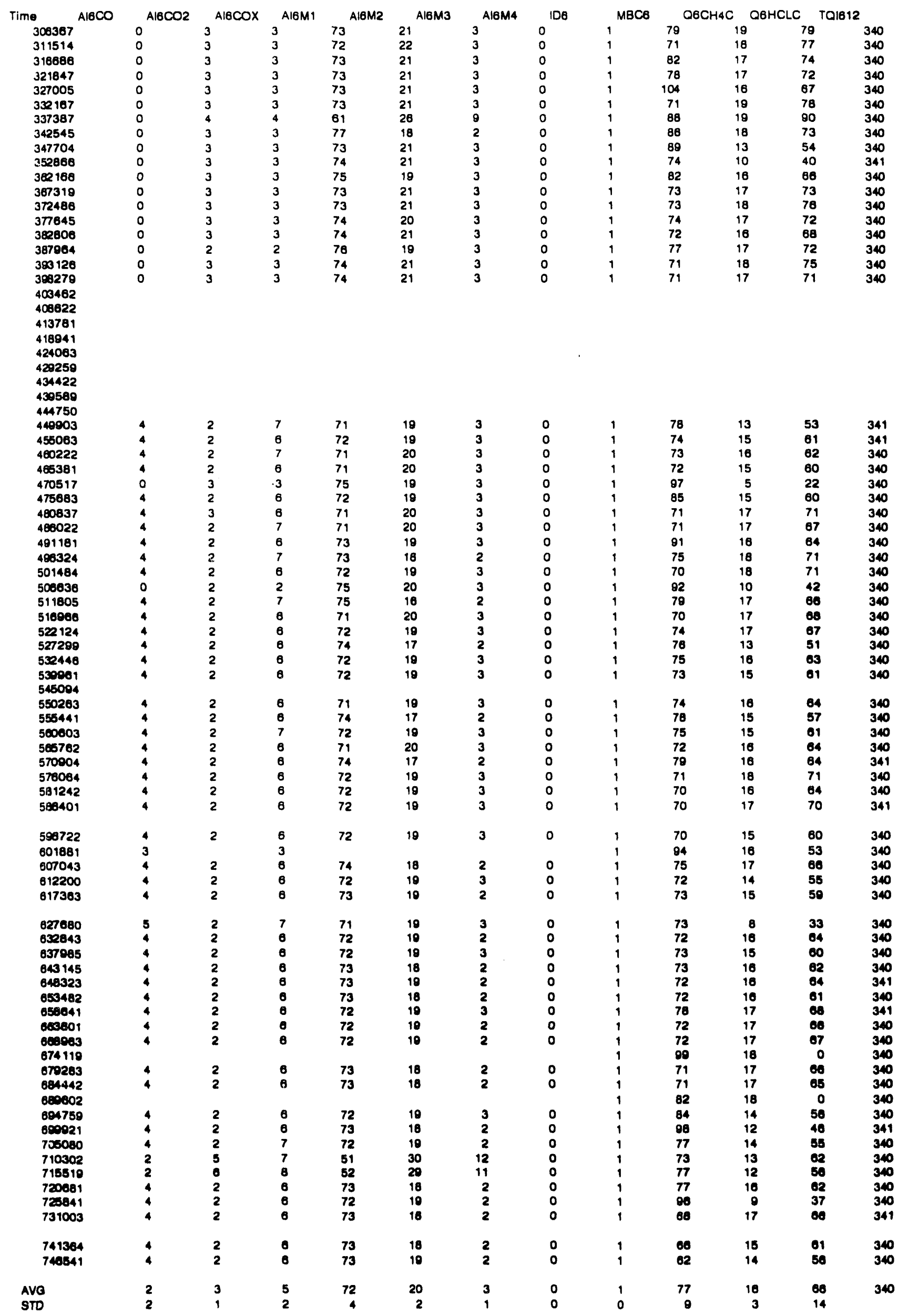


RUN 11046009

CATALYST 538D

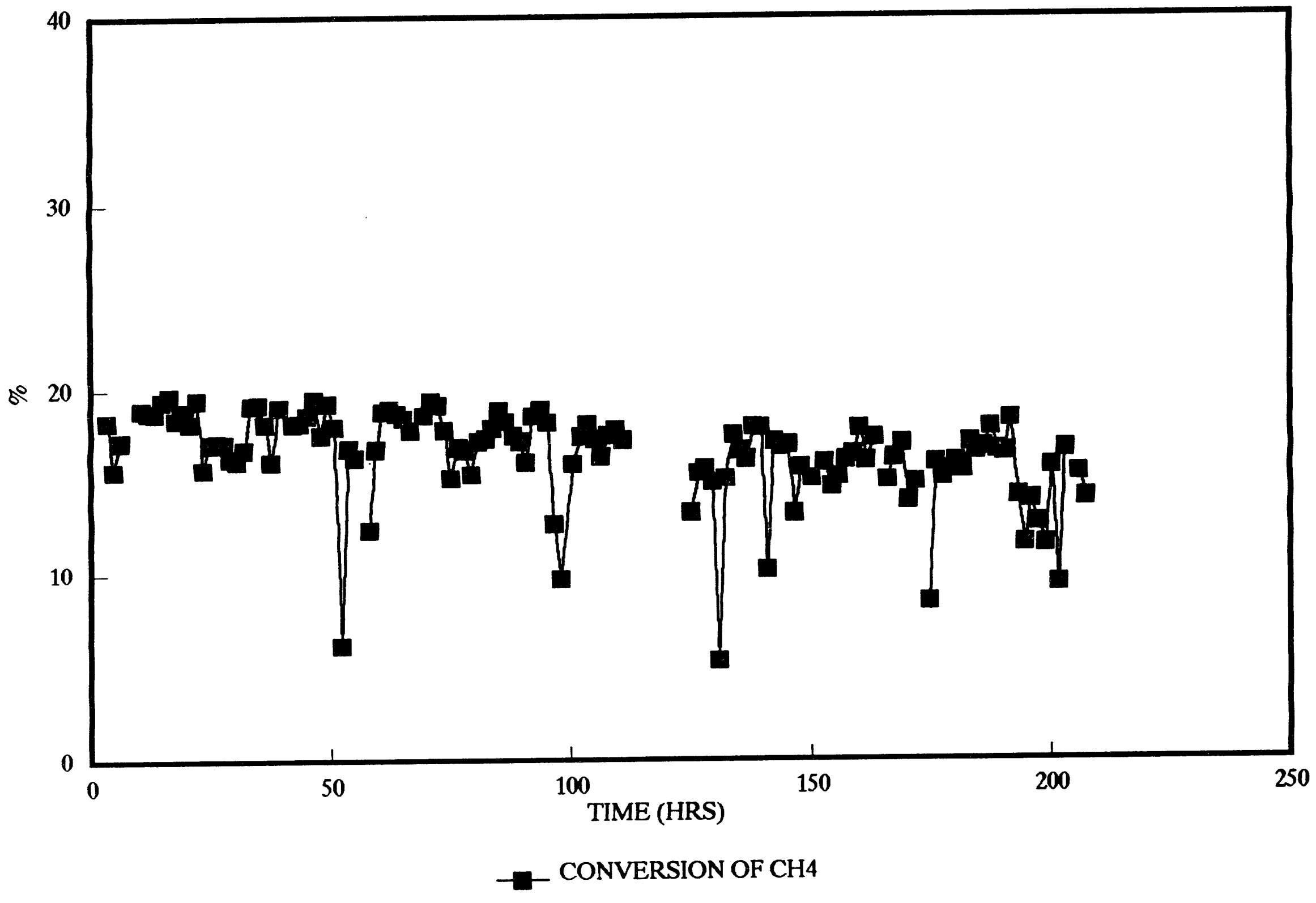




\section{RUN 11046009}

CATALYST 538D

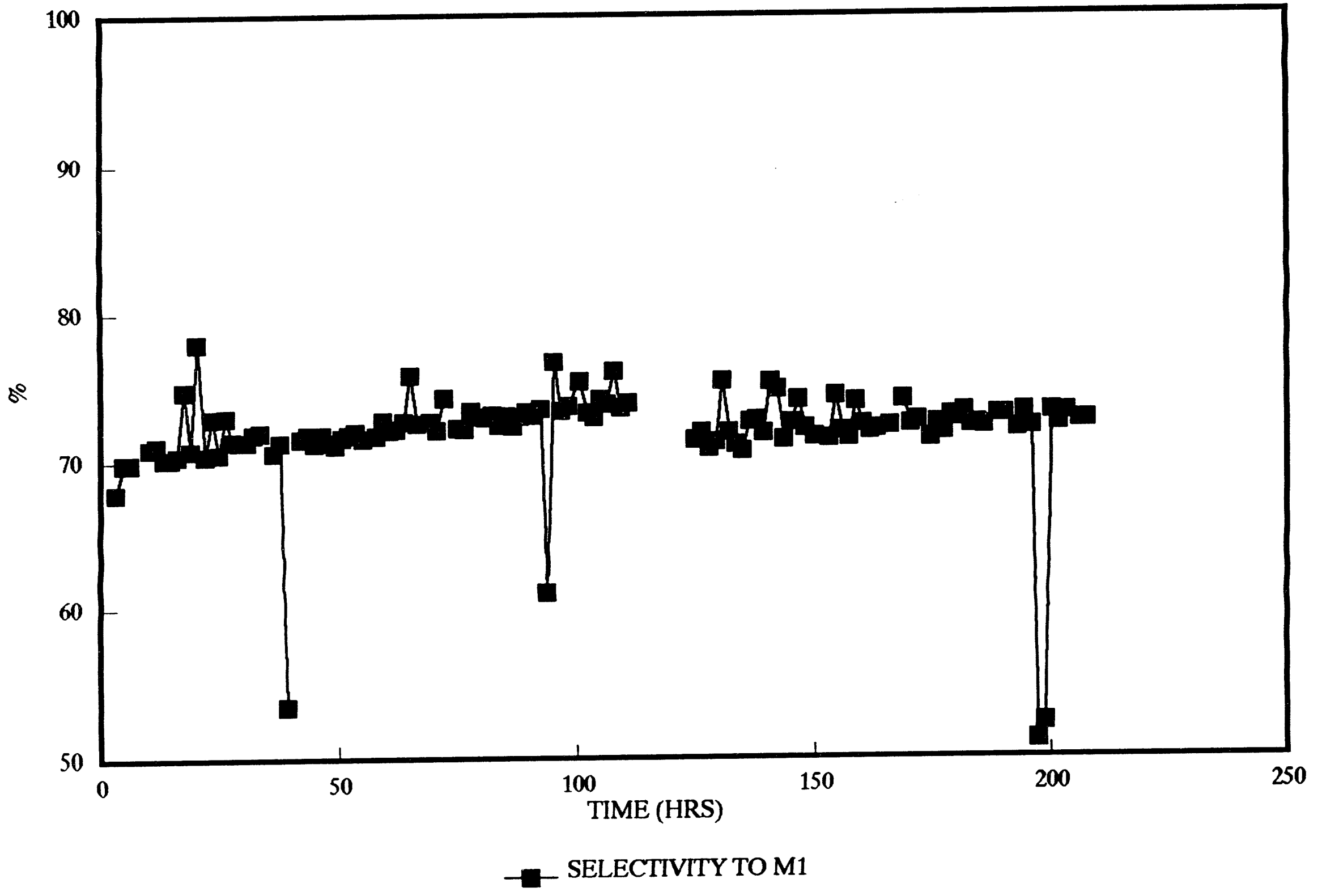




\section{RUN 11046009}

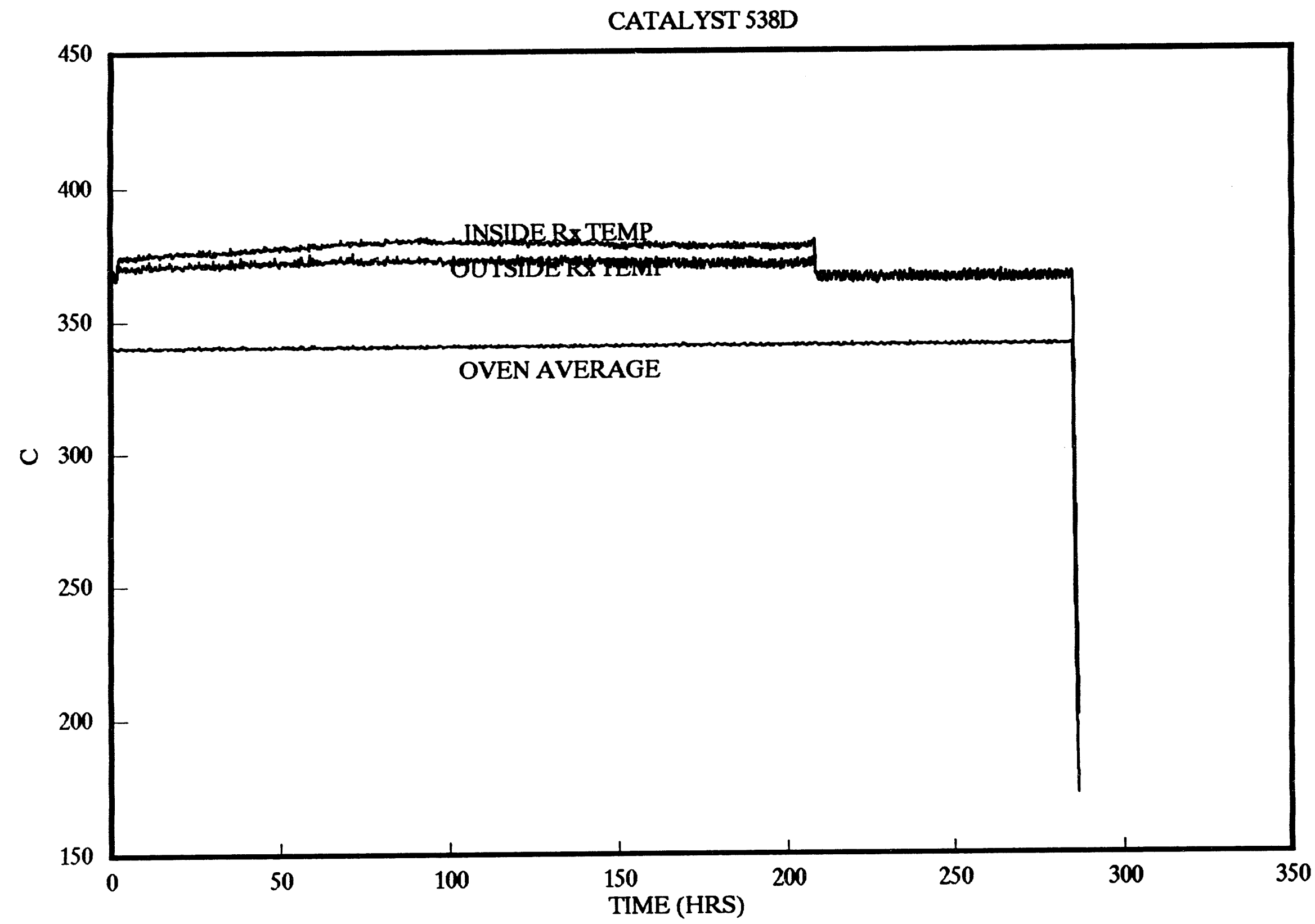


HOOD 7 PEFFORMANCE SUMMAYY

23 APFIL 93 TO 26 APRL 93

RUN

9521036

METAL HCREACTOR 1/4" OD

$\begin{array}{ll}\text { CAT } & 513 \\ G & 0.63 G\end{array}$

TEMP 316-325 OVEN TEMP

BEDHT $\quad 10.2 \mathrm{CM}$

ABSORBEA

SOLVNT MUTTHERM 503

SOUVENT TEMP IN $4-16 \mathrm{C}$ ?

MSSMN

PAOANG

ROGH

4.5 AND2.6 1/8' RP

CD:PD 24 INCHES

PRESSURE

$5: 1$

32 AND 18.7

RUNDATA CONV MI. MR

12
13
29
29
25
25
1
1
1
10
10
10
10
10
10
19
10
10
10

AVG AND STD CONVERSON

\begin{tabular}{|c|c|c|c|c|c|}
\hline M1. & MR & $\infty$ & $\infty 2$ & $\infty x$ & \\
\hline 12 & 81 & 6 & 8 & 5 & 13 \\
\hline 13 & 70 & 6 & 18 & 6 & 24 \\
\hline 29 & 69 & 10 & 14 & 7 & 21 \\
\hline 29 & 69 & 11 & 13 & 7 & 21 \\
\hline 28 & 69 & 8 & 14 & 8 & 21 \\
\hline 25 & 71 & 8 & 12 & 8 & 21 \\
\hline 8 & 77 & 0 & 16 & 7 & 23 \\
\hline 9 & 75 & 0 & 17 & 8 & 25 \\
\hline 8 & 75 & 0 & 17 & 8 & 25 \\
\hline 12 & 71 & 15 & 9 & 5 & 15 \\
\hline 11 & 78 & 0 & 15 & 7 & 22 \\
\hline 10 & 77 & 0 & 16 & 7 & 23 \\
\hline 10 & 78 & 0 & 17 & 8 & 24 \\
\hline 10 & 76 & 0 & 17 & 8 & 24 \\
\hline 10 & 78 & 0 & 15 & 7 & 22 \\
\hline 10 & 76 & 0 & 16 & 8 & 24 \\
\hline 10 & 78 & 0 & 15 & 7 & 22 \\
\hline 10 & 80 & 0 & 12 & 8 & 20 \\
\hline 9 & 76 & 0 & 16 & 7 & 24 \\
\hline 9 & 77 & 0 & 16 & 7 & 23 \\
\hline 8 & 76 & 0 & 16 & 8 & 24 \\
\hline 10 & 78 & 0 & 15 & 7 & 22 \\
\hline 10 & 77 & 0 & 16 & 7 & 23 \\
\hline 10 & 76 & 0 & 16 & 8 & 24 \\
\hline 10 & 76 & 0 & 16 & 8 & 24 \\
\hline M1 & Ne & $\infty$ & $\infty 2$ & $\infty x$ & \\
\hline 13 & 75 & 3 & 15 & 7 & 2 \\
\hline 7 & 3 & 4 & 2 & 1 & 3 \\
\hline
\end{tabular}

****NOTE****

THS CATALYST BED WAS NOT FRESH WHEN RUN

3 RUNS HAD BEEN STARTED AND STOPPED EEFOFE THS RUN

\section{PRESSURE3OPST}

(2)

$\mathrm{CH} 4$
$\mathrm{CQ}$
$\mathrm{HQ}$

80

18.3
23.7 $\infty$

\section{ABSORBERDATA \%MI FEMOVED SOLFOW NTES}

74 MMN NOIES 45 OVENTEMP 320

3.12E-03

$8.26 \mathrm{E}-03$

$1.34 E-02$

$1.28 E-02$

$3.96 E-03$

$2.78 E-03$

$2.90 E-03$

$5.39 E-03$

C.7.

$3.91 E-03$
$3.84 E-03$

$3.63 E-03$

$3.90 \mathrm{E}-03$

3.71E-03

3.75E-03

$4.16 E-03$

$3.50 E-03$

3. $46 \mathrm{E}-03$

2.98E-03

$3.74 E-03$

$3.74 E-03$

$3.87 E-03$

3.83E-03

ABSORBERDATA

GM1/GSOLENT

$5.02 E-03$

3.12E-03
4.5

.6 SOL TEMP DOWN 4C SQ FLOW 2.6

2.6

2.6

2.6

2.6

2.6

2.6

2.6

2.6

2.6

2.6

2.6

2.6

2.6

2.6

2.6

2.6
2.6

2.6
2.6 OVENTENP 325 
HOOD 7 PERFORMANCE SUMMARY

5 MAY 93 TO 13 MAY 93

RUN

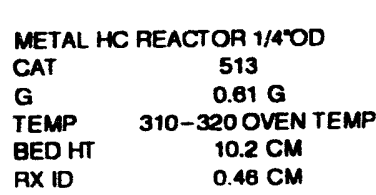

ABSOFBER

SOLVENT MULTITHERM 503

4-16 C?

MLS/MIN $\quad 4.5$ AND

$\begin{array}{ll}\text { PACKING } & \text { T/E RR } \\ \text { HEIGHTH } & 24 \text { INCHES }\end{array}$

\begin{tabular}{ll} 
PEIGHTH & 24 INCHES \\
CD:PD & $5: 1$ \\
\hline & $30 T 0$
\end{tabular}

PRESSURE 30 TO 40

RUN DATA

\begin{tabular}{|c|c|c|c|c|c|}
\hline COrN & M2 & CO & $\mathrm{CO} 2$ & $\operatorname{cox}$ & \\
\hline 8 & 93 & 0 & 0 & 7 & 7 \\
\hline 9 & 85 & 0 & 9 & 8 & 15 \\
\hline 10 & 86 & 0 & 7 & 7 & 14 \\
\hline 10 & 83 & 0 & 10 & 7 & 17 \\
\hline 10 & 84 & 0 & $\theta$ & 7 & 18 \\
\hline 10 & 84 & 0 & 10 & 7 & 16 \\
\hline 10 & 85 & 0 & 8 & 7 & 15 \\
\hline 8 & 84 & 0 & 8 & 7 & 16 \\
\hline 10 & 84 & 0 & 9 & 7 & 16 \\
\hline 8 & 85 & 0 & 8 & 7 & 15 \\
\hline 10 & 84 & 0 & 9 & 7 & 18 \\
\hline 13 & 77 & 6 & 10 & 7 & 17 \\
\hline 13 & 77 & 5 & 11 & 7 & 18 \\
\hline 9 & 60 & 8 & 18 & $\theta$ & 25 \\
\hline 12 & 75 & 5 & 12 & 8 & 20 \\
\hline 13 & 78 & 6 & 11 & B & 18 \\
\hline 13 & 80 & 0 & 7 & 7 & 14 \\
\hline 13 & 77 & 6 & 11 & 7 & 18 \\
\hline 13 & 78 & 5 & 11 & 7 & 18 \\
\hline 28 & 54 & 12 & 21 & 12 & 33 \\
\hline 29 & 67 & 8 & 17 & $\theta$ & 25 \\
\hline 28 & 46 & 13 & 27 & 14 & 42 \\
\hline 20 & 66 & 9 & 18 & 8 & 25 \\
\hline 28 & 66 & 8 & 16 & $\theta$ & 25 \\
\hline 28 & 65 & 9 & 17 & 8 & 26 \\
\hline $\begin{array}{l}20 \\
27\end{array}$ & 64 & 7 & 20 & $\theta$ & 29 \\
\hline 25 & 61 & 8 & 23 & 9 & 32 \\
\hline 21 & 80 & 6 & 5 & $\theta$ & 14 \\
\hline 8 & 83 & 0 & 12 & 4 & 17 \\
\hline 11 & 85 & 0 & 11 & 5 & 15 \\
\hline 11 & 84 & 0 & 11 & 5 & 16 \\
\hline 11 & 80 & 0 & 14 & 6 & 20 \\
\hline 11 & 75 & 0 & 17 & 8 & 25 \\
\hline 12 & 73 & 1 & 18 & $\theta$ & 28 \\
\hline 12 & 71 & 1 & 19 & 9 & 28 \\
\hline 12 & 75 & 1 & 14 & 10 & 24 \\
\hline 14 & 71 & 1 & 19 & $\boldsymbol{\theta}$ & 9 \\
\hline
\end{tabular}

RUN DATA

$\mathrm{co2}$

Ave

15
8

NOTE

PRESSUFE 30 TO 40 PSIG

FLOWS MLMIN

$\mathrm{CH} 4$

60
18.3

$\mathrm{HCL}$

FAT 36 HAS THEN PLUGCED. NOT SURE DATA COLlECTED AT STEADY STATE N..NOTE*...* ABSORBER

$2.79 E-\infty 3$

$3.83 E-03$
$4.27 E-03$

3.89E- -03

$4.21 E-\infty 3$

$4.43 E-03$
$4.70 E-03$

$4.04 E-\infty 3$

$4.73 E-03$
$4.11 E-03$

$4.01 E-03$

4.34E- $-\infty$

$4.56 E-03$

$4.08 E-04$

$3.45 E-03$

3.71E- $-\infty$

$4.87 E-\infty$

4. $30 E-\infty$

$1.19 \mathrm{E}-03$

$7.08 E-04$

$1.76 E-\infty$

$1.71 E-\infty 2$

$165 E-02$

$0.00 E+\infty$

$0.00 E+\infty$

$0.00 E+\infty$

$5.48 E-\infty 03$

6.17E-O4

$7.01 E-\infty$

$5.58 E-\infty 03$

$4.00 E-\infty 3$

$4.00 E-\infty 3$

$470 E-03$

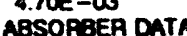

GMI/GSOLVENT

XM1 REMOVED

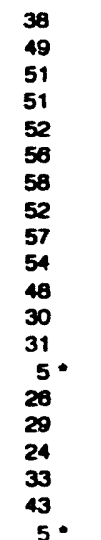

SOL FLOW NOTES

2.1 PX TEMP 316 SYSTEM PAESSURE 30*

2.1

2.1

2.

2.1

2.1

2.1 SHUTDOWN SYSTEM FOR WEEKEND NE PURCE

1.1 REST ARTED SYSTEM PX TEMP 320

1.4

1.4

1.4

1.4 SYSTEM PRESSURE TO 40

1.4 OVEN TIMPTO 315

1.4

$4^{\circ}$

63

63

1.4

- Datanot in avg or sto calcuration

$4.78 E-\infty$

4.17E- $\infty$

50

XM1 REMOVED 
Data Appendix B

Catalyst Synthesis and Composition Information 


\section{CATALYST 513}

SUPPORT

SOURCE

LOADING

IMPREGNATION METHOD

PRETREATMENT

COLOR
Silica CS-1040, PQ Corp. Lot \#1229-2201

$\mathrm{Li}_{2} \mathrm{CuCl}_{4} .9947$ lab-book page 36

$2.27 \% \mathrm{Cu}, 0.50 \% \mathrm{Li}, 3.58 \% \mathrm{Cl}$.

The THF solution of the salt was added to the suppon impregnation overnight. While heating the solvent removed under vacuum.

Under vacuum for 3 hours at $350^{\circ} \mathrm{C}$. In the beginning color of the catalyst was orange but as the solvent being removed and the temperature was increased following color changes took place. Orange to yello black to yellow to olive green to gray.

Final color is gray. In water it becomes almost black later dark olive green. 


\section{CATALYST 538A}

SUPPORT

SOURCE

LOADING

IMPREGNATION METHOD

PRETREATMENT

COLOR
Silica CS-1040, PQ Corp. Lot \#1229-2201

$\left[\mathrm{Cu}\left(\mathrm{CH}_{3} \mathrm{CN}\right)_{4}\right]\left\{\mathrm{PF}_{6}\right\} .9947$ lab-book page 91.

$2.5 \% \mathrm{Cu}$ and $1.0 \% \mathrm{P}$.

The support was heated at $400 \mathrm{C}$ under full vacuum $\mathrm{fi}$ hours. Next the solution of the complex was made ur nitrogen ( completely clear soluton, no undissolved sc and was added under nitrogen to the support. suspension was left overnight at room temperature. I day the solvent was removed by nitrogen flow.

Under vacuum for 2 hours at $350^{\circ} \mathrm{C}$.

Gray. 


\section{CATALYST 538B}

SUPPORT

SOURCE

LOADING

IMPREGNATION METHOD

PRETREATMENT

COLOR
Silica CS-1040, PQ Corp. Lot \#1229-2201

$\left[\mathrm{Cu}\left(\mathrm{CH}_{3} \mathrm{CN}\right)_{4}\right]\left\{\mathrm{PF}_{6}\right\}$ and $\mathrm{LaCl}_{3} .9947$ lab-book page 91 .

$1.8 \% \mathrm{Cu}, 0.65 \% \mathrm{P}, 6.9 \% \mathrm{Cl}$, and $10.2 \% \mathrm{La}$.

This catalyst is the same as $538 \mathrm{~A}$ but it has been promot. with $\mathrm{LaCl}_{3}$. The $\mathrm{LaCl}_{3}$ (anhydrous) was dissolved distilled water and heat was used to enhance solubili: Suspension was gravity filtered to obtain a clear solutic Water was removed at $100 \mathrm{C}$ with flowing nitrogen.

Under vacuum for 3 hours at $330^{\circ} \mathrm{C}$.

Yellow. 


\section{CATALYST 538C}

SUPPORT

SOURCE

LOADING

IMPREGNATION METHOD

PRETREATMENT

COLOR
Silica CS-1040, PQ Corp. Lot \#1229-2201

$\left[\mathrm{Cu}\left(\mathrm{CH}_{3} \mathrm{CN}\right)_{4}\right]\left\{\mathrm{PF}_{6}\right\}$ and $\mathrm{LiCl} .9947$ lab-book page 91.

$2.5 \% \mathrm{Cu}, 1.3 \% \mathrm{Li}$ and $1.0 \% \mathrm{P}$.

This catalyst is the same as $538 \mathrm{~A}$, but it has been promoted with $\mathrm{LiCl}$. The $\mathrm{LiCl}$ was dissolved in water, Catalyst 538A was impregnated overnight with the $\mathrm{LiCl}$ solution. After impregnation, the water was removed in flowing nitrogen.

Under vacuum for 2 hours at $350^{\circ} \mathrm{C}$.

Pale green blue. 


\section{CATALYST 538D}

SUPPORT

SOURCE

91.

LOADING

IMPREGNATION METHOD

PRETREATMENT

COLOR
Silica CS-1040, PQ Corp. Lot \#1229-2201

$\left[\mathrm{Cu}\left(\mathrm{CH}_{3} \mathrm{CN}\right)_{4}\right]\left\{\mathrm{PF}_{6}\right\}, \mathrm{LiCl}$ and $\mathrm{LaCl}_{3} .9947$ lab-book page

$2.5 \% \mathrm{Cu}, 0.7 \% \mathrm{Li}, 13.5 \% \mathrm{La}$ and $0.5 \% \mathrm{P}$.

This catalyst is the same as $538 \mathrm{~A}$, but it has been promoted with $\mathrm{LiCl}$ and $\mathrm{LaCl}_{3}$.

Under vacuum for 2 hours at $350{ }^{\circ} \mathrm{C}$.

Gray. 

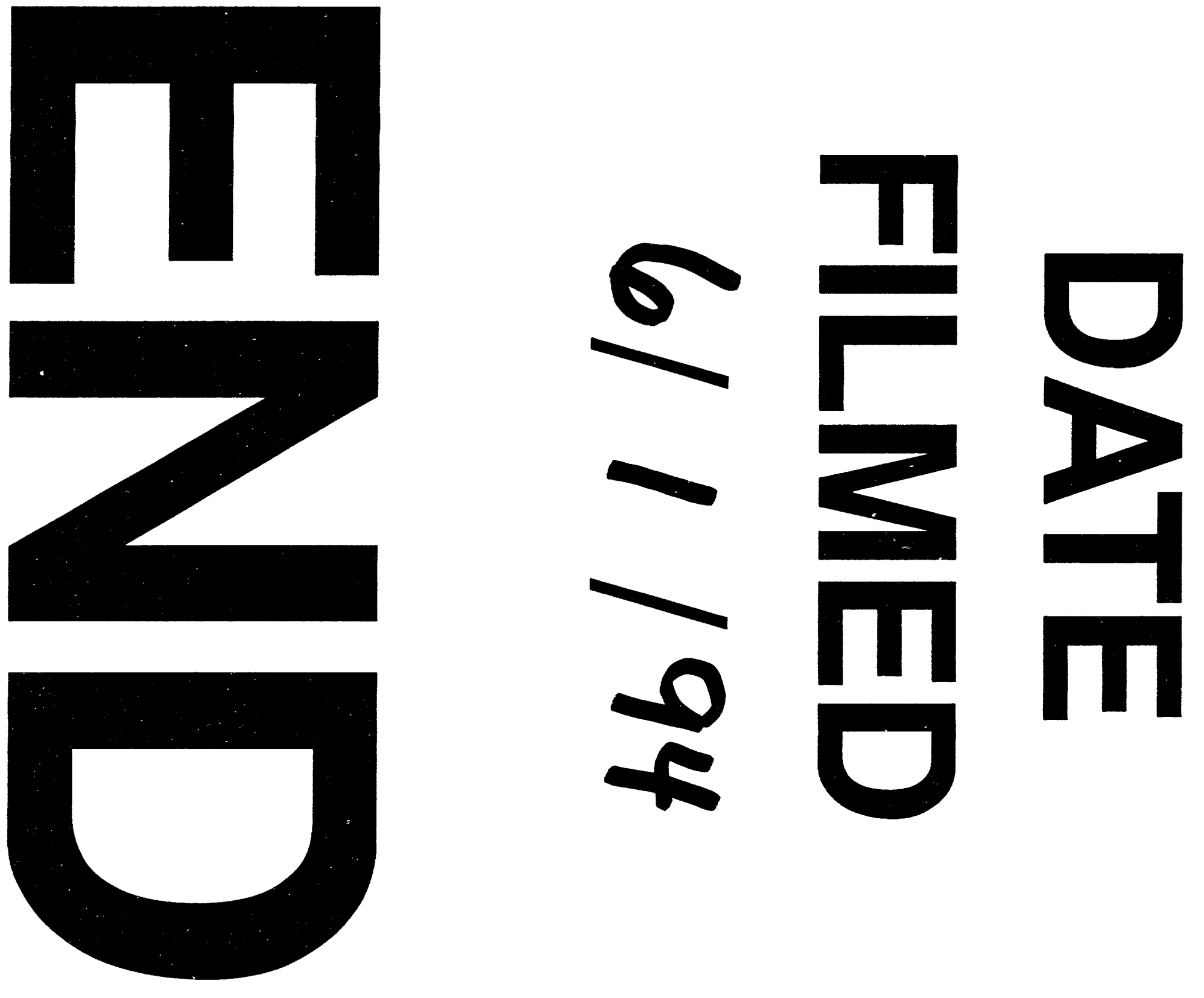
